Florida International University FIU Digital Commons

\title{
Development of Local Homeland Security Networks in the State of Florida: A Social Network Analysis Approach
}

Patrick M. Bell

Florida International University, pbell@fiu.edu

DOI: $10.25148 /$ etd.FI12042307

Follow this and additional works at: https://digitalcommons.fiu.edu/etd

\section{Recommended Citation}

Bell, Patrick M., "Development of Local Homeland Security Networks in the State of Florida: A Social Network Analysis Approach" (2012). FIU Electronic Theses and Dissertations. 574.

https://digitalcommons.fiu.edu/etd/574 


\title{
FLORIDA INTERNATIONAL UNIVERSITY
}

Miami, Florida

\section{DEVELOPMENT OF LOCAL HOMELAND SECURITY NETWORKS IN THE}

STATE OF FLORIDA: A SOCIAL NETWORK ANALYSIS APPROACH

\author{
A dissertation submitted in partial fulfillment of the \\ Requirements for the degree of \\ DOCTOR OF PHILOSOPHY \\ in \\ PUBLIC AFFAIRS \\ by \\ Patrick Michael Bell
}


To: Dean Kenneth Furton

College of Arts and Sciences

This dissertation, written by Patrick Michael Bell, and entitled Development of Local Homeland Security Network in the State of Florida: A Social Network Analysis Approach, having been approved in respect to style and intellectual content, is referred to you for judgment.

We have read this dissertation and recommend that it be approved.

Ellen Cohn

Howard Frank

Keith Revell

Meredith Newman Major Professor

Date of Defense: March 28, 2012

The dissertation of Patrick Michael Bell is approved.

$\begin{array}{r}\begin{array}{r}\text { Dean Kenneth Furton } \\ \text { College of Arts and Sciences }\end{array} \\ \hline \begin{array}{r}\text { Dean Lakshmi N. Reddi } \\ \text { University Graduate School }\end{array}\end{array}$

Florida International University, 2012 
(C) Copyright 2012 by Patrick Michael Bell

All Rights Reserved. 


\section{DEDICATION}

Without the encouragement and moral support of family and friends, this process would not be possible. I; therefore, dedicate this dissertation first to my family whose patience and understanding gave me the support I needed to finish this project. Also, I

dedicate this dissertation to the friends who helped me see the larger picture, a picture that I would not have been able to see without their help. 


\section{ACKNOWLEDGMENTS}

No one can complete this project alone. Beyond the logistics of writing and researching, there are people who go above and beyond what anyone can expect or hope for. I have had the pleasure of working with such people and find it fitting that they be acknowledged. I must thank my committee members, including my dissertation chair, Dr. Meredith Newman for all of her wise counsel and encouragement during this process. Dr. Keith Revell, whose insightful comments made this project far better than it would have been otherwise. Dr. Howard Frank, for suggesting this subject and for comments that often sent me in search of better ways to express my "non-linear thinking" and in so doing made this project intelligible and Dr. Ellen Cohn, for her willingness to serve as my outside committee member and for consistently bringing fresh insights to this project.

I must also give a special note of thanks to two people who are not on my committee. Without their assistance, this project would not have been possible. Dr. Lianne Dornheim worked tirelessly with me as we fashioned each draft from a proposal to the final project. I am forever in your debt. Ms. Ketsia Julmeus, whose diligence and hard work as an editor were invaluable. All of your hard work with me finally paid off in the end.

Finally, I must thank the first responders who generously gave of their time during the interview phase of this dissertation. My interactions with them helped me to focus not just on the attributes but on the interconnections that exist between them. 


\begin{abstract}
OF THE DISSERTATION
DEVELOPMENT OF LOCAL HOMELAND SECURITY NETWORKS IN
\end{abstract}

THE STATE OF FLORIDA:

A SOCIAL NETWORK ANALYSIS APPROACH

by

Patrick Michael Bell

Florida International University, 2012

Miami, Florida

Professor Meredith Newman, Major Professor

How do local homeland security organizations respond to catastrophic events such as hurricanes and acts of terrorism? Among the most important aspects of this response are these organizations ability to adapt to the uncertain nature of these "focusing events" (Birkland 1997). They are often behind the curve, seeing response as a linear process when in fact it is a complex, multifaceted process that requires understanding the interactions between the fiscal pressures facing local governments, the institutional pressures of working within a new regulatory framework and the political pressures of bringing together different levels of government with different perspectives and agendas.

This dissertation has focused on tracing the factors affecting the individuals and institutions planning, preparing, responding and recovering from natural and man-made disasters. Using social network analysis, my study analyzes the interactions between the individuals and institutions that respond to these "focusing events." In practice, it is the 
combination of budgetary, institutional, and political pressures or constraints interacting with each other which resembles a Complex Adaptive System (CAS).

To investigate this system, my study evaluates the evolution of two separate sets of organizations composed of first responders (Fire Chiefs, Emergency Management Coordinators) and community volunteers organized in the state of Florida over the last fifteen years. Using a social network analysis approach, my dissertation analyzes the interactions between Citizen Corps Councils (CCCs) and Community Emergency Response Teams (CERTs) in the state of Florida from 1996- 2011. It is the pattern of interconnections that occur over time that are the focus of this study.

The social network analysis revealed an increase in the amount and density of connections between these organizations over the last fifteen years. The analysis also exposed the underlying patterns in these connections; that as the networks became more complex they also became more decentralized though not in any uniform manner. The present study brings to light a story of how communities have adapted to the ever changing circumstances that are sine qua non of natural and man-made disasters. 


\section{TABLE OF CONTENTS}

CHAPTER

PAGE

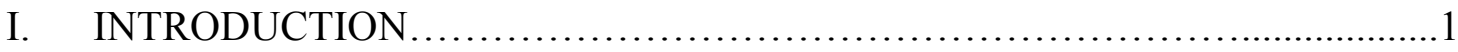

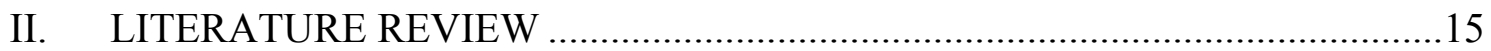

Institutional Adaptation among Local Homeland Security Officials: The Case

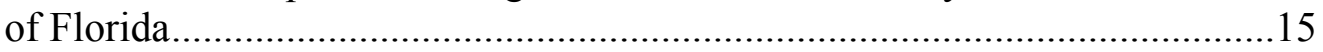

Local Homeland Security Networks in Analytical Perspective: Developing a

Typology for Homeland Security Related Networks ......................................18

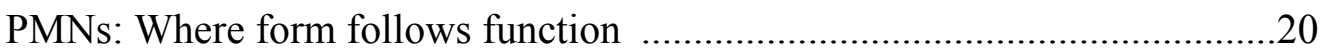

"Flying below the radar": The importance of analyzing local PMNs .............23

Interdependence: a key construct in understanding institutional

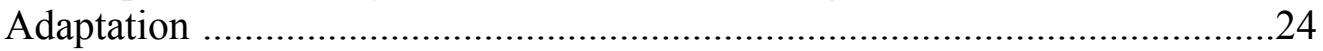

Distinguishing among forms of interdependence ……………………............25

Measuring Interdependence: Developing operational measures ......................26

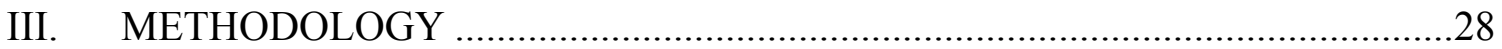

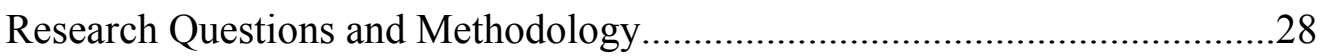

Defining the "patterns" that bind ........................................................................

Measuring the "ties" that bind: Centrality and the Interconnectedness of Local

Homeland Security Networks .........................................................................32

Degree Centrality: Connectedness \& Interdependency ....................................32

Betweenness: Evaluating the influence of actors on information flow in local

homeland security networks ....................................................................33

From ties to relations: Developing a schema for analyzing relations in a local

homeland security network .........................................................................

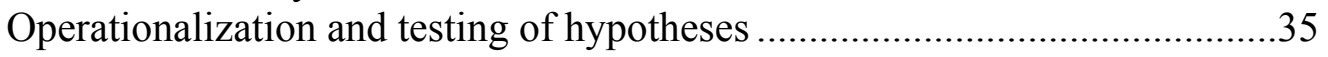

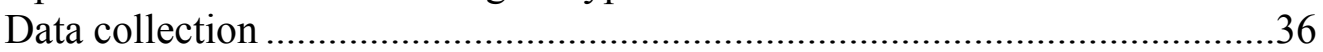

Constructing the Network ................................................................................

An important note in terms of jurisdiction..........................................................39

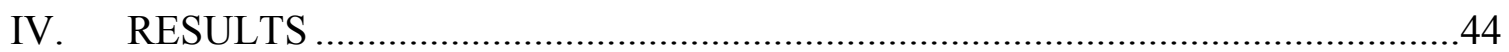

Analysis of Local Homeland Security Networks in the State of Florida..........44

Evolution of Local Homeland Security Networks in the State of Florida........44

Evaluating the Network as a Complex Adaptive System (CAS) .....................52

Evaluating the Communication within the System: Measuring Information

Flow..................................................................54

Tracing the Development of Local Homeland Security Networks in Florida:

Two Case Studies of Institutional Adaptation ...................................................56

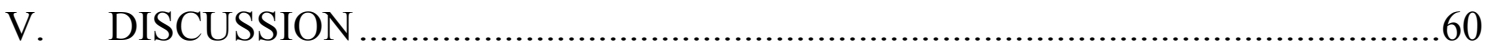

Implications of the institutional adaptation of Local Homeland Security

Networks 
Analyzing the Patterns of Covariation: Types of Interactions among Local Homeland Security Organizations in the State of Florida ................................62 Addressing Temporal Precedence in the Adaptation of Local Homeland Security Networks 63

Accounting for Alternatives: Plausible Rival Explanations of the Formation of CCCs and CERTs in the State of Florida

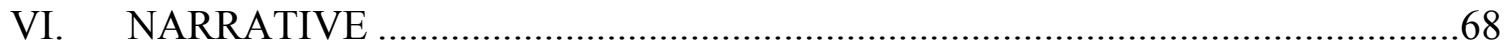

Developing a narrative for the development of Local Homeland Security

Networks: the Case of Florida ........................................................................68

Mandated or Improvised Change: the role of CCCs and CERTs in measuring adaptation in local homeland security organizations ………….....................71

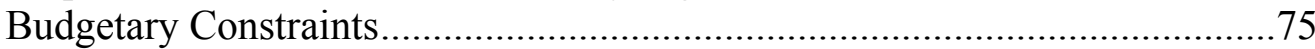

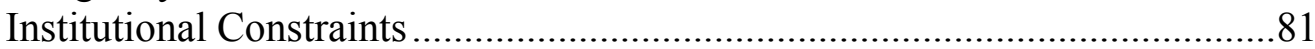

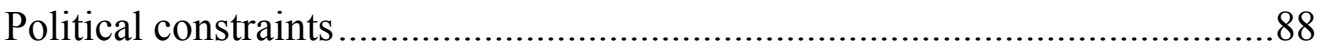

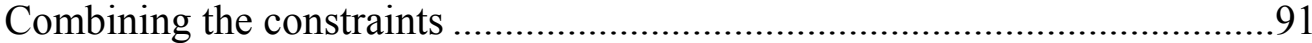

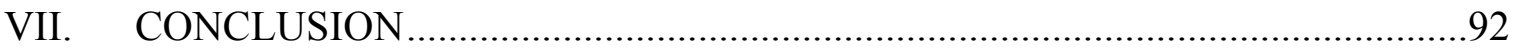

Getting Ahead of the Curve: The Implications of Viewing Local Emergency

Management in the State of Florida as a Complex Adaptive System..............92

Limitations of the Study...........................................................................99

Implications for Public Administration Theory and Practice ...........................99

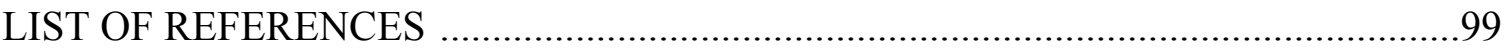

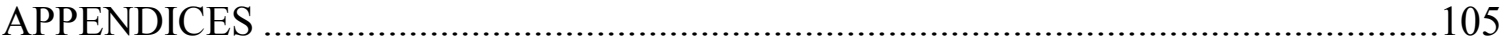

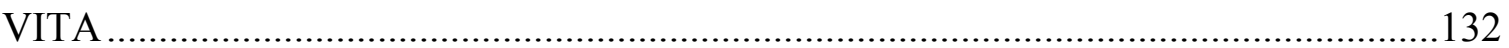




\section{LIST OF TABLES}

TABLE

PAGE

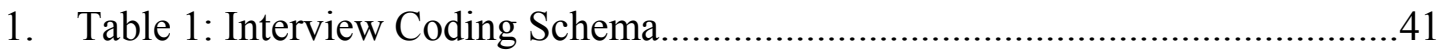

2. Table 2: Top Five Florida CCCs and CERTs by their Normalize Degree Centrality in 2002, 2005, and 2011

3. Table 3: Florida CCCs and CERTs overall degree centrality measures for 2002, 2005, and 2011.

4. Table 4: Florida CCCs and CERTs overall normed mean degree centrality measures for 2002, 2005, and 2011

5. Table 5: Information Flow in overall Freeman Betweenness Centrality measures for Florida CCCs and CERTs in 2002-2011. 


\section{LIST OF FIGURES}

FIGURE

PAGE

1. Figure 1: Typology of Local Homeland Security Public Management Networks based on the schema of Agranoff (2007)

2. Figure 2: Statewide view of the seven Regional Domestic Security Task Forces (RDSTFS)

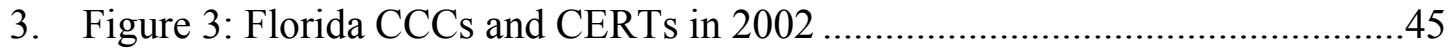

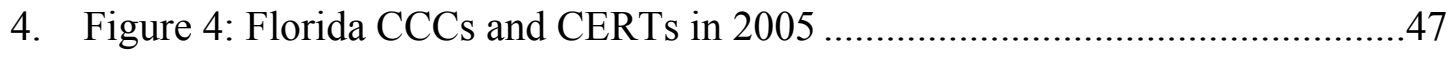

5. Figure 5: Florida CCCs and CERTs in 2011( Freeman Degree Centrality) .........49

6. Figure 6: Region One of the Florida CERT Association ..................................59

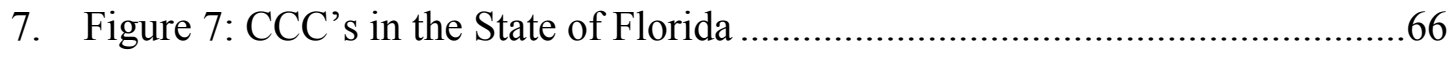

8. Figure 8: Total and State and Local Government Coordination Program SLGCP

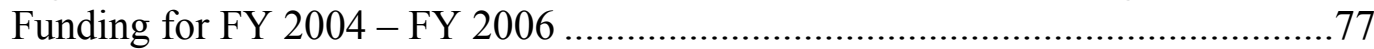

9. Figure 9: U.S. Department of Homeland Security Funding Breakdown for

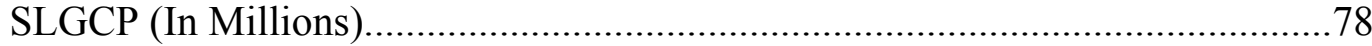

10. Figure 10: Total USDHS State and local funding by program type for: FY 2004 to FY 2006 


\section{ACRONYMS AND ABBREVIATIONS}

\begin{tabular}{|c|c|}
\hline $800 \mathrm{MHz}$ & 800 Megahertz radio frequency \\
\hline $\mathrm{BSO}$ & Broward Sheriff's Office \\
\hline BJA & Bureau of Justice Assistance \\
\hline CAD & Computer Assisted Development \\
\hline CERT & Community Emergency Response Team \\
\hline $\mathrm{CCC}$ & Citizen Corps Council \\
\hline CAS & Complex Adaptive System \\
\hline DHS/USDH & United States Department of Homeland Security \\
\hline DSOC & Domestic Security Oversight Committee \\
\hline EMAC & Emergency Management Assistance Compact \\
\hline EOC & Emergency Operations Center \\
\hline FY & Fiscal Year \\
\hline FL-TF1 & Florida Task Force 1 \\
\hline FL-TF2 & Florida Task Force 2 \\
\hline FDOEM & Florida Division of Emergency Management \\
\hline FDLE & Florida Department of Law Enforcement \\
\hline FEMA & Federal Emergency Management Agency \\
\hline HSPD & Homeland Security Presidential Directive \\
\hline ICS & Incident Command System \\
\hline
\end{tabular}




\begin{tabular}{|c|c|}
\hline IQV & Index of Qualitative Variation \\
\hline NGA & National Governor's Association \\
\hline NIMS & National Incident Management System \\
\hline NRF & National Response Framework \\
\hline NRP & National Response Plan \\
\hline PMN & Public Management Network \\
\hline RDSTF & Regional Domestic Security Task Force \\
\hline SERP & Statewide Emergency Response Plan \\
\hline S\&L Grants & State and Local Grants \\
\hline S\&L T\&E & State and Local Government Training and Education Grants \\
\hline SLGCP & $\begin{array}{l}\text { Office of State and Local Government Coordination and } \\
\text { Preparedness }\end{array}$ \\
\hline SNA & Social Network Analysis \\
\hline UASI/TIPP & $\begin{array}{l}\text { Urban Area Security Initiative/Targeted Infrastructure } \\
\text { Preparedness Program }\end{array}$ \\
\hline UCINET 6/ & Computer software package for Social Network Analysis \\
\hline NetDraw & Network Visualization Tool \\
\hline USCM & United States Conference of Mayors \\
\hline USPS ZC & United States Postal Service Zip Code \\
\hline
\end{tabular}




\section{CHAPTER ONE}

\section{DEVELOPMENT OF LOCAL HOMELAND SECURITY NETWORKS IN THE STATE OF FLORIDA: A SOCIAL NETWORK ANALYSIS APPROACH INTRODUCTION}

On the morning of September 11th, thousands of fire fighters, police, federal agents and medical personnel responded to a plane hitting one of the towers of the World Trade Center. Fire fighters put on their gear and rushed to the scene, police cornered off the affected streets, federal agents began to investigate, and medical personnel set up triage facilities. Each group reacted to the disaster using their own standard operating procedures. As the morning progressed, it became apparent that all of their procedures and protocols were inadequate to deal with the crisis at hand.

Among the most important impediments facing these officials in their response was the inability to communicate with each other because the various first responders (fire, police, medical) all had different radio systems and operating frequencies $(9 / 11$ Commission Report). The inability to communicate led to a lack of coordination as dozens of fire companies (so-called ladders), police precincts, and hospital districts prepared for a massive rescue effort that quickly became a massive recovery effort. The length and depth of the crisis was not readily apparent initially as the entirety of lower Manhattan was closed to vehicular traffic.

Media accounts centered on the enormity of the event and news anchors spoke in hushed tones as the number of casualties increased. Senior governmental officials stated that "no one expected this to happen" (Brush, 2002). Various factors interacted with each other to create a unique series of events; a plane striking a building that was designed to 
withstand the impact of a plane; a building's steel girders designed to withstand high temperatures for short but not long periods of time, and the voluminous amounts of smoke choking the stairwells designed to provide an escape to those trapped in the buildings. As firefighters rushed into the towers and police controlled the massing crowds, the unthinkable finally happened; the towers fell.

Fire fighters, police, and medical personnel each planned and conducted their responses and operations separately from each other. Each of these groups followed standard operating procedures, developed over many years of practice, not taking into account the possibility of a missing factor or "variable"(the towers falling) as they were unable to "connect the dots" (9/11 Commission Report and Zakaria, 2011).

The response to $9 / 11$ is not unique; there is in fact a pattern of institutional responses that have taken a similar path. Other recent events like the 2004/ 2005 hurricane season and the Gulf Oil Spill (2010) revealed that local governments and their various agencies were overwhelmed when confronted with either of two types of events; (1) low-probability/ high impact events such as a act of terrorism or an offshore oil spill, and (2) high impact/ higher probability events such as a category five hurricane (Comfort et. al, 2010, Eisenger 2006, Scavo et. al, 2006, Waugh 2004, Birkland, 1997).

Both types of events galvanize public attention and serve to "focus" the attention of both the public and governmental officials on rescue and recovery operations. These responses often do not deal with the underlying causes that led to the event. In essence, both the public and governmental officials are consistently responding to the latest "focal" event. They are behind the curve with regard to planning, preparing, responding, and recovering; thus leaving themselves vulnerable to low probability/ high impact 
events such as the towers falling (9/11), levees breaking (Hurricane Katrina) and safety systems failing on a deep water drilling platform (Gulf Oil Spill). While, at all levels of emergency management, some homeland security officials were behind the curve in making critical decisions, others, at the same time, were able to prevent significant loss of life and damage to property. To understand these differences, a shift in how we look at emergency management as an institutional system is necessary. Until now, theory saw emergency management as a linear process focusing on planning, preparing, responding, and recovering from natural and man-made disasters. But these processes (in practice) are dynamic and multifaceted. Furthermore, these processes take place within an institutional setting (or system) that also adapts its strategies to a constantly changing environment reflecting a denoted Complex Adaptive System (CAS).

\section{General Statement of the Research Problem}

My dissertation follows the development of local homeland security organizations in the state of Florida since 2001. These organizations, also in charge of emergency management, are seen as complex adaptive systems (CAS) as defined by Johnson (2007) and applied to emergency management by Kapuchu (2010). My dissertation describes the manner in which these organizations and the individuals that coordinate their actions have adapted to three types of constraints: (1) budgetary, (2) institutional and (3) political. While these constraints existed before, they recently have been modified to deal with 'focal events' such 9/11 and Hurricane Katrina. In adapting to these constraints, these organizations and the individuals that coordinate their actions have developed novel methods of achieving their missions. 
To demonstrate agency adaptation in a quantitative manner, my dissertation charts the development of two sets of interconnected organizations, Citizen Corps Councils and Community Emergency Response Teams, from 2002 to 2011. To explain the adaptation in a qualitative manner, interviews were conducted with local emergency management officials in South Florida, to show how local first responders such as fire chiefs, have changed their management of natural or man-made disasters. Florida was chosen due to its experience with natural disasters and it reputation as a leader in the area of emergency preparedness and response.

The management of natural and man-made disasters used to be the responsibility of localities, leading to a variety of "policies and practices" adopted by the various levels of government. These focusing events like $9 / 11$ and the 2004/2005 hurricane season revealed a serious lack of coordination and communication among the various agencies involved in preparing, planning, responding, and recovering from a homeland security incident (Kettl, 2003).

Research investigating the response to $9 / 11$, revealed the need for a new type of coordination among public administrators at all levels (Comfort et. al. 2010, Kapucu et. al, 2009, Kettl, 2003, MacManus and Caruson, 2004). The initial development of a national emergency plan (the National Response Plan or NRP) organized the different levels of government (local, tribal, regional, and national) through a system based on interoperability, joint planning, and training. An example of this: the use of the NRP (that was implemented in 2004) occurred during the response to Hurricane Katrina. The response to Hurricane Katrina also exposed the weaknesses of the National Response Plan; specifically the lack of coordination and cooperation evident in the evacuation of 
the City of New Orleans. The National Response Plan was deemed "bureaucratic and internally repetitive [and] insufficiently national in its focus" and was replaced by the National Response Framework or NRF issued in January 2008 (NRF, FEMA, 2008, 2).

Specifically, the NRF is defined by the Federal Emergency Management Agency or FEMA as:

"A natural evolution of the national response architecture. Although the NRP was originally called a plan, it was actually a framework written to guide the integration of local, tribal, state, and federal response efforts. By adopting the term "framework" within the title, this document is now more accurately aligned with its intended purpose (Source: website: http://www.fema.gov/pdf/emergency/nrf/about_nrf.pdf)

Among the key purposes of the NRF is to define the roles of individuals and organizations involved in responding to natural and man-made disasters. This was through detailing the "key principles of response doctrine" These principles include: "Engaged Partnership" to ensure "no one is overwhelmed in a time of crisis" "Tiered Response" to ensure that "incidents are managed at the lowest level possible"

"Scalable, Flexible and Adaptable Operational Capabilities" to ensure that response is "able to meet requirements [as] incidents change in size, scope and complexity" "Unity of Effort through Unity of Command" to ensure that all organizations involved have a "clear understanding of the roles and responsibilities of each participating organization.”

"Readiness to act" to ensure that actions are "balanced with an understanding of risk" (NRF brochure, FEMA, 2008, 4) 
The focus of these principles lies in the proposition that individuals, governmental organizations of all levels, private sector organizations and non-governmental organizations all have a role to play in responding to natural and man-made disasters.

To address the inadequacies revealed by Hurricane Katrina, the National Response Framework mandated three actions including (1) increased use of training exercises in which all agencies (local, tribal, state, federal) involved in homeland security planning to participate, (2) adoption of a common radio frequency standard, the $800 \mathrm{mhz}$ radio frequency, and (3) adoption of standardized radio protocols by all officials (local, state or federal) involved in responding to a homeland security related incident.

The basis of both the NRP and NRF is the National Incident Management System or NIMS which serves as the blueprint for all preparation, planning, response, and recovery from man-made and natural disasters. As a result, local and state emergency response plans are required to "implement the NIMS" according to Homeland Security Presidential Directive 5 (FEMA, 2006, 2). The number and scope of these mandates have increased in the ensuing fiscal years. There are twenty-eight "metrics" by which local governments are judged in FY 2009, the latest year for which "implementation objectives" were issued (FEMA, 2009, 1). Among these objectives is the creation of training programs for first responders, objectives 9-15, ensuring all "Federal Preparedness Awards" including those to local governments support NIMS compliance, objective 4, and "develop and/or promote intrastate and interagency mutual aid agreements", objective 8 (FEMA, 2009, 1). 
Various factors affect the implementation of the National Incident Management System. Two of the most important factors include: (1) the congressional appropriations process, and (2) the likelihood of a possible threat. For example, the original funding formula adopted by the Department of Homeland Security allocated seven times more funding per capita to Wyoming than to New York City (Scalet, 2006). The current funding formula mandates that a majority of an area's funding be based on the threat assessment provided by the Department of Homeland Security (DHS website).

Concurrently, federal funding for local homeland security related projects have remained flat or decreased. Specifically, all funding provided from the Department of Homeland Security have amounted to ten percent less of all DHS funding in any fiscal year since 2003 (DHS Budget in Brief, FY 2004-2011). In order to receive funding, localities have to be rated NIMS compliant by the Department of Homeland Security. The fundamental issue confronting local homeland security decision makers is that they must devote time and staff to a resource intensive bureaucratic process. Despite the increased workload, staffing levels in most jurisdictions have remained the same, thus leading officials to "wear multiple hats" in terms of their roles in complying with NIMS protocols. In spite of the federal mandate and the emphasis on training and equipment, some necessary tools have only been partially implemented.

What the National Response Plan and the National Response Framework have in common is that they both form part of a larger pattern; they were largely "responses" to "focal events." Each time a "focal event" occurred, the plan was revised to include new policies and procedures yet they did not address the underlying issue; that governmental responses are reactive and not proactive. The plans continually fail to address the missing 
variable and are not connecting the dots. The plans are behind the curve in viewing the stages of emergency management as a linear process (as mandated by NIMS i.e. planning, preparation, response and recovery) when in fact they are a nonlinear process in which planning, preparing, responding and recovering occur in an iterative fashion that is reciprocally causal in nature.

\section{Statement of Purpose}

My study focuses on the response of local homeland security officials in dealing with the inadequate implementation of NIMS standards. It is hypothesized that local homeland security officials developed compensatory strategies through the creation and use of formal and quasi-formal networks. It is important to note here that a number of these changes, such as training, funding and mutual aid agreements were mandated by National Incident Management System. Others, such as the development of organizations such as a Community Emergency Response Team were not mandated. Furthermore, the most important factor in the development of Community Emergency Response Teams is that of citizen interest since these organizations are staffed, except for their coordinator, entirely by volunteers. Therefore, evaluating the number and density of network connections between these organizations will reflect the complexity of the network thus outlining a mixture or blend of mandated and improvised institutional change after the implementation of NIMS compliance objectives. My dissertation evaluates how local homeland security organizations, which while operating with the constraints of their institutions, have had to adapt to the new requirements.

The evolution of Broward county homeland security organizations (BSO) provided one example; specifically, that the BSO has initiated a program entitled 
"Automatic Aid" in which local first responders are dispatched to incidents based on geographic proximity, rather than jurisdictional boundaries (Interview with Broward County first responder (3C)). To gauge institutional change, the relationship between these organizations was evaluated via Social Network Analysis (SNA) using the following indicators: 1) the number of organizations existing within these networks (the mutual aid agreements between jurisdictions in Broward and Dade County) and 2) the density of connections between these networks at the local level (communications between various first responders, i.e., fire chiefs or police chiefs within and between Dade and Broward Counties).

The number of organizations working in tandem to respond to natural and manmade disasters has increased significantly during the years of 2002 to 2011. In particular, the organizations that increased the most were the Community Emergency Response Teams or (CERTs) and (CCCs) or Citizen Corps Councils. Community Emergency Response Teams (CERTs) are groups of volunteer neighborhood point-persons that communicate with first responders in the event of a natural or man-made disaster and are trained and overseen by local first responders. Citizen Corps Councils are umbrella organizations consisting of public, private, and non-profit organizations involved in preparing for and responding to natural and man-made disasters. In 2005, there were five CERTs and no CCCs in Broward County. By 2011, the number of organizations had grown to one County CCC, (Broward County), one Municipal CCC (Miramar) and eighteen Community Emergency Response Teams. 


\section{Research Questions and Methodology}

The research question this dissertation explores is how local homeland security organizations and their officials have adapted to the budgetary, political, and institutional constraints in the last decade. To answer this question, a mixed approach employing both quantitative and qualitative techniques was used. To evaluate the interaction of the existing homeland security organizations in the state of Florida, an analysis regarding the number and density of connections among these networks was conducted using Social Network Analysis (SNA). Data for evaluating these networks were gathered through "dash-boards" covering the years 2001-2011. These data are readily available on the internet on websites like www.citizencorpscouncil.gov and the Florida CERT association www.floridacertassociation.net. To obtain a more detailed picture of the institutional adaptation processes, additional data were collected through a series of interviews of local homeland officials. The interviews consisted of open-ended questions designed to evaluate the extent of changes that have occurred in these networks since 2001.

According to Kapuchu and co-authors (2009), emergency management resembles a complex adaptive system (CAS) in which the organizations interact in a reciprocally causal manner that is characterized by the "interdependence" of local homeland security organizations, the individual who manages them, and the changes through the adaptation to budgetary, institutional, and political constraints. For example, the basis of the National Incident Management System (NIMS) is the Incident Command System (ICS). The ICS was developed by a task force of local, state and federal agencies in California after a series of deadly wildfires in the early 1970's which were caused by a severe drought worsened by increasing urbanization. The two factors (wildfires and 
urbanization) interact, and neither factor is the "clear driver" causing a change in the others signifying "interdependence". While there are several forms of interdependence, this study makes use of two main types: (1) political interdependence and (2) spatial interdependence. Political interdependence is defined as "the interdependence and interconnectedness of political processes in different jurisdictions" (Hay 2010, 6-7) like CCCs and CERTs in the State of Florida. Spatial interdependence is defined as "the interdependence of spatial scales" (Hay 2010, 6-7), meaning different levels of government, like local first responders and elected local officials.

\section{Hypotheses}

In my study, it is hypothesized that after the implementation of NIMS policies and procedures, local homeland security officials have increased their connections the organizations that make up local homeland security policy

Thus it is hypothesized that:

As local homeland security networks become more complex over time (2002 to 2011), they become more decentralized. Decentralization is operationally defined by an increase in the number and density of connections between organizations that make up local homeland security policy during the last ten years. This is measured by the presence

of a common jurisdictional boundary that is determined by the areas served by two sets of local homeland security organizations; i.e. CCCs and CERTs.

\section{Operationalizing Variables}

Following the work of Agranoff (2007), for the purpose of this study, a formal network is operationally defined as a chartered network which exists as a "formally established organized entity" such as a 501(c) 3 non-profit organization, and was 
established by the action of a legislative body, or an executive order of a governor, or through registration with the Secretary of State; CERTs and CCCs are examples of formal networks.

Social Network Analysis is a procedure that quantitatively evaluates and graphically displays the number and density of connections among "actors" in these organizations (homeland security officials or organizations). Social Network Analysis (SNA) has been used to evaluate other aspects of homeland security policy including Emergency Management Assistance Compacts (Kapuchu, 2009). Using SNA reveals how the evolution of these networks took place. Analyzing the number and density of connections between these networks will help to depict local governments' responses to administrative mandates following focal events such as 9/11 and Hurricane Katrina.

\section{Significance of the Study}

The present dissertation focuses on the adaptation of local homeland security organizations and their officials to institutional mandates and constraints using a longitudinal approach and applying a complex adaptive system model. While there is a growing body of research in public administration concerning the institutional adaptation of homeland security organizations, relatively few other researchers (Bellavita, 2006; Currao, 2009, Kapuchu, 2009) have seen these institutional adaptation processes as a complex adaptive system and applied CAS methodology to local homeland security organizations. Furthermore, most of their research followed on a cross-sectional approach. 
Using a longitudinal approach and viewing these institutional adaptation processes as a non-linear development, my study employs social network analysis to depict the "pattern" or variety of interactions among CCCs and CERTs in the state of Florida. In addition, the outcome of social network analyses was enhanced by a series of interviews of local homeland security officials outlining the breadth and depth of the adaptations within the framework of institutional, budgetary, and political constraints. The results of the present research describe how both the number and density of connections between CCCs and CERTs in the state of Florida have increased over the last decade. My analysis also revealed how the decision making processes of local homeland security officials became more decentralized while adapting to institutional, budgetary, and political constraints.

\section{Overview of Chapters}

Chapter one, gives an outline of the study, its purpose and significance.

Chapter two presents the theoretical underpinnings of the study through a synthesis of the literature on emergency management, social network analysis (SNA) and complexity theory. In this chapter, key concepts of emergency management such as "focal events," key concepts of SNA such as "centrality," and key concepts from complexity theory such as "interdependence" and their importance to analyzing local homeland security networks are expounded upon in depth.

Chapter three details the methodology used to collect, analyze, and evaluate the hypotheses under study. In particular, chapter three will include a description of the techniques used to collect and analyze the data collected as well as any software packages utilized in the study. 
Chapter four presents the results of the SNA of the CCCs and CERTs in the state of Florida. Included in this section, will be several tables and maps that are produced using a SNA software program entitled UCINET 6 which is the primary program for this type of analysis.

Chapter five presents a discussion of the results of chapter four in relation to the hypothesis presented in chapter one.

Chapter six presents the contents of a series of interviews that are woven into a narrative providing context for chapters four and five.

Chapter seven presents a conclusion to the study in terms of its hypothesis. It also discusses the limitations of the study and provides guidance regarding questions raised by the study for further research. 


\section{CHAPTER TWO}

\section{INSTITUTIONAL ADAPTATION AMONG LOCAL HOMELAND SECURITY \\ OFFICIALS: THE CASE OF SOUTH FLORIDA}

Before 9/11, in the state of Florida, various local governmental organizations were in charge of emergency management. Each organization had their own: functions, standard operating procedures, communication protocols and operated in an independent fashion. After 9/11, new institutional mandates were issued by the federal government to address the lack of cooperation and coordination displayed during the response to the attacks on the World Trade Center and the Pentagon. A new institutional framework was put in place to increase cooperation and coordination, both within and between levels of government in charge of emergency management.

A senior Broward County Fire official made the following statement concerning this framework.

Well, I think the training requirements may have changed, made us change. We'veeverybody has to be trained in NIMS to their level- required level and we have to manage that now. It's a - one of those unfunded mandates (Senior Broward Fire Official (9I))

As a result of this increased cooperation and communication, local homeland security officials reported a growing interdependence:

The State of Florida - I'm not sure if every state does it, but the State of Florida after September $11^{\text {th }}$ then coordinated a joint effort between the Florida Department of Law Enforcement, that's kind of the lead agency, FDLE, and the local sheriff's offices. Every county in Florida, all 67, have a sheriff's office, created Regional Domestic Security Task Forces. There are seven in the state. They created them along the lines of our Division of Emergency Management Zones, so the seven regions have already existed. (Senior Miami Dade Fire Official (4D))

There is evidence from the existing literature (Macmanus and Caruson 2006) that the growing interdependence among local organizations is the result of mandates from 
federal and state governments dealing with homeland security-related issues. The National Incident Management System is one example of these mandates. In response to NIMS mandates and focal events like 9/11 and Hurricane Katrina, Florida's local homeland security organizations formed a group or network of organizations, CCCs and CERTs and increased their reliance on Mutual Aid Agreements to adapt to budgetary constraints. To provide evidence of local government's response to administrative mandates such as NIMS, the evolution and interaction of existing homeland security networks in the state of Florida, were analyzed via "Social Network Analysis" (SNA). Specifically, the number and density of connections among two sets of organizations, CCCs and CERTs, were evaluated.

In particular, interactions between CCCs and CERTs were operationalized as the degree of connectedness or "centrality" (Kapucu et al. 2009, Knoke and Yang 2008). The more connections an organization has, the more "central" it is to the network. Each CCC and CERT is part of a larger network in which each organization serves as an "actor" or connection point in the network. ${ }^{1}$

Analyzing local homeland security networks in the state of Florida via SNA necessitates understanding SNA's theoretical bases. "[S]ocial networks" are defined as "finite set or sets of actors and the relation or relations set on them (Wasserman and Faust, 1994, 20)." "Actors" can be people in a group, departments within an organization, or even nations in the world geopolitical system (Wasserman and Faust, 1994, 17, Knoke

\footnotetext{
${ }^{1}$ The concept of "actors" is central to social network analysis and forms the basis for the analysis that will follow in this dissertation. A more detailed discussion of this concept will be made in the next chapter. Additional information on social network analysis can be found at the following website: http://faculty.ucr.edu/ hanneman/nettext/
} 
and Yang, 2008, 6-7). These organizations can be connected by a variety of factors they have in common. Such factors are denoted "relational ties" where a "relational tie" is defined as a "linkage between a pair of actors" (Wasserman and Faust, 1994, 18, Knoke and Yang, 2008, 6-7).

There are two basic types of relations between actors, (1) directed in which "one actor initiates and one actor receives" or (2) non-directed in which each actor initiates and receives. My dissertation concerns the directed relational ties between CCCs and CERTs in the last ten years. It is important to note here that the tie itself is not an attribute of the actors individually, but a separate property of the relation itself. In other words, the relation/tie itself has a value that is separate and distinct from the other actors and "exists only as long as the association occurs" (Knoke and Yang, 2008, 7).

In terms of homeland local security policy, a fire chief has a specific relational tie with another fire chief which only exists within their professional capacity. There may be other informal relations such as those of a friendship that impact the professional relation, but from an analytical standpoint, these are separate relations. The distinction between types of relations i.e. professional or friendship is important, because the individuals that make up these local first responder organizations often must "wear multiple hats." For example, nearly all of the CCCs and CERTs in the state of Florida are coordinated by a first responder (fire or police official) or a local emergency manager. The importance of these organizations lies in the fact that they have come to represent a significant resource for local first responders in adapting to the institutional constraints placed on them by other higher levels of government. 
But how can we analyze the various types of relations represented in a network in a clear, concise and efficient manner? One way is to develop a "structure" for analyzing the "network data" collected. It is important to emphasize that "network data" is in many respects the same as the "conventional data" collected from surveys or focus groups. It can be quantified and arranged in arrays that depict how these data relate to each other. This can be done by creating a matrix that defines the relations between the actors in a network where the presence of a relation is denoted by a 1 and the absence of a relation is denoted with a $0^{2}$ (Hanneman and Riddle, 2008, 69-70).

\section{Local Homeland Security Networks in Analytical Perspective: Developing a Typology for Homeland Security Related Network}

Now that we have defined a network in general and its components in detail, it is appropriate to move on to define networks within the area of homeland security policy. Robert Agranoff, in his book Managing Within Networks, provides a basic typology for what he terms "Public Management Networks (PMNs). Using the definition first proffered by O’Toole, Agranoff states that PMNs are "structures of interdependence involving multiple organizations... where one unit is not merely the formal subordinate of the others in some larger hierarchical arrangement" (O'Toole quoted in Agranoff, 2007, 7).

A key distinction between PMNs and the more traditional public bureaucracies is the locus of authority for management. In more traditional public bureaucracies, authority is vested legally in the positions of officials in the hierarchy of their organization. In

\footnotetext{
${ }^{2}$ An "incidence or affiliation matrix" is a special type of square array that is used to record and display data about the relationships between two types of organizations (Hanneman and Riddle, 2008, 69-70).
} 
PMNs, management is more collaborative and based more on consensus building (Agranoff, 2007, 8-9). The concept of collaborative management is crucial to the understanding of how a network functions since the "structure" (i.e., relationships between organizations and even between individuals engaged in their operation) are the locus of network activity. Overall, the management in networks is different than in most public bureaucracies because the authority among network actors is interdependent. Specifically, it is a network's ability and agility to respond to novel threats arising from natural and man-made disasters that determines the success of the network's responses. For example, reliance on the Emergency Management Assistance Compact in the wake of Hurricane Katrina is an example of the use of a PMN in practice (Kapuchu, 2009).

Proceeding from this general definition of networks as interdependent structures, PMNs can be characterized by two general types 1) chartered and 2) non-chartered. Chartered networks are "formally established as organized entities" such as 501(c) 3 nonprofit organizations, actions of a legislative body or an executive order of a governor, or through registration with the Secretary of State. Non-chartered networks have no "formal-legal status"; they make an impact through various activities, including meetings and other organized activities (Agranoff, 2007, 7). An example of a chartered network is CERTs, which includes a volunteering neighborhood point-person who communicates with first responders in the event of a natural or man-made disaster.

Both of these types of networks share common characteristics, such as regular formal meetings and identifiable participants, partners and governance structures through which their members participate including websites, newsletters and holding of offices. In order to better understand how local homeland security officials and their institutions 
have adapted to changing administrative mandates, it is important to evaluate both types of chartered and non-chartered networks- for two reasons: (1) As stated by Agranoff (2007), many institutional adaptations of the last five years have occurred outside the mandates of chartered organizations, like the Automatic Aid Agreements between different municipalities, and (2) these adaptations have taken the form of dynamic instead of static interactions between chartered and non-chartered networks.

\section{PMNs: Where form follows function}

In practice, PMNs span the boundaries of public, private and non-profit organizations which make up both chartered and non-chartered networks. Public Management Networks also serve different functions, just as the organization they are composed of serve different functions. This dissertation concentrates on four different types of networks: (1) Informational Networks, (2) Developmental Networks, (3) Outreach Networks, and (4) Action Networks.

(1) Informational networks can be seen as clearinghouses for information. Action based on the exchange is left to the discretion of the participants. In homeland security policy, informational networks exist among various first responders and elected officials.

(2) Developmental networks combine "information and technical exchange... with education and member service" (Agranoff, 2007, 10). These networks function as a conduit for capacity building among member organizations. In homeland security policy, these networks serve to assist member organizations by providing not only information but expertise that assists members in implementing best 
practices. The development of regional or statewide security task forces, such as the Regional Domestic Security Task Forces employed in the State of Florida, is an example of a developmental network. Outreach networks integrate information exchange and technologies that "lead to new programming avenues" (Agranoff, 2007, 10). In homeland security policy, these networks not only serve to exchange information and expertise, but also to assist in implementing new programs. One example would be the Council of Governments operating throughout the United States of which the South Florida Regional Planning council is a member.

Action networks are those in which member organizations "formally adopt collaborative courses of action" (Agranoff, 2007, 10) in addition to exchanging information, expertise and technology. These networks deliver services that are agreed upon by the network itself. The collection of CCCs and CERTs that have formed in the last decade in the state of Florida are an example of an action network. Not only do they provide information, expertise and technology, when mobilized for a man-made or natural disaster, they deliver services to their neighborhood. As described by a Broward County official:

"We're pulling in volunteers... the key part of its they're out in the community in their neighborhoods where the people know them, so if they come up to their neighbors and they, you know, see that they're flooded or they're lightly trapped or they need first aid, it's not like a stranger, you know, coming up to them." (Senior Broward County Fire Official (3C)). 
Figure 1: Typology of Local Homeland Security Public

Management Networks based on the schema of Agranoff (2007)

TYPOLOGY OF LOCAL HOMELAND SECURITY PUBLIC MANAGEMENT NETWORKS

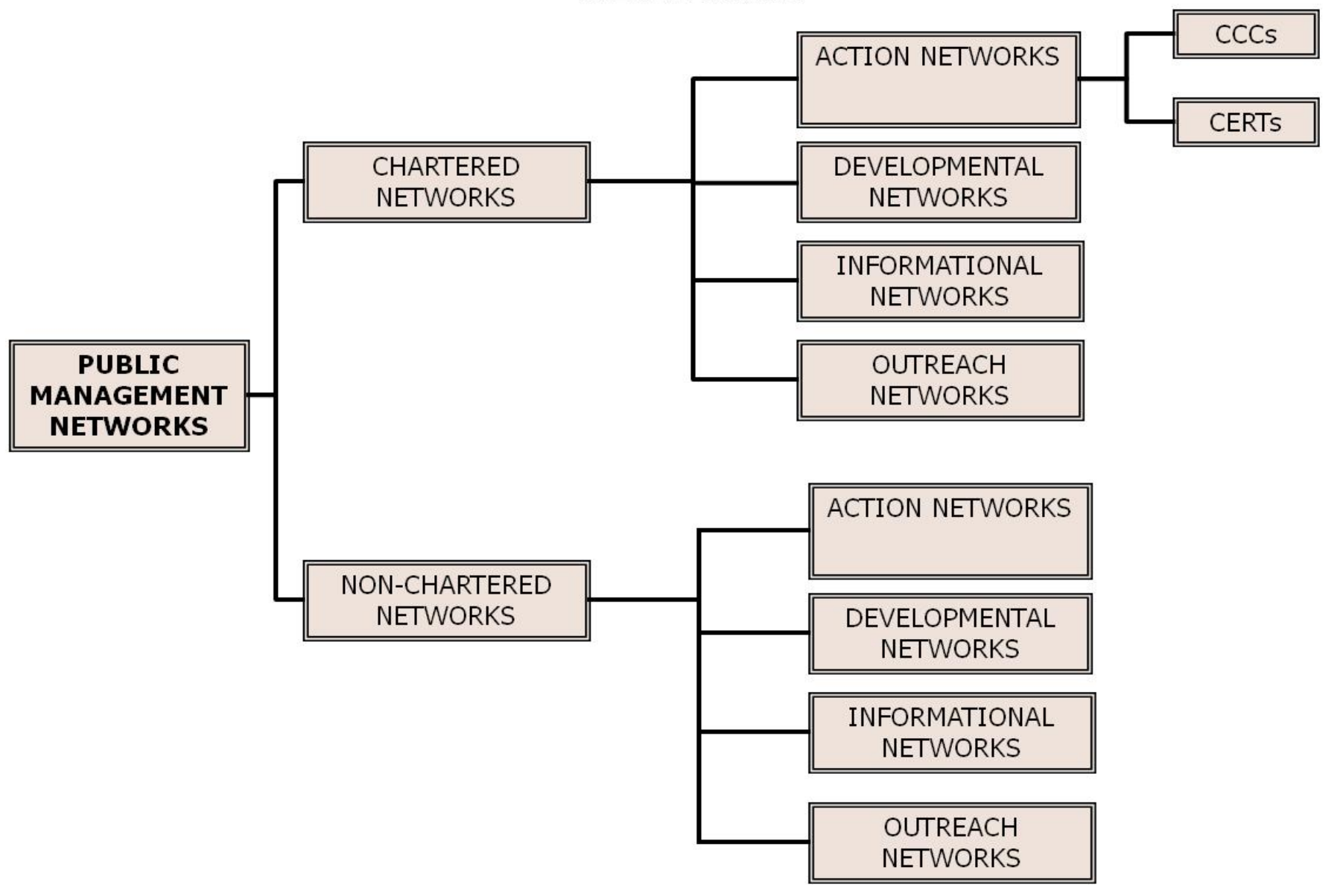




\section{"Flying below the radar": The importance of analyzing local PMNs}

Given that PMNs exist at all levels of government, why study PMNs at the local level? The main reason is that on this level "most of the real work is done". For example, first responders respond to either a natural disaster such as a hurricane or a man-made disaster such as a terrorist attack at the local level. Furthermore, while responses to disasters involve multiple actors at all levels (local, state, federal, and even international), these responses must be coordinated for delivery at the local level. For example, though the response to Hurricane Katrina involved dozens of organizations, these responses needed to be coordinated with local officials, who had more first- hand experience with the conditions on the ground (Agranoff, 2007,11, Kapucu et al, et. 2009, Lagadec, 2007). Thus interactions between the levels of government represent an important variable in analyzing how emergency managers respond to natural and man-made disasters.

One example of this coordination is the use of Emergency Management Assistance Compacts (EMACs) in the response to Hurricanes Katrina and Rita. Specifically, EMAC's are defined as "mutual aid agreement[s] and partnership[s] between states that allow states to assist one another in the event of a natural or manmade disaster" (Kapucu et al. 2009, 297). EMAC's are seen as a result of “dissatisfaction with emergency response operations following Hurricane Andrew" (Kapucu et al. 2009, 297).

Finally, one must differentiate between the various types of interactions. Specifically, there are three types of interactions among governments: (1) partnerships, (2) collaborations and (3) networks. The factors differentiating these interactions are the level of formality, range of issues and duration of the relationships created by these 
interactions. Partnerships exist at one end of this continuum where public or private organizations informally "agree together to achieve a desired goal" that is limited in scope and have no enduring relationship outside of this goal. Networks are more formal in terms of both the length of the relationship and the range of issues they deal with over time. Specifically, networks can have a range of relationships that run along the continuum from those that are loosely affiliated to those that are heavily interdependent and create new autonomous organizations as a result of their interactions (Kapucu, 2009, 298). This study focuses on the interactions between the CCCs and CERTs in the state of Florida.

Using social network analysis (SNA), my study will examine the extent of interdependence present among local homeland security organizations. Specifically, my study will analyze the adaptations that occurred in response to new forms of interdependence that have presented themselves in the last decade.

\section{Interdependence: a key construct in understanding institutional adaptation}

But what does interdependence look like in practice? Interdependence is defined in this study as "a relationship between two or (invariably) more factors, processes, or variables characterized by reciprocal causation or, perhaps better, mutual conditioning" (Hay, 2010, 6). There are two specific conditions which characterize interdependent interactions: (1) a change in one of the "factors, processes, or variables" must lead to a change in the "other factors, processes or variables" under study and (2) there is no "clear driver (or determinant) of the change in the others" (Hay, 2010, 6). Thus these interactions can be seen not as dependent on any one factor, process or variable, but on many factors taken together and thus interdependent. 
For example, the Incident Command System (ICS) was a response of a task force of local, state, and federal agencies to a series of wildfires in California in the early seventies. After the $9 / 11$ attacks, the ICS became the basis of the National Incident Management System. While the emergency management policy existed for decades prior to the implementation of NIMS, it needed a "focusing event" to provide the impetus for centralization.

\section{Distinguishing among forms of interdependence}

While there are several forms of interdependence, this study makes use of three types based on the work of Moran (Moran in Hay, et. al., 2010); (1) institutional, (2) spatial interdependence, and (3) policy interdependence. In the world of emergency management, mutual aid agreements are examples of institutional interdependence, coordination of different levels of government are an example of spatial interdependence, and interdepartmental cooperation is an example of policy interdependence.

For the purpose of my study, institutional (also called political) interdependence is operationalized as the jurisdictions of municipalities as characterized by United States postal service zip-codes. Spatial interdependence on local homeland security organizations will be analyzed through the interaction of Citizen Corps Councils (CCCs) and Community Emergency Response Teams (CERTs) in the state of Florida. In addition, policy interdependence or interdepartmental cooperation is evidenced by the interviews of local homeland security officials which also provide the context within which the interactions among local homeland security organizations can be evaluated.

Using these three types of interdependence as a theoretical framework, this study analyzes the "inter-connectedness" of the different jurisdictions that make up the 
Regional Domestic Security Task Force (RDSTF) of the state of Florida. The RDSTF is an organization that involves municipalities, counties, and the State Department of Emergency Management. These jurisdictions will be evaluated in terms of the interconnectedness of local homeland security organizations that have developed along side local first responder organizations such as Police and Fire Departments. Specifically, these jurisdictions will be evaluated in terms of the interconnectedness of two organizations, Citizen Corps Councils (CCCs) and Community Emergency Response Teams (CERTs). In practice, CCCs serve as umbrella organizations that bring together public, private and non-profit sector organizations in preparing, responding and recovering from natural or man made disasters. Community Emergency Response Teams (CERTs) are groups of volunteer neighborhood point-persons that communicate with first responders in the event of a natural or man-made disaster and are trained and overseen by local first responders.

Of particular interest in this analysis is the presence of new forms of institutional, spatial, and policy interdependence that characterize the "catastrophic risks" associated with man-made and natural disasters (Hay, 2010, 38). For example, the RDSTF deals with natural and man-made disasters and uses so called CCCs and CERTs as clearing houses of information for "actionable knowledge" (Agranoff, 2007, 10).

\section{Measuring Interdependence: Developing operational measures}

How can you measure interdependence in a network? Specifically, how can this measure be operationalized? My study will use "Centrality" as a measure of the amount of decentralization present in the network as hypothesized in the previous chapter. Specifically, this study will measure the amount of centrality present in the CCCs and 
CERTs in the state of Florida. Figure two displays the seven Regional Domestic Security Task Forces that make up the State of Florida System under the State of Florida Division of Emergency Management within which the CCCs and CERTs operate.

Figure 2: Statewide view of the seven Regional Domestic Security Task Forces (RDSTFs).

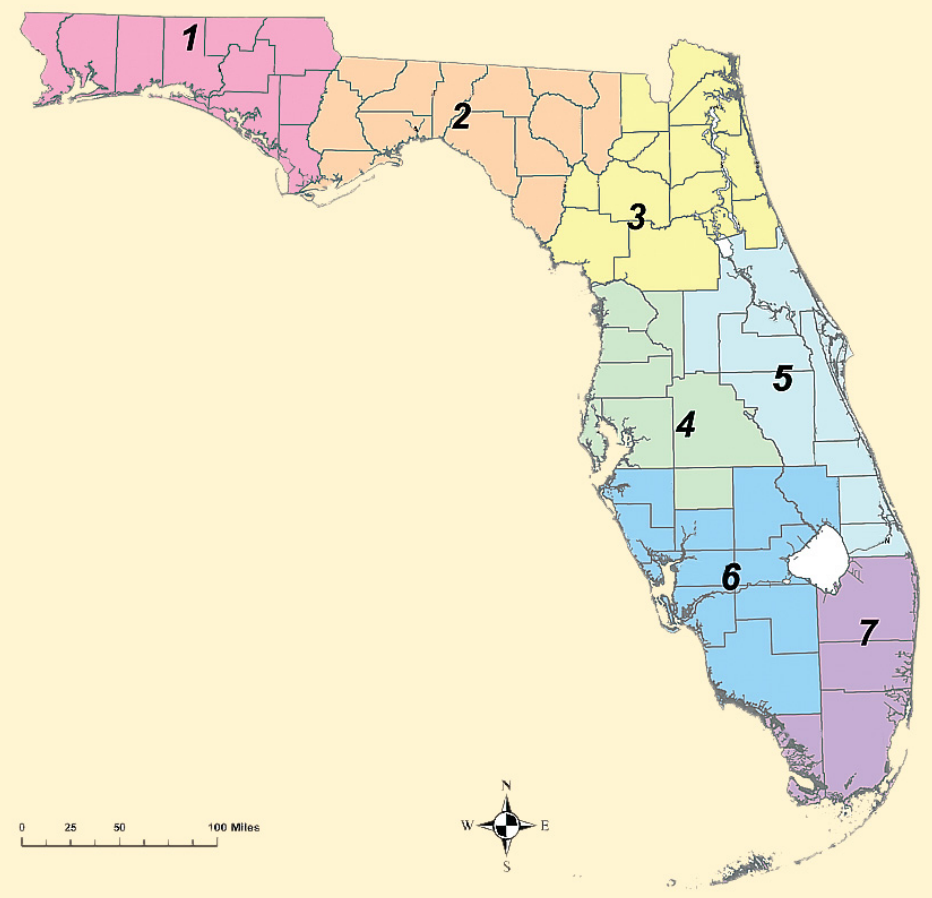

Source: 2010 Annual Report of the Florida Division of Emergency Management and found at http://www.floridadisaster.org/documents/2010ARfinal.pdf

In practice, Centrality will be measured in terms of the interconnectedness of CCCs and CERTs that operate in tandem with the RDSTFs that make up the Florida Division of Emergency Management system. The concept of centrality will be further elaborated on in the next chapter which deals with the methodology of this study. 


\section{CHAPTER THREE}

\section{RESEARCH QUESTIONS AND METHODOLOGY}

My dissertation has developed a theoretical framework to analyze the institutional adaptation of local homeland security organizations in Florida over the last ten years. A core construct in the framework is that these local homeland security organizations form a network that is a complex adaptive system (CAS). Complex adaptive systems are those that have the following: (1) the existence of many active parts that (2) respond to feedback and are (3) able to adapt their strategies to respond to previous experience. They (4) seem to be "alive" as they evolve in a non-linear manner without a single identifiable controller. These complex adaptive systems display an "emergent" behavior or a behavior that occurs as the result of the interactions of the parts together as opposed to individually. As denoted in Ryan (2006), “...Emergence is not a property of a system at any point in time, it is a relationship between system properties at two different moments in time" (Ryan 2006, 11). An example of emergence is the response of the individuals forming new CCCs and CERTs in the aftermath of the Macondo Well explosion in April 2010. A more detailed explanation is given in chapter four about this focal event.

In order to better evaluate the evolution of homeland security organizations during the last decade in response to mandatory changes, a case study approach was used. It is hypothesized that as both the number and density of connections between CCCs and CERTs have increased; the networks have become more decentralized. But why has this case study approach been chosen? It has been chosen on the basis of the "focusing events" that have occurred in the last decade. A "focusing event" is defined as a "rare, harmful, sudden event that becomes known to the public and policy elites virtually 
simultaneously" (Birkland, 1997, 7). The importance of the focusing event lies in its ability to affect the agenda-setting process of public policy making. A focusing event's power comes in part from its rarity and its unusual and sudden nature. To evaluate the effect of focusing events through the presence of adaptation to institutional constraints, the following methodology was applied to the network of CCCs and CERTs in the state of Florida over the time period $2002-2011$.

The first section evaluates the number and density of connections among organizations through the use of sociograms or "directed-relations graphs" of the network structure created with the NETdraw program within the UCINET 6 software package. The size of the nodes or "actors" is determined by the number of connections. The second section describes the network interconnectedness using the measures of Degree and Betweeness Centrality calculated using the UCINET 6 software package.

In the previous chapter, a theoretical framework was developed to analyze the institutional adaptation of local homeland security organizations in South Florida over the last ten years. A core construct in this theoretical framework is that emergency management resembles a complex adaptive system (CAS) in which the organizations interact in a reciprocally causal manner that is characterized by interdependence. But how is this interdependence measured? My study will measure interdependence by using the ideas denoted in Michael Moran's article "Policy Making in an Interdependent world" (2010).

My study; however, will go beyond Moran's conceptual framework concerning interdependence in complex adaptive systems, but it will apply his methods by using the techniques of social network analysis (SNA). By using SNA, I will analyze the "patterns" 
of interconnectedness found in these two sets of organizations: Citizen Corps Councils and Citizen Emergency Response Teams.

Among the most important "patterns" existing among local homeland security networks are that of interdependence. The ubiquity of mutual aid agreements among local first responder organizations in the State of Florida is an example of this pattern of interdependence. Mutual Aid Agreements are defined by FEMA as:

"Agreements [that exist] between agencies, organizations, and jurisdictions that provide a mechanism to quickly obtain emergency assistance in the form of personnel, equipment, materials, and other associated services. (FEMA Website)"

Analyzing the level and density of interdependent relationships is the key to understanding these organizations' adaptations to institutional constraints.

\section{Defining the "patterns" that bind}

In order to understand the various types of relations that exist among local homeland security networks, it is necessary to further define the "patterns" that link them together. In general, there are four patterns of interaction: dyadic, triadic, subgroup and group. Dyads form the basis for most social network analysis. Dyadic relationships consist of ties between two actors. Specifically, a dyad "consists of a pair of actors and the 'possible' ties between them." "Dyadic analyses" concern the characteristics of relationships between two actors (a dyad) which may be either two-way ("reciprocated") or one way ("not reciprocated"). Dyadic analyses also concern whether these patterns of interaction occur by themselves or in multiples (Wasserman and Faust 1994, 18). For example, a dyadic two-way relationship exists between a Mayor and the Fire chief or Police Chief of a municipality such as Miami or Fort Lauderdale. 
Likewise, triadic relationships consist of ties between three actors. Triadic relationships are more complex than dyadic relationships; there is also the possibility of a more complex "structure" among the actors (Wasserman and Faust, 1994, 19). Within the structure, there are now three possible interactions. For example, a triadic relationship exists between the Fire Chiefs of the Metro Dade, Broward County Sheriff's Office and the Palm Beach County Sheriff's Office Coordinators in Miami Dade, Broward and Palm Beach Counties.

The third type of a relationship is a "sub group." This relationship is defined as "any subset of actors, and all the ties among them". In terms of homeland security, this sub group could include all dyadic or triadic relationships. An example would be all the relationships between fire chiefs and mayors in Miami Dade, Broward and Palm Beach counties or the relationship between all fire chiefs, police chiefs and mayors in these three counties (Wasserman and Faust, 1994, 19, Knoke, and Yang, 2008, 13).

The fourth type is concerned with the behavior of entire "groups" defined as the "collection of all actors on which ties are to be measured" (Wasserman \& Faust, 1994, 19). However, for measurement to take place, the "group" must be defined more specifically. Inclusion in the group must be made on one of three bases; conceptual, theoretical, or empirical (Wasserman \& Faust, 1994, 19-23). In practice, my dissertation treats the Citizen Corps Councils and Community Emergency Response Teams of the state of Florida as the group used for social network analysis (Wasserman and Faust, 1994, 19, Knoke, and Yang, 2008, 13). Conceptually, these organizations are responsible for implementing the plans created by governmental authorities and deal with focal 
events. Theoretically and empirically, the state of Florida is the geographic boundary of the group.

\section{Measuring the "ties" that bind: Centrality and the Interconnectedness of Local Homeland Security Networks}

Now that we have described the types of ties and relations, one can now move on to specify measures by which local homeland security networks will be evaluated. This study will concentrate on Centrality which is a measure of the prominence of actors at "both, the individual and groups level" (Knoke and Yang, 2008, 62). There are two types of centrality used in this dissertation (1) degree centrality and (2) betweenness centrality.

\section{Degree Centrality: Connectedness \& Interdependency}

Degree centrality measures "the extent to which an [actor] connects to all other [actors] in a social network" (Knoke and Yang, 2008, 63). For example, at the individual level of analysis, it measures the extent to which a local fire chief is connected to other first responders, other local fire chiefs, emergency managers, police chiefs, hospital officials, and local volunteers, etc. At the group level of analysis, degree centrality assesses to what extent a local organization such as a local fire department is connected to other first responder organizations, such as other local fire departments, emergency management organizations, police departments, hospitals and non-profit/voluntary organizations.

These two measures of degree centrality, individual and group centrality, can be thought of as analogous to measures of central tendency (i.e., the mean) and dispersion (i.e., the standard deviation) in descriptive statistics (Knoke and Yang 2008, 64 - 65). Each of these measures has a range of values between 0 and 1, with 0 meaning no 
connectivity to other actors and 1 meaning connectivity to all other actors in the network. These values can also be normed to account for the size of the network itself to allow for comparisons between networks (Knoke and Yang, 2008, 62 -63).

When taken together, these measures assess the overall centralization of the group as a whole and are denoted in the term "network centralization index" (Hanneman, 2008, 149). Organizations that contain more horizontal than vertical connections are seen to be more flexible and adaptable in terms of their ability to respond to both natural and manmade disasters. Measuring the amount of degree centrality is one method of assessing the “adaptability" of a network (Wise, 2006 and Wise and Nader 2006).

\section{Betweenness: Evaluating the influence of actors on information flow in local homeland security networks}

Betweenness centrality is a measure of how much an actor controls or "mediate[s] the relations" between other actors that are not directly connected. In other words, how many actors exist in the "direct path" between the two actors under study? As the number of actors "mediating the relations" increases, so does the Betweenness centrality. In this sense, Betweenness centrality is a measure of the flow of information between actors who are not directly connected. As the amount of Betweenness centrality increases, so does the concentration of information until all information must flow through a single actor in the network (Knoke and Yang, 2008, $67-68$ ).

In terms of homeland security policy, Betweenness centrality is an important indicator of the flow of information among actors or groups. It is defined as "a communication relation where actors could not form new lines, central actors could refuse to pass along messages." (Wasserman and Faust, 1994, 189-190). Prior to 9/11, 
agencies such as the CIA and the FBI were statutorily barred from sharing information. One of the main conclusions of the 9/11 Commission Report was that intelligence from one agency was not being shared with other agencies, not allowing them to "connect the dots" concerning the plot to use airliners to attack the World Trade Center and the Pentagon (9/11 Commission Report). Consequently, there were various institutional barriers present when sharing information regarding a possible terrorist threat. For example, a high degree of Betweenness centrality among the federal agencies prevented these "actors" from connecting the dots. Reducing the amount of Betweenness centrality has been a major aim of homeland security policy since the 9/11 attacks. Using Betweenness centrality in an analysis of the local homeland security networks in Florida will evaluate the impact of local efforts to respond to administrative mandates from the United States Department of Homeland Security (USDHS) and the Florida Department of Emergency Management.

\section{From ties to relations: Developing a schema for analyzing relations in a local homeland security network}

In order to put the various kinds of ties between dyads, triads, sub groups, and groups into a larger perspective, one must categorize similar ties together through a "relation". A relation is defined as "the collection of ties among members of a group of a specific kind" (Knoke \& Yang, 2008, 12). In general, there are four types of "relations" being evaluated in this study:

(1) Communication relations in which "linkages between actors are channels through which messages may be transmitted" (Knoke \& Yang, 2008, 12). Specifically, my dissertation focuses on the exchange 
of "actionable intelligence" or "actionable knowledge" between horizontal and vertical networks of emergency management personnel. Instrumental relations where "actors contact one another in efforts to secure valuable goods, services, or information.”(Knoke \&Yang, 2008, 12) This dissertation focuses on personnel and resource connections between network actors, like a fire chief and other first responders.

Boundary penetration relations in which "ties consist of membership in two or more social formations which may have overlapping relations." (Knoke \& Yang, 2008, 12) This dissertation focuses on membership in formal organizations such as voluntary organizations (CERTs and CCCs) as vehicles for the exchange of information and assistance.

(4) Authority/power relations, which consist of ties "usually occurring in formal hierarchical organizations" such as elected offices, and emergency management institutions (Knoke and Yang 2008, 12).

These relations were used as a framework for analyzing the interconnections between the actors in the network of CCCs and CERTs in the state of Florida.

\section{Operationalization and Testing of Hypotheses}

For the purposes of this dissertation, local homeland security organizations are operationally defined as Citizen Corps Councils (CCCs) and Community Emergency Response Teams (CERTs) in the state of Florida. Both CERTS and CCCs are formal networks. Following the work of Agranoff (2007) and for the purpose of this study, a 
formal network is operationally defined as a chartered network which is a "formally established organized entity" such as a 501(c) 3 non-profit organization, action of a legislative body, or an executive order of a governor, or through registration with the Secretary of State.

Social Network Analysis was used to quantitatively evaluate and graphically display the number and density of connections among so-called "actors" (homeland security organizations). The purpose of using Social Network Analysis (SNA) in this dissertation is to reveal how the evolution of these networks took place. The number and density of connections between these networks is an example of local government's response to administrative mandates to compensate for institutional constraints. In particular, it is the degree of connectedness or "centrality" (Kapucu et. al. 2009, Knoke and Yang 2008) that is an important variable in measuring these connections. The use of SNA serves to measure the level of connectedness or "centrality" in these networks as they respond to administrative requirements as a result of focal events such as $9 / 11$ and Hurricane Katrina.

To further test the above-mentioned hypothesis concerning the institutional adaptation of local homeland security networks in Florida, a series of nine interviews were conducted with the leadership of the regional domestic security task force for the state of Florida.

\section{Data collection}

Data were collected on the activities of the twenty-one (CCCs) and their affiliated organizations. I used data from the ninety- one Community Emergency Response Teams (CERTs) currently registered with the CCC website for the state of Florida (as of 
10/31/2011). ${ }^{3}$ The CCCs' and CERTs' participation were measured with regard to mobilizations for actual disasters.

Mobilizations are operationally defined as the activation of one or more CCCs and/or CERTs in response to a warning or disaster declaration of a natural or man-made disaster by at least one local government. Increased activity is reflected in denser connections among the CCC and the CERT organizations. The measure of activity serves as an operationalization of the "interconnectedness" of these organizations with more activity corresponding to greater interconnectedness and thus a "denser" network of connections. For example, an organization that has participated in three mobilizations is more active than one that has participated in a single mobilization.

Data for mobilizations were acquired from publicly available websites such as http://www.citizencorps.gov/cc/CertIndex.do?reportsForState\&cert=\&state=FL and from the State level Citizen Corps Council for the state of Florida. Using the UCINET 6 software package, an "incidence or affiliation matrix" was developed to record the presence of emergency management organizations, first responder organizations, and affiliate organizations such as CERTs' responding to natural and man-made disasters. Examples of disaster response include mobilization of personnel in response to natural disasters such as hurricanes during the 2004-2005 hurricane season (DHSG, 2011, 38). An "incidence or affiliation matrix" is a special type of square array that is used to record and display data about the relationships between two types of organizations (Hanneman

\footnotetext{
${ }^{3}$ The one exception is that of the Lee County CERT which was registered with the Florida State CERT association but not with the CCCs website.
} 
and Riddle, 2008, 69-70). This type of matrix is commonly used in Social Network Analysis to evaluate the relations or ties between organizations.

If it is true that the complexity of homeland security networks is positively correlated with their decentralization, then the number of these organizations and the density of connections between them should increase. Thus creating incidence or affiliation matrices are a way of operationalizing and testing the hypothesis. Furthermore, by evaluating the nature and extent of these connections, this study is a first step in revealing the "agency and structure" of local homeland security networks in the state of Florida (Hanneman and Riddle, 2008, 69-70).

\section{Constructing the Network}

The sociograms produced in my dissertation were constructed by using a four step process. The first step included creating a database that contained a common reference point with which to compare all of the actors in the network. In my dissertation, zip codes were chosen because they are the primary method by which membership in a CCC or CERT is determined for the network in question. For example, when the Gulf Oil Spill occurred, thousands of citizens wanted to volunteer; they were assigned to the nearest CCC by their zip code. These data were obtained by viewing the "Areas served section" of the Town of Century CCC webpage found at http://www.citizencorps.gov/cc/showCouncil.do?id=47762. Second, a matrix was created to display which organizations were connected to each other. This matrix contained a list of all the connections of the organizations in the network. In my dissertation, a connection was determined to exist if and only if two organizations served the same zip code. The third step included choosing a measure by which to evaluate the connections 
present among the organizations in the network. The organization with the most connections is the most "central" actor or node in the network. This actor will have a greater "centrality" than the other actors. The fourth and final step involved using the matrices to produce directed relation graphs or sociograms. In my dissertation three matrices, for the years 2002, 2005, and 2011, were created. The larger the node, the more central it is to the network.

\section{An important note in terms of jurisdiction}

In order to better understand this "agency and structure," one must begin with an analysis of how CCCs and CERTs are organized jurisdictionally. Citizen Corps Councils are organized to be run at the lowest governmental level possible. A map of the jurisdictional boundaries can be found page sixty- six. In the event of a natural or manmade disaster, the CCC will serve as a clearinghouse for information and coordinate the actions of member organizations in responding to natural or man-made disaster in their jurisdiction. Additional CCCs may be chartered at anytime once they have met the criteria for the formation of a Citizen Corps Councils ${ }^{4}$.

For the purposes of this study, a CCC and a CERT are considered to be connected if and only if they share one common jurisdictional boundary. Jurisdictions for CCCs and CERTs are determined by the United States Postal Service Zip Codes (USPS ZC) which they serve.

\footnotetext{
${ }^{4}$ In addition to citizen interest, the main qualification for starting a council is that it be "sponsored or endorsed by an elected local government official or city or county administrator who has responsibility over the local government's operations." (http://www.citizencorps.gov/about/faq.shtm\#councilformed) on September 8, 2011. For more complete information on the guidelines for forming a CCC a guide can be found at http://www.citizencorps.gov/downloads/pdf/councils/council.pdf
} 
Thus if a CCCs' or CERTs' jurisdiction is countywide then it is connected to all other CERTs in that county. The only exception to this is the case in which a CCC has been created for a specific municipality. It is possible that a municipality will have a CERT created that is connected to other municipal CERTs but not to all of the CERTs in a county. The key to this "interconnectedness" lies in the common jurisdictional boundary, in this case the USPS ZC.

Data for this study were generated from three sources: 1) Interviews of local homeland security officials such as first responders (fire and police officials), 2) Data gathered from government websites such as http://www.citizencorps.gov/cc/CertIndex.do?reportsForState\&cert=\&state=FL and the Florida association of CERTs at www.floridacertassociation.net, 3) data from news stories from public newspapers such as the Miami Herald and news sources such as Associated Press and Reuters.

The interviews were conducted with a series of senior homeland security decision makers including fire officials, police officials, former elected officials and state emergency management personnel. These interviews were conducted in the months from April to October 2010. These interviews were based on an elite interview style and were based on a series of open ended questions. The interviewees were selected both for their expertise and their experience with local homeland security policy. To protect their confidentiality the following interview coding schema was used: 
Table 1: Interview Coding Schema

\begin{tabular}{|c|c|}
\hline INTERVIEW NUMBER & OFFICIAL'S TITLE \\
\hline $\mathbf{1}$ & $\begin{array}{c}\text { Senior Miami Dade County } \\
\text { Fire Official (1A) }\end{array}$ \\
\hline $\mathbf{2}$ & $\begin{array}{c}\text { Senior Miami Dade County } \\
\text { Fire Official (2B) }\end{array}$ \\
\hline $\mathbf{3}$ & $\begin{array}{c}\text { Senior Broward County Fire } \\
\text { Official (3C) }\end{array}$ \\
\hline $\mathbf{4}$ & $\begin{array}{c}\text { Senior Miami Dade County } \\
\text { Fire Official (4D) }\end{array}$ \\
\hline $\mathbf{5}$ & $\begin{array}{c}\text { Senior Broward County Fire } \\
\text { Official (5E) }\end{array}$ \\
\hline $\mathbf{6}$ & $\begin{array}{c}\text { Senior Palm Beach County } \\
\text { Official (6F) }\end{array}$ \\
\hline $\mathbf{7}$ & Senior State Official (7G) \\
\hline $\mathbf{8}$ & $\begin{array}{c}\text { Senior Miami Dade County } \\
\text { Police Official (8H) }\end{array}$ \\
\hline $\mathbf{9}$ & $\begin{array}{c}\text { Senior Broward County Fire } \\
\text { official (9I) }\end{array}$ \\
\hline
\end{tabular}

The data were used to construct three matrices that summarize the connections between the organizations. Connections are evaluated on the basis of the existence of common jurisdictional boundaries since they are the basis of mutual aid agreements. These matrices represent "one mode networks" since they evaluate connections based on the existence of "one mode" or piece of information; the existence of overlapping jurisdictional boundaries.

These data measured both the number of organizations and the density of connections between them. These data formed the basis of a "network census" that measures connections between local Community Emergency Response Teams (CERTs) and the Citizen Corp Councils (CCCs). Currently, there are fifty-six statewide CCCs and there are 1,170 county, local, tribal CCCs nationwide. There are 1,995 CERTs nationwide. The present study focuses only on (1) the twenty-one CCCs in the state of 
Florida with sixteen existing at the county level and five at the local level and (2) the ninety-one CERTs in the state of Florida (as of 10/31/2011).

Each of the CCCs and CERTs has a coordinator, usually a first responder. In order for these organizations to work together, the coordinators have to communicate with each other when a natural or man-made disaster occurs. In order to know which coordinators to contact, they must ascertain which CCCs and CERTs are closest to the disaster and that is determined by their jurisdictional boundaries. Knowing the jurisdictional boundaries of each CCC and CERT is crucial to determining how these organizations interact with each other. It is reflected in the Citizen Corps website, for each CCC and CERT can be found at the above listed website.

Using these data, a database was created which contains all of the CCCs and CERTs and their jurisdictional boundaries. Three matrices were created to reflect which organizations had overlapping jurisdictional boundaries and would be contacted in the event of a focal event. These matrices contain a series of $1 \mathrm{~s}$ and $0 \mathrm{~s}$ which denote the presence (1) or the absence (0) of a common jurisdictional boundary. These matrices are then analyzed to determine which CCCs and CERTs have the most overlapping jurisdictions and are more "central" to the network than those organizations which have overlapping jurisdictional boundaries.

To evaluate the growth and change of these networks over time, a network census was conducted for the past fifteen fiscal years using the UCINET 6 Software package developed by Borgatti, Everett, and Freeman. The NETDRAW program was used to produce the diagrams which are derived from these matrices and appear in chapter four. 
The matrices of 2002 and 2005 can be found in Appendix A and the matrix of 2011 can be found in Supplementary File 1.

Specifically, a series of sociograms or directed relation graphs were created for the network of CCCs and CERTs in 2002, 2005 and 2011. Then, a series of Centrality measures were calculated for the network of CCCs and CERTs in 2002, 2005 and 2011. Specifically, Degree and Betweenness centrality measures were calculated for each network in 2002, 2005 and 2011. These measures are reported as tables found in chapter four. The tables containing values reported for each of the CCCs and CERTs can be found in appendix B. An analysis of each of the network in terms of the number of organizations and the density of connections was undertaken. Finally, a comparison of these two networks was completed to determine the changes that have occurred over the intervening ten years. 


\section{CHAPTER FOUR}

\section{ANALYSIS OF LOCAL HOMELAND SECURITY NETWORKS IN FLORIDA}

Mainly, the focal events of September $11^{\text {th }} 2001$ and Hurricane Katrina have had a major impact on how local emergency managers plan, prepare, respond and recover from natural disasters. Especially the case in Florida since it has experienced seven hurricanes from 2004-2005 and the Gulf Oil spill in 2010. The chapter reports the results of the social network analysis to trace the evolution of CCCs and CERTS in the state of Florida during the last decade. Although the network of CCCs and CERTs was established in 2002, there were eighteen CERTs that existed at that time with the earliest CERT being founded in 1995, in Hillsborough County. CCCs were selected as the unit of analysis as they are the umbrella organization through which the public, private, and non- profit sector organizations interconnect on a routine basis as well as in the event of the mobilization for natural or man-made disasters.

\section{Evolution of Local Homeland Security Networks in the state of Florida}

In 2002, the year the network was established following the attacks of $9 / 11$, there were only two CCCs, the statewide and the Palm Beach County Citizen Corps Council. However, there were eighteen CERTs with fifteen of them being connected to the statewide CCC while the Palm Beach County CCC was connected to the three Community Emergency Response Teams. The sociogram (Figure 3) reveals this structure organizationally, though not geographically. It clarifies that, in 2002, the statewide CCC and to a much smaller degree, the Palm Beach County CCC is the most central actors to the operation of the network. 
Figure 3: Florida CCCs and CERTs in 2002

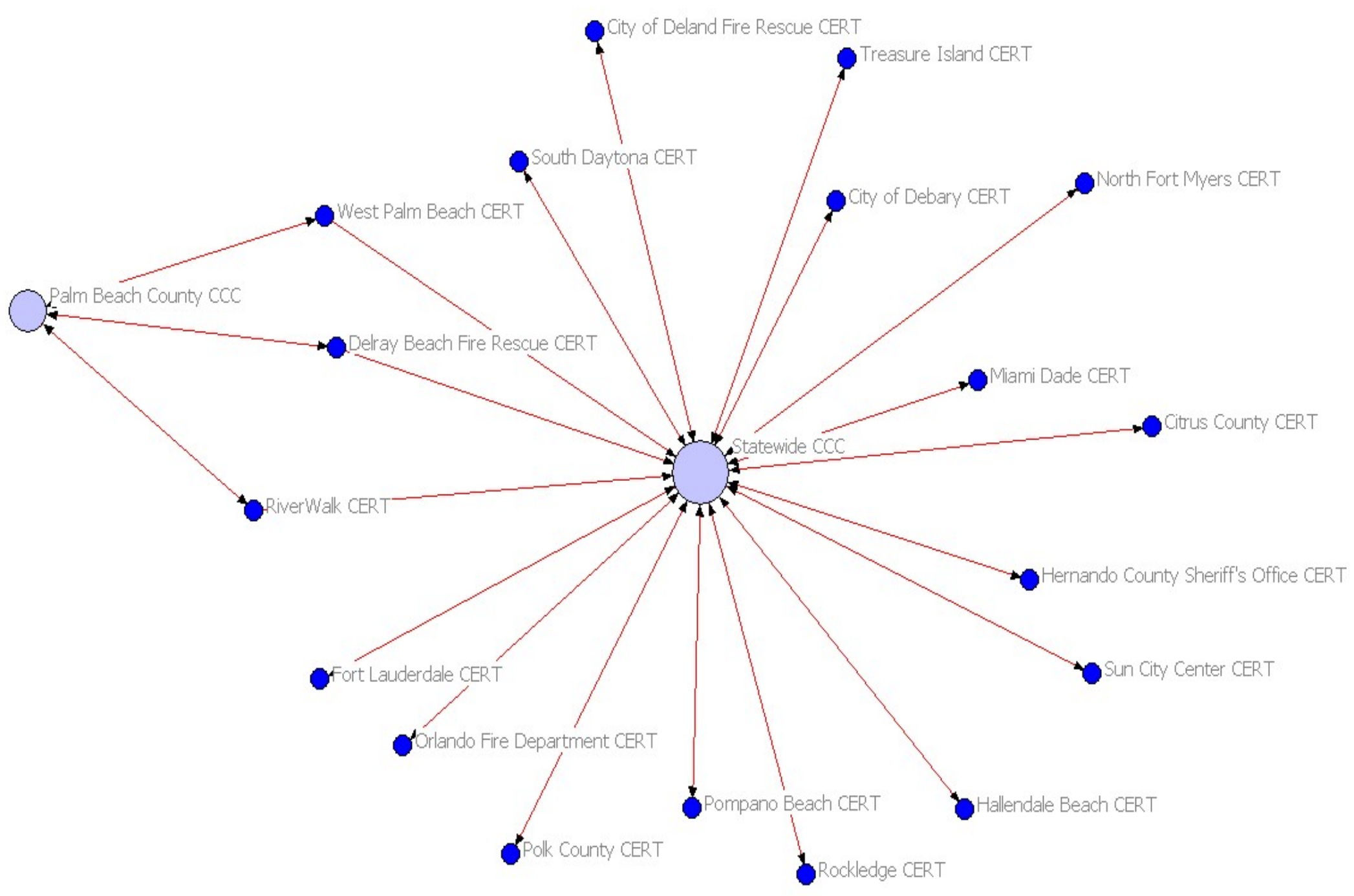


By the time of the next focal event, Hurricane Katrina in 2005, there was substantial growth in the network of CCCs and CERTs (Figure 4). The number of actors in the network expanded to contain forty-eight organizations composed of seven CCCs and forty-one Community Emergency Response Teams. There are seven "components" or sub-graphs to this network that include a total of one hundred and twelve connections. ${ }^{5}$ These components are connected according to their respective county $\mathrm{CCC}$ or if nonexistent, the statewide Citizen Corps Council. These seven components of the graph include the statewide CCC and the CCCs of Hernando, Hillsborough, Orange, Palm Beach, Pasco, and Sarasota counties.

\footnotetext{
${ }^{5}$ A "component" or sub-graph is a part of a network in which the actors are all connected to each other through some other actor of the graph but not to the larger graph itself. In this way components are "disconnected" from other parts of the network (Wasserman and Faust, 1994, 109-110).
} 
Figure 4: Florida CCCs and CERTS in 2005

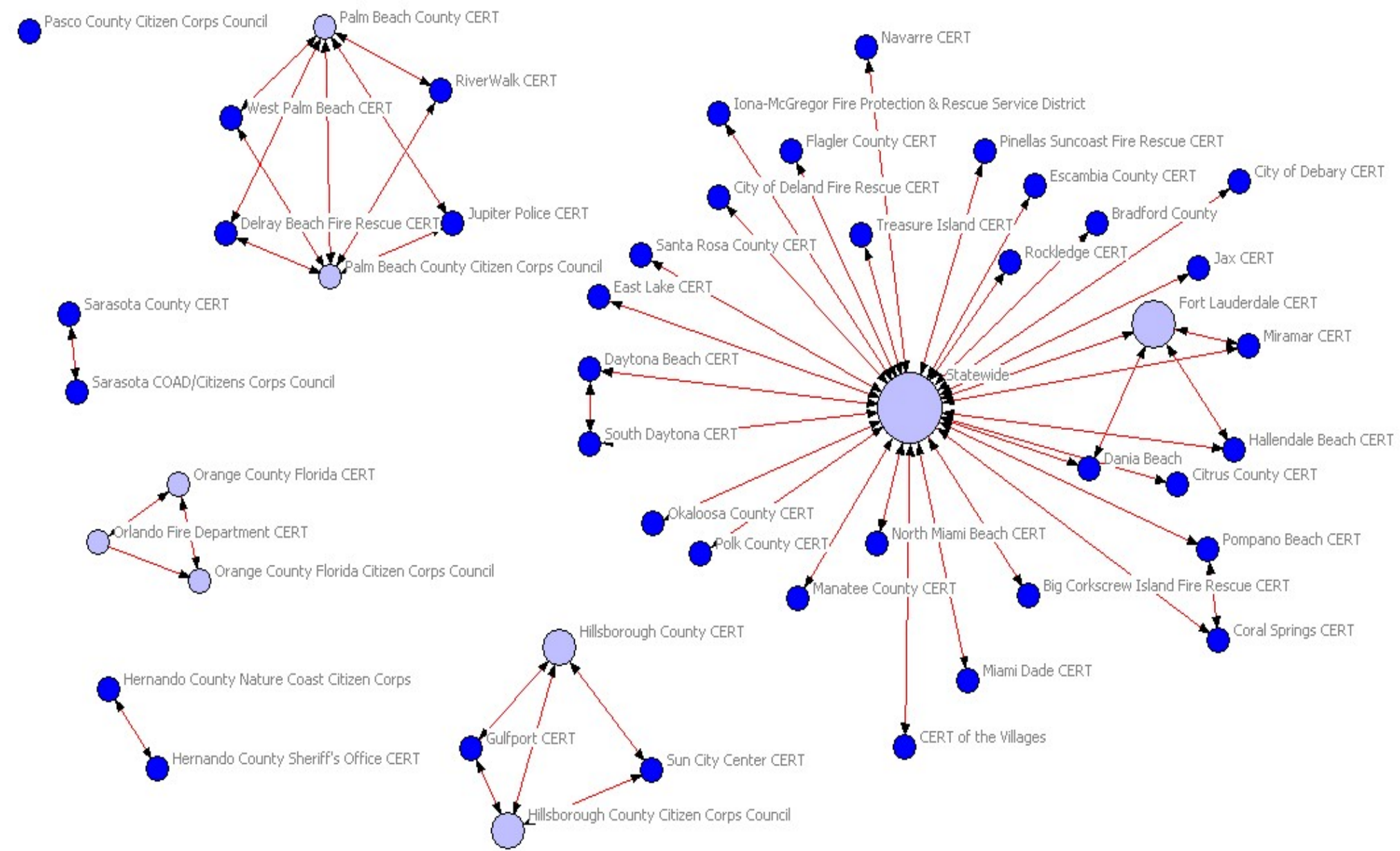


Figure 5 along with Table 2 show that the statewide CCC is the most central actor in the 2011 network. It reveals the relative number of connections, both to and from the statewide CCC and the CERTs. This proportion of connection is denoted normed degree centrality and it allows comparisons longitudinally as it is a standardized measure (like a z-score). Over the last decade, the most central actor was the statewide CCC; however, its relative importance decreased over time by two thirds, from a normed degree centrality of 94.73 (2002) to 36.36 (2011). 
Figure 5: Florida CCCs and CERTs in 2011 (by Freeman Degree Centrality)

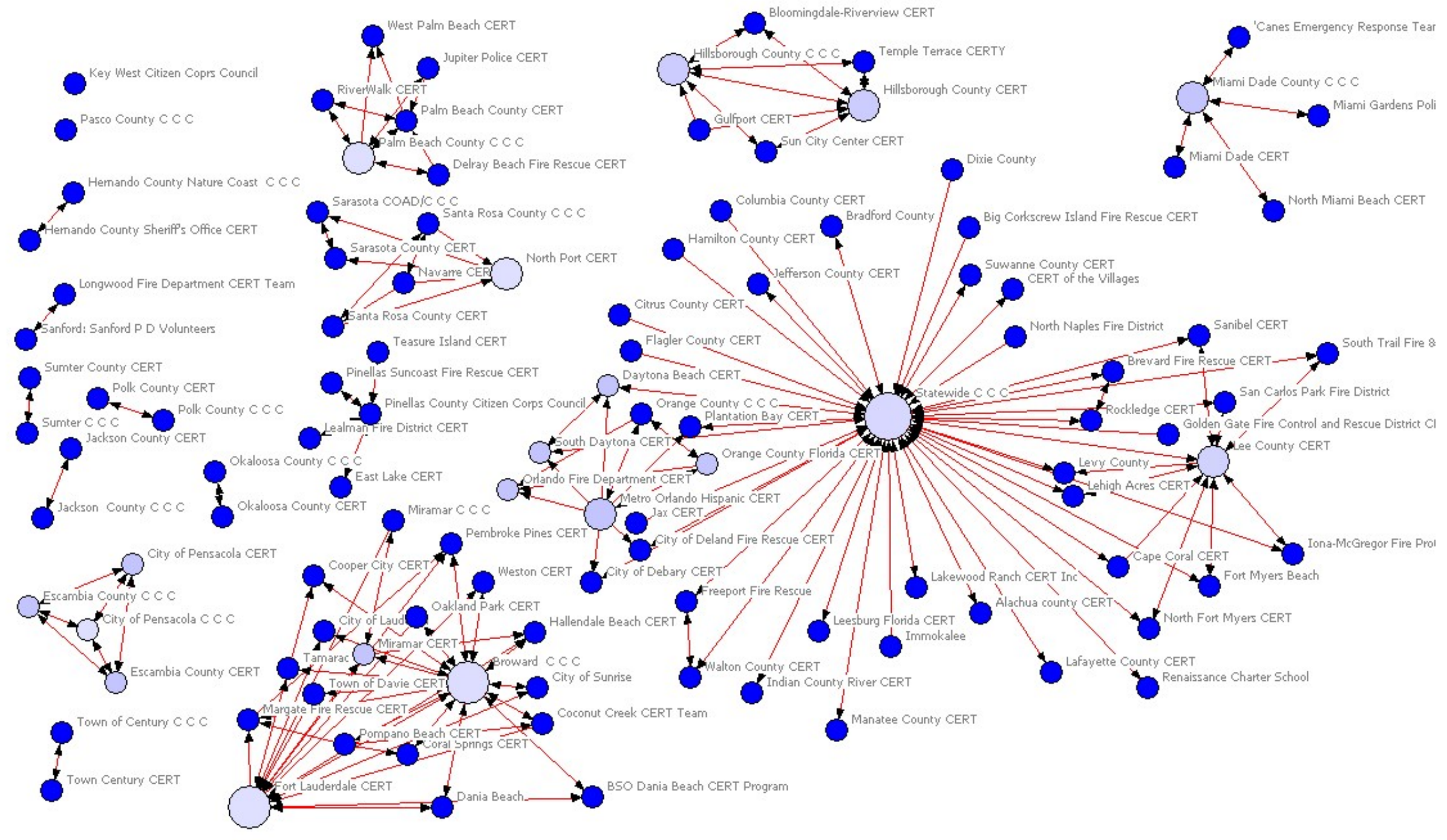


Table 2: Top five Florida CCCs and CERTs by their Normed Degree Centrality in 2002, 2005, 2011

\section{ORGANIZATION}

Statewide

Palm Beach County Citizen Corps 15.78

Council

Delray Beach CERT

River Walk

West Palm Beach CERT

Palm Beach County CERT

Fort Lauderdale CERT

Hillsborough County Citizen Corps N/A

Council

Metro Orlando Hispanic CERT

Broward County CCC

Lee County CERT
YEAR 2002

94.73

10.52

10.52

10.52

N/A

5.26

N/A

N/A

N/A
10.63

4.54

10.63

4.25

4.25

10.63

4.54

8.51

14.54

6.38

4.54

N/A

7.27

N/A

15.45

N/A

9.09 
The next largest component in 2002 was the Palm Beach County CCC which has a normed degree centrality of 10.6. It also decreased its centrality by one-third from 2002 to 2005 and two-thirds by 2011 from 15.78 to 4.54. In 2005, the Palm Beach County CERT has an identical normed degree centrality score to that of its CCC which means that they are equally connected to all parts of its network; not the case in all counties. The Fort Lauderdale CERT, which had a normed degree centrality score of 5.26 in 2002, had no CCC at all. Unlike the other CERTs, its normed degree centrality increased by $161 \%$ (8.51) from 2002 to 2005 and $276 \%$ (14.54) from 2005 to 2011 . The Fort Lauderdale CERT became more central to its network over the last decade. A complete list of all actors and their respective normed degree centrality scores can be found in Appendix B.

In 2011, there were one hundred and twelve organizations composed of twentyone CCCs and ninety-one CERTs featured in figure 5. There are seventeen components which contain two hundred and fifty-seven connections. These components are also organized by their county CCC or the Statewide CCC. These components include the Statewide CCC, Broward County, Escambia County, Hernando County, Hillsborough County, Jackson County, Miami Dade County, Okaloosa County, Palm Beach County, Pasco County, Pinellas County, Polk County, and Sarasota County. There are also a number of municipal CCCs including, the City of Pensacola CCC, the Miramar CCC, the Sanford CCC, The Town of Century CCC, and The City of Key West CCC.

Figure 5 and table 2 display the results of the analysis for the network of CCCs and CERTs in 2011. The most central actor of the network continues to be the Statewide CCC; however, with a reduced normed degree centrality of 36.06 . Furthermore, the 
position of the top five actors has changed with the most recent creation of a Broward CCC that has a normed degree centrality of 15.31. The Fort Lauderdale CERT has a normed degree centrality of 14.41 and nearly doubled its importance since 2005 . Overall, all CERTs (except for the Fort Lauderdale CERT and the newly established Metro Orlando Hispanic CERT) decreased with regard to normed degree centrality, meaning, they became more decentralized.

\section{Evaluating the Network as a Complex Adaptive System (CAS)}

What has happened to the networks in the intervening ten years? Notice that the number of organizations has expanded from twenty to one hundred and twelve, an increase of $560 \%$. There are an increased number of CCCs as well as CERTs. The number of CCCs has grown from two to twenty-one, an increase of $1050 \%$. The number of CERTs has increased from eighteen to ninety-one, an increase of 505\%.

While it is noteworthy that the order and relative centrality of actors has changed between 2002 and 2011; however, this does not tell us whether the entire network is more decentralized. To assess decentralization, we need to analyze the summary measures of the network in terms of the connections of their actors in both 2002 and 2011. Tables 3 and 4 present these results.

When these measures for the network in 2002, 2005 and 2011 are compared, they show a significant amount of decentralization. The first measure is the Network Centralization Index, a measure of central tendency for the system as a whole. Over the last decade, network centralization has decreased from $92.98 \%$ in 2002 to $34.25 \%$ in 2011. The second measure is the Blau Heterogeneity, which is a measure of variability. The decentralization is even more pronounced with Blau Heterogeneity decreasing from 
$20.41 \%$ in 2002 to $3.20 \%$ in 2011 . When the measure of variability denoted normed (IQV) is used, the network is still more than six times as variable in $2002(16.22 \%)$ as it is in $2011(2.33 \%)$.

Table 3: FLORIDA CCC and CERT overall degree centrality measures for 2002, 2005, and 2011

$\begin{array}{llll} & \mathbf{2 0 0 2} & \mathbf{2 0 0 5} & \mathbf{2 0 1 1} \\ \begin{array}{l}\text { Network } \\ \text { Centralization }\end{array} & 92.98 \% & 59.48 \% & 34.25 \% \\ \begin{array}{l}\text { Blau } \\ \text { Heterogeneity }\end{array} & 20.41 \% & 9.02 \% & 3.20 \% \\ \begin{array}{l}\text { Normalized } \\ \text { (IQV) }\end{array} & 16.22 \% & 7.09 \% & 2.33 \% \\ \begin{array}{l}\text { No. of } \\ \text { Observations }\end{array} & 20 & 48 & 112 \\ \end{array}$

Another way to measure decentralization is denoted Normed Mean Degree Centrality, which is a standardized mean of the network connections within the entire system. Comparing the network of 2002, 2005 and 2011, found in Table 4 below, it is apparent that the network of 2011 is more decentralized than the network of 2002 and 2005. The normed mean degree centrality in 2002 is 11.5 . In 2005, it decreased to 4.699 and in 2011 to 2.441 , meaning the proportional share of these connections has decreased indicating a more decentralized network. In terms of CCCs and CERTS, this network decentralization indicates that fewer first responders of any specific organization are needed to cover a certain area. 
Table 4: FLORIDA CCC and CERT overall normed mean degree centrality measures for 2002, 2005, and 2011

YEAR

Overall Mean

Normed Degree

Centrality

Number of Observations
2002

YEAR

2005

4.69

11.05

20

48
YEAR

2011

2.39

112

\section{Evaluating the Communication within the System: Measuring Information Flow}

Given that the network of CCCs and CERTs in Florida have become more decentralized between 2002, 2005 and 2011 in terms of their normed degree centrality, it is also important to evaluate the connections between individual actors by calculating each network's Freeman Normed Betweeness Centrality and Network Centralization. Freeman Betweeness Centrality is a measure of information flow which after normalization allows longitudinal comparisons of the distance that information between individual CCCs and CERTs have to travel. Network Centralization is a measure for the entire system regarding information flow. 
Table 5: Information Flow in overall Freeman Betweenness Centrality measures for Florida CCCs and CERTs 2002 - 2011

$2002 \quad 2005 \quad 2011$

$\begin{array}{llll}\text { Freeman Mean } & 3.991 & .787 & 0.127 \\ \text { Betweenness Centrality } & & & \end{array}$

Network Centralization $\quad 73.36 \quad 36.94 \quad 9.74$

$\begin{array}{llll}\text { Number of Observations } & 20 & 48 & 112\end{array}$

As shown in Table 5, when the network is compared for the years 2002, 2005 and 2011, two trends were revealed. First, the information flow as measured by the Freeman Mean Normed Betweeness Centrality has significantly decreased which means that CCCs and CERTs are receiving critical information faster, despite the fact that there are five times as many actors in the network. Also, the overall Network Centralization has decreased significantly from 73.4 to 9.7 over the last decade. Meaning that although the number of connections has increased, the time it takes for information to flow through the entire system has decreased. In terms of CCCs and CERTs, this increased number of organizations and connections mean that assistance is much closer than before. In the past, hurricane damage assessments were conducted by first responders directly. Hurricane damage assessments can now be communicated directly with an Emergency Operations Center (EOC) by each CERT instead of first responders. This allows first responders to better prioritize available staff and resources.

The analyses discussed above indicate that the network of CCCs and CERTs in Florida has become significantly more decentralized in 2011 than it was in 2002 as was hypothesized at the beginning of this dissertation. This is true despite the increased 
number of organizations and the increased number of connections between them. Thus as the network has become more complex over time, it has become more decentralized. Overall, less first responders are needed to cover a municipality as assistance is now around the corner and information flow has increased.

\section{Tracing the Development of Local Homeland Security Networks in Florida: Two Case Studies of Institutional Adaptation}

To illustrate these results, the institutional adaptation of CCCs and CERTs in recent emergency management history were analyzed. The first was a series of seven hurricanes in 2004 and 2005 that impacted the state of Florida. The second was the Gulf Oil Spill of 2010.

Hurricane Charley made landfall on the Southwest Florida coast on August $13^{\text {th }}$, 2004 initially impacting Charlotte County, Florida and then traversing across Central Florida including Orange, Osceola and Volusia Counties. Hurricane Frances made landfall along the Treasure Coast and St. Lucie and Martin Counties on September $5^{\text {th }}$, 2004 and crossed Central Florida exiting Florida in Pasco County and reentering Florida in the Northeastern part of the state known as the "Big Bend Region" that includes Region two (Bevens II National Hurricane Center, 2004, 1-2). Hurricane Ivan made landfall along the Alabama/Florida boarder on September $16^{\text {th }}, 2004$. It weakened but continued east and then south where it eventually made landfall again in Southern Florida traversing the Florida Peninsula and emerging in the south eastern Gulf of Mexico (Stewart NHC, 2004, 2-3). Hurricane Jeanne made landfall in approximately the same

area as Hurricane Frances on September $25^{\text {th }}$, 2004. It then traversed westward across 
Central Florida, exiting at Hernando County, approximately thirty nautical miles north of Tampa. (Cobb and Lawrence, NHC, 2005. 1-2)

In 2005, two hurricanes, Katrina and Wilma made landfall along the coast of Southeastern Florida while another one, Rita, turned into a hurricane while passing through the Florida Straits near Key West. Hurricane Katrina, one of the worst natural disasters in United States history, made landfall first along the Broward/Miami Dade County Border on August $25^{\text {th }}, 2005$ as a Category one hurricane. It traversed across the Southeastern portion of the Florida Peninsula exiting Monroe County near Cape Sable into the Gulf of Mexico. It then strengthened into a category five hurricane on the Saffir Simpson Hurricane Scale (SSHS), but weakened to a Category three before it made landfall and impacted much of the Gulf Coast of the United States including the states of Alabama, Florida, Louisiana, Mississippi and Texas. Hurricane Wilma first made landfall in the Southwestern Coast of Florida in Collier County near Naples, Florida (Cape Romano) as a Category three hurricane on the SSHS on October $24^{\text {th }}$, 2005. It traversed across the Florida Peninsula in a northeastern direction exiting the state from Palm Beach County near the town of Jupiter, Florida. (Nabb, Rhome, Brown, NHC, 2005, 1-4 and Pasch, Blake, Cobb III, and Roberts 2006 1-2)

During the eighteen month period that encompassed the 2004-2005 hurricane seasons (June 2004 - November 2005) a total of ten organizations, three CCCs and seven CERTs were formed along the paths of the hurricanes. Within one month of the landfall of the first hurricane (Charley), one CERT (Orange County, September 2004) and one CCC Hillsborough County, (August 2004) were formed. By January 2005, two more CERTs were formed, Gulfport (Pinellas) and Coral Springs (Broward County). By the 
beginning of the 2005 hurricane season (June 2005), another six organizations, two CCCs and four CERTs were formed. Overall, while no one hurricane can be seen as the sole factor affecting the creation of CCCs and CERTs, taken together these focal events are a significant contributing factor.

The second case study concerns the gulf oil spill in April 2010 after the Macondo Well Platform located in the Gulf of Mexico exploded and sank (DHSG, 2011, 38). As a result of the disaster, there was an outpouring of support from the public which needed to be organized. To direct the thousands of volunteers that were coming, local emergency managers agreed to sponsor two Citizen Corps Councils, one in the Town of Century and One in the City of Pensacola. As in the other cases, volunteers were assigned to a Citizen Corps Council based on the Zip Code of their primary residence. For example, residents from the surrounding towns of Century (32535), MC David (32568) and Molino (32577) were a part of the Town of Century CCC. Furthermore, all of these organizations in Escambia County are administered by one Coordinator, DeAnna Polland-Stemock, who is also working for the Be Ready Alliance or (BRACE). BRACE is the "successor organization" created to assist families when the Escambia Long Term Recovery Committee was disbanded after the landfall of Hurricane Ivan in September $2004 .^{6}$ Figure 6 below is a map of the counties impacted by the Gulf Oil Spill.

\footnotetext{
${ }^{6} \mathrm{http} / / /$ www.bereadyalliance.org/what_is/
} 
Figure 6: Region One of the Florida CERT Association

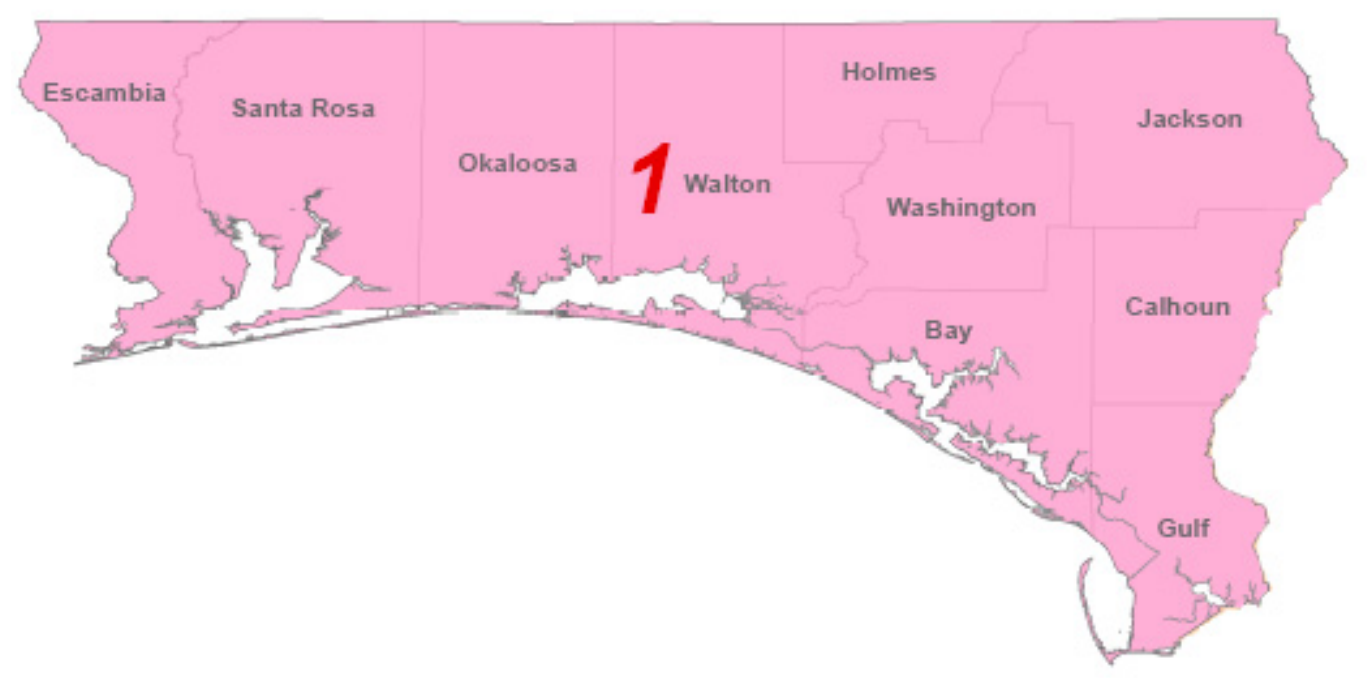

Source: http://www.floridacertassociation.net/area1.html

The most compelling evidence for institutional adaptation of this network comes from the fact that all these additional CERTs and CCCs were formed after each focal event occurred. Stated another way, the focal events (the 2004- 2005 hurricane season and the Macondo Well Explosion) occurred directly before the formation of these organizations, thus increasing the likelihood that the more recent experience of manmade and natural disasters had a direct impact on the network of CCCs and CERTs. 


\section{CHAPTER FIVE}

\section{IMPLICATIONS OF THE INSTITUTIONAL ADAPTATION OF LOCAL HOMELAND SECURITY NETWORKS}

The previous chapter detailed the ways in which two interconnected groups of local homeland security organizations in the state of Florida, the CCCs and the CERTs have adapted to changing conditions from January 2002 to October 2011. The results of this analysis revealed that the network of local homeland security organizations has become more complex and decentralized over time. These institutional adaptations did not occur in a vacuum. They are the product of the interactions not just of organizations but of the individuals who both coordinate and participate in preparing, planning, responding and recovering from natural and man-made disasters. It is important to note that analyzing the development of the two sets of organizations provides a vehicle for understanding the actions of these individuals as they do not act on their own but in the context of budgetary, institutional and political constraints.

The implications of this development have important ramifications for understanding how these networks develop over time. In particular, this development is best described as a complex adaptive system which has four characteristics:

(1) The individuals and the organizations that they represent interact with each other in a non-linear fashion.

(2) The individuals and the organizations they represent respond to feedback from their environment such as the landfall of a hurricane or an oil spill. 
The individuals and the organizations they represent adjust their strategies for planning, preparing, responding and recovering from both man-made and natural disasters.

The actions of the individuals and the organizations they represent can not be linked in a linear fashion to any one specific causal mechanism or series of mechanisms.

To investigate the factors underlying this institutional adaptation, this chapter will focus on three facets of these interactions.

(1) Covariation: Do the interactions of the individuals and the organizations they coordinate vary in a directly or an inversely proportional manner over time? In other words, is the level of decentralization positively or negatively correlated with the size of the network over time?

(2) Temporal precedence: Do these adaptations precede or follow the changes in their environment?

(3) What plausible alternative explanations exist for the observed adaptations?

Using these three facets, a better understanding of the factors affecting the development of local homeland security networks in the state of Florida can be made.

In answering these questions, this dissertation has used the complex adaptive system (CAS) model developed by Johnson (2010) and others (Bellavita, 2006; Currao, 2009, Kapuchu, 2009; and Machal, 2011) as a theoretical framework from which to analyze the interactions present among two types of organizations (CCCs and CERTs). In 
the model, it is important to note that the adaptation present in this network (and used in the analyses in the previous chapter) is the result of individual as well as collective action. It is not only the organizations but the individuals coordinating these actions that are the focus of this study. In particular, it is the patterns of the interactions among CCCs and CERTs and the individuals that coordinate them that are the focus of this study.

\section{Analyzing the Patterns of Covariation: Types of Interactions among Local Homeland Security Networks in the State of Florida}

What is the pattern of interactions among CCCs and CERTs in the state of Florida over the time period 2002-2011? Specifically, is there a correlation between these interactions as they become more complex over time? As shown in Table 3 and Table 5 of the previous chapter, there is an increased amount of decentralization present in the network during the last decade, the overall Freeman degree network centralization index decreased from $93 \%$ to $34 \%$ and overall Freeman betweenness centralization index decreased from $73 \%$ to $10 \%$. Moreover, this trend is present for all the variability measures presented in Table 5 .

The results indicate that there is an inversely proportional relationship between network centralization and network size. As the network becomes larger, it becomes more decentralized. It can; therefore, be asserted that there is a positive correlation between network size and the amount of decentralization present in the network over time.

Over time, there are not only more organizations but more connections between

these organizations. For example, the network started with twenty organizations having 
thirty- nine connections and grew to one hundred and twelve organizations having two hundred and fifty-seven connections. Given that there are more organizations the question then becomes when did these organizations form?

\section{Addressing Temporal Precedence in the Adaptation of Local Homeland Security Networks}

Given the presence of a positive correlation between network size and level of decentralization, a second important question comes to the surface: exactly when did this decentralization occur? The data of the Regional Domestic Security Task Force were analyzed in terms of their regional responses to two more recent disasters, the 2004-2005 hurricane Seasons and the Gulf Oil Spill (2010). "Regional responses" are operationally defined as the month and year that each CCC and CERT within a certain area was created. The creation of these organizations reveals (1) how local homeland security organizations respond to feedback and (2) adjust their strategies in responding to their environments. Therefore, institutional changes (like the creation of additional regional CCCs and CERTs) after a disaster are very likely to be an institutional adaptation to a recent experienced need.

It is also important to note here that the formation of new organizations is predicated on two important individual actions, citizen interest and the willingness of an elected or appointed official to sponsor a CCC or a CERT. The fact that these organizations were formed in the wake of a series of hurricanes and a man-made disaster is prima facie evidence of both citizen interest and the willingness of local officials to sponsor these organizations. For example during the 2004-2005 hurricane seasons, a total of six hurricanes made landfall in the state of Florida and one passed through the Florida 
straights on its way to the Gulf of Mexico. All of these hurricanes caused significant damage in terms of property, and in some cases, caused great loss of life. After these hurricanes, a total of ten new CCCs or CERTs were formed. A second example concerns the Gulf Oil Spill where two CERTs and two CCCs were formed as the disaster evolved in Escambia County. Furthermore, in 2010, two CERTs located in Hamilton County, Lafayette County and one CCC in located in Sumter County was established in Region 1 (Northwest Florida).

\section{Accounting for Alternatives: Plausible Rival Explanations of the Formation of CCCs and CERTs in the State of Florida}

Given the presence of institutional adaptation, what are the plausible rival explanations for the development of the network and the increased amount of decentralization? Among the first plausible explanations to consider is the tenet that all networks per se become more decentralized with increasing complexity. To say that there is a linear relationship between complexity and decentralization would be an assumption. If the assumption were true, then one could predict the level of decentralization given the network's size and the number of organizations it contained, whether the growth curve was linear, geometric or even exponential.

The results, as outlined in Chapter four, reveal that it is not just the size of the network that matters in determining its level of decentralization, but the pattern of decentralization. In the network of CCCs and CERTs in the state of Florida, different regions developed at different rates, despite being exposed to the same hurricanes. For example, the number of CERTs in Broward County grew from three in 2002 to six in 2005 and then to twenty in 2011, while the number of CERTs in Orlando grew from two 
to four. The growth pattern is indicative of a non-linear relationship between complexity and decentralization among the different regions of the state. Given the presence of several hurricanes crossing the state why were there not more CCCs and CERTs founded? The answer to this question is beyond the scope of this dissertation but would be an interesting topic for further research.

A second plausible explanation is that the development of the network of CCCs and CERTs over the last ten years is simply the product of the devolution of responsibility from higher to lower levels of government. For example, the share or proportion of CERTs connected to the statewide CCC decreased from .429 in 2002 to .274 in 2005 and by nearly half from .274 in 2005 to .134 in 2011 . A uniform pattern of devolution should also depict a regular pattern with each county maintaining their Citizen Corps Council. This is not the case, according to the most recent map of CCCs in the state of Florida (Figure7); only sixteen counties have CCCs. Why this is the case is beyond the scope of this dissertation but would be a notable topic for further research. 
Figure 7: CCCs in the State of Florida (2011)

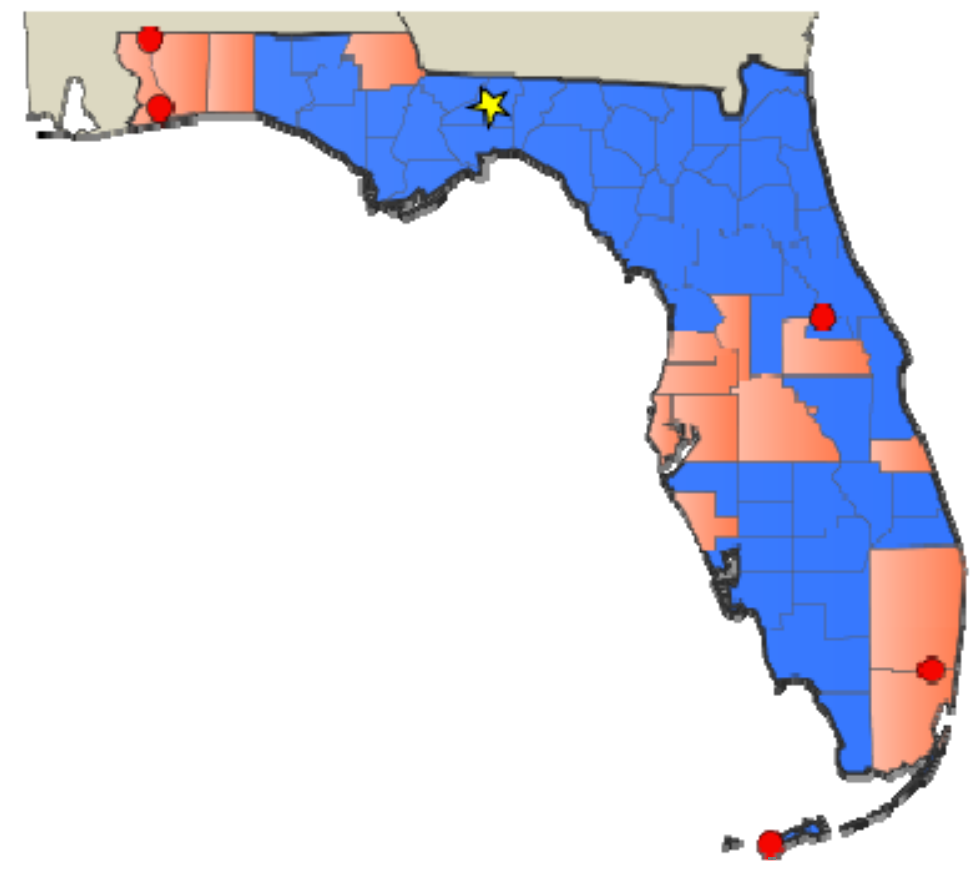

\section{Jurisdiction Key}

$\square$ Statewide
$\square$ Countywide
Local
Tribal

Source: Citizen Corps Council Website found at http://www.citizencorps.gov/cc/CouncilMapIndex.do?submitState\&state=FL

A third reason why devolution is not a viable explanation for the development of the network of CCCs and CERTs is that not all of the State's CCCs were formed before their respective CERTs. As described in Chapter four, eighteen CERTs existed before the formation of the CCCs program and are still operating.

Overall, there is no single factor accounting for the pattern of variation in the development of CCCs and CERTS in the state of Florida during the last decade. All of these plausible alternative explanations (decentralization by nature, devolution of authority to local governments, hierarchy within programs) give a partial reason, but no 
single or combination of these alternatives account for the non- linear development and the "emergent" behavior of CCCs and CERTs. There is no single overarching factor controlling this development. Given the presence of covariation, temporal precedence and the lack of plausible alternative explanations, the development of local homeland security networks most closely resembles that of a complex adaptive system. 


\section{CHAPTER SIX}

\section{DEVELOPING A NARRATIVE FOR THE}

\section{DEVELOPMENT OF LOCAL HOMELAND SECURITY NETWORKS: THE CASE OF SOUTH FLORIDA}

How do local homeland security organizations respond to catastrophic events such as hurricanes and acts of terrorism? Answering this question requires tracing the factors affecting the individuals and institutions planning, preparing, responding and recovering from natural and man- made disasters. The most important aspect of this response is these organizations' ability to adapt to the uncertain nature of these "focusing events."

Responses to focal events such as the attacks of September $11^{\text {th }}, 2001$ or Hurricane Katrina revealed weaknesses inherent in the governmental organizations charged with responding to these natural and man-made disasters. As stated throughout my dissertation, the lack of coordination and cooperation among governmental organizations was one of the primary weaknesses revealed by these focal events. Furthermore, the lack of federal funds, the presence of a "one size fits all approach", and the lack of a coherent risk assessment strategy (Frank and Reddick, 2006, 2) hampered implementation of institutional mandates especially at the local level.

These events served as a wake up call for many local governments in this regard. In the case of South Florida, the wake up call came much earlier. One Miami Dade County official when asked what effect 9/11 had on how his organization responded to natural or man-made disasters stated: 
Well, we actually I think learned our lessons long before September $11^{\text {th }}$ in the State of Florida because of our vulnerability to natural disasters and, you know, to quote our chief at the time in 1992 when Hurricane Andrew hit us, you know, all the help that came was the best thing that ever happened to us and all the help that came was the worst thing that ever happened to us because it wasn't coordinated. (Senior Miami Dade Fire Official (4D))

Thus the lack of coordination and communication are the main factors affecting how local homeland security organizations, plan, prepare, respond and recover from natural and man-made disasters. When asked how this lack of communication and coordination affected emergency response before September $11^{\text {th }}$, the Miami Dade County Official stated:

I mean prior to September $11^{\text {th }}$, everything was pretty much stove-piped, you know, law enforcement did their job, the Feds did their job, fire rescue did their job. We're seeing a lot of inter-discipline type communication, so I think - and I think that because of that, there's a tremendous opportunity. The gap is not that wide in closing this whole intelligence sharing part. (Senior Miami Dade Fire Official (4D))

To better coordinate the communication and interaction of the individuals and institutions involved, a change was made in how natural and man-made disasters or "hazards" (DHS, 2004, ix) were managed. The change focused on an "event" centric approach which is based on the likelihood of potential incidents and their localization.

The methodology is referred to as an "all hazards" approach in which natural and man- made disasters are treated the same for planning purposes and is the standard used by the United States Department of Homeland Security. The integral component of this "all hazards" approach is the National Incident Management System or NIMS, which was mandated by Homeland Security Presidential Directive 5 (HSPD-5) on February 23, 2003 and issued by President George W. Bush (DHS, 2004, 1). When asked what affect NIMS 
had on how they responded to natural and man-made disasters a second Miami Dade County official stated:

There are things within NIMS that obviously we had to adopt and practice, you know, credentialing and typecasting and that kind of thing and making sure everybody attended all those NIMS classes, ... . Yeah, we did have to, you know, do the formal training and the formal education process on there and, you know, implementing NIMS is a resource resource - I don't want to call it rich, but it's a system that requires us to dedicate resources to be able to comply with it, so it is a little bit of a challenge to do it but, you know, we're able to do it. As far as our partners, when I talk about partners, we're talking about our state, federal, local partners. (Senior Miami Dade County Fire Official (2B))

The National Incident Management System focuses on four aspects of an incident (preparation, prevention, response and recovery) and is designed to develop a "core set of concepts, principles, procedures" for dealing with disaster management for those officials managing homeland security related incidents, be they man-made or natural (DHS, 2004, 2). The emphasis is placed on creating a high level of both "interoperability and compatibility" among those agencies called upon to deal with an incident or hazard, it is done through creating a system that has the optimal amount of both "flexibility and standardization" (DHS, 2004, 2). The regulatory framework is the administrative or institutional constraint within which all local homeland security organizations must operate.

A common response among local homeland security officials was the increased amount of work necessary to comply with the National Incident Management System. Below is an example of how one county adapted to the NIMS:

Well what it did was it, I mean, the federal government put mandates on you - certain things that you had to do, you know, we had to write a comprehensive emergency management plan that flows along with the counties and the states. That comprehensive emergency management plan - you'll hear the term CEMP - basically is a blueprint for how we handle disasters, and you can see the document right there. It's a nice thick 
document and we follow it, you know, prior to Katrina there wasn't anything so after '05 we created one, we wrote it. (Senior Miami Dade Fire Official (2B))

\section{Mandated or Improvised Change: The role of CCCs and CERTs in measuring adaptation among local homeland security organizations}

National Incident Management System was not the only response to the focal events mentioned above. In addition to the NIMS protocols, programs were created to assist local governments in complying with the new institutional framework mandated by Department of Homeland Security. These federal programs did not replace local or state programs but were often superimposed onto existing state and local efforts. There are two types of responses or changes that have occurred over the last decade: (1) change that has a result of Federal or state mandates and (2) improvised change that has occurred as a result of shifting conditions brought on by focal events such as man-made and natural disasters.

For example, changes occurring due to institutional mandates can be seen in the response of local governments to the implementation of the National Incident Management System. When Homeland Security Presidential Directive 5 (HSPD-5) was issued in 2003, it mandated that all local homeland security organizations that desired to receive funding become NIMS compliant. The mandate required several actions including the adoption of common radio protocols and the adoption of a common radio frequency, the $800 \mathrm{MHz}$ frequency, for all emergency management personnel. It mandated the use of the Incident Command System (ICS) as the standard protocol for handling the responses to natural and man-made disasters. This can be seen in the response of a Broward County official interviewed in April of 2010 when he stated: 
We were very, very fortunate when we were faced with the challenges like everybody else of having to, you know, come on board with certain terminology, etc., radio protocol, operational connectiveness to the different public safety entities. We were very fortunate. We are well ahead of the curve for a lot of agencies. We were already using ICS anyway. We had been since the 80 's. (Senior Broward County Fire Official (3C))

In addition to the mandated changes in protocols, there were also improvised changes which included the development of organizations at the local level. One prominent example is the creation of the federal program entitled Citizen Corps. Initiated in January 2002, the Citizen Corps program was designed to:

...harness the power of every individual through education, training, and volunteer service to make communities safer, stronger, and better prepared to respond to the threats of terrorism, crime, public health issues, and disasters of all kinds. (http://www.citizencorps.gov/about/ accessed March 5, 2012)

These organizations operate through state, local and tribal councils are designed to:

Build on community strengths to implement the Citizen Corps preparedness programs and carry out a local strategy to involve government, community leaders, and citizens in all-hazards preparedness and resilience. (http://www.citizencorps.gov/about/ accessed March 5, 2012)

Combined with the Community Emergency Response Team (CERT) program, an affiliated organization of the Citizen Corps program, these programs serve to supplement the existing resources of local first responders before, during and after a man-made or natural disaster. Both the CCC and CERT programs are staffed by local volunteers and must be sponsored by a local official such as first responder or other county/municipal officials. Thus analyzing the pattern of development of these local voluntary programs is essential in documenting the pattern of local improvised change or adaptation to focal events.

Accordingly, my dissertation has documented the development of two sets of homeland security organizations, CCCs and Community Emergency Response Teams 
(CERTs). Taken together these organizations form a network that must respond to a number of institutional mandates within the context of budgetary and political constraints. As with the growth of the network generally, the response of these organizations is the result of a number of factors. Among these factors include (1) institutional mandates such as the NIMS, (2) the presence of flat or decreasing budgetary resources and personnel, and (3) the tensions that exist between elected and appointed officials as they seek to implement the mandates of both the federal and state governments.

These mandated and improvised changes tend to mix together since not all jurisdictions have the resources, either in terms of budget or personnel, to comply with the mandates. This is especially true of rural jurisdictions where small groups of officials, led by the fire or police chief, are often charged with implementing the National Incident Management System. Thus both mandated and improvised changes are evidence of adaptations of local homeland security organizations to their institutional, budgetary and political environments.

Despite these limitations, all jurisdictions are required to respond when natural or man-made disasters occur. In addition to changes mandated by the new institutional framework (i.e., NIMS), there have been "improvised changes" or adaptations as well, including an increasing reliance on the series of mutual aid agreements signed decades earlier beginning in the 1980's. These changes were not mandated by NIMS but happened as the network of organizations has become increasingly complex and decentralized. One example of this improvised change is the development of "automatic aid" in which units are dispatched to an incident based on their geographic proximity, 
regardless of whether the incident lies within the jurisdictional boundaries of the organization. The implementation of automatic aid agreements in Broward County is one example of these adaptations as stated by the following Broward County Official:

One of the things that - to take it to the next level is we've started to do and you'll see possibly in your discussions with others is, you know, local agreements that allow for automatic aid as opposed to mutual aid. Mutual aid is essentially the first step in you would be requesting assistance ... automatic aid [consists of ] where we would be able to see in our dispatch center on the CAD screens, we would be able to see their vehicles, their units, their - and they would likewise be able to see ours so if we needed assistance from another fire engine from Westin or something we would be able to essentially, just like there are people dispatching our units, we would be able to dispatch their units from a previously agreed upon protocol that would allow for that... (Senior Broward County Fire Official (3C))

Improvised adaptations are not limited to mutual aid agreements. An example of this adaptation can be found in the response to the Gulf Oil Spill in April 2010 in the area of Escambia County. Despite little institutional development of the network before the Gulf Oil Spill, there was only one CERT present before 2010; two CCCs were formed in the same month, April, in which the Macando Well platform exploded in the Gulf of Mexico. The development was not the result of an institutional mandate as the CCC program is driven by voluntary participation and must be coordinated by local emergency management officials. Moreover, the network of organizations that developed in the wake of the Gulf Oil Spill coordinated the actions of 1,550 volunteers logging 16,601 volunteer hours in $2010^{7}$

The adaptations documented above did not occur independently. To better understand the context in which they occur, these adaptations will be evaluated in light of 
three types of constraints; (1) budgetary, (2) institutional, and (3) political. The following three sections of this chapter will investigate in detail the presence of these constraints.

\section{Budgetary Constraints:}

Lack of funding has been a major complication in the NIMS implementation. The lack of federal funding, in particular, was due in part to the mechanisms used to fund municipalities. A Miami Dade County official stated that funding was among the greatest challenges that faced his jurisdiction, and federal funding was the hardest to get due to the amount of paper work that was required:

Our greatest challenge, I believe, is always going to be funding. I'm sure you'll hear that. With funding comes a lot of cooperation, so once we're able to secure enough funding for our region, I think you get a very good buy in from all our partners, so I'd say funding is always going to be number one. (Senior Miami Dade County Fire Official (2B))

A series of directives entitled Homeland Security Presidential Directives established the funding mechanisms that regulate the conduct of homeland security policy. The main directive governing homeland security financing is the Homeland Security Presidential Directive 8. According to HSPB8, in order to receive funding, states and localities have to adopt the National Incident Management System (NIMS) in responding to homeland security incidents (http://www.ojp.usdoj.gov/odp/welcome.htm).

To measure compliance with NIMS, DHS evaluates each municipality on a series of twenty-eight "mission critical" functions. Once approved, municipalities" funding is coordinated by the Office of State and local Government Coordination and Preparedness

\footnotetext{
${ }^{7}$ This data comes from the Citizen Corps website, http://www.citizencorps.gov/cc/showCouncil.do?id=46591 and http://www.citizencorps.gov/cc/showCouncil.do?id=47762 accessed on March 4, 2012
} 
(SLGCP). The fundamental issue that confronts local homeland security decision makers is that they must devote time and staff to a resource intensive, bureaucratic process.

When asked about the effect of NIMS on their operating procedures, a Miami Dade county official made the following statement:

There are things within NIMS that obviously we had to adopt and practice, you know, credentialing and typecasting and that kind of thing and making sure everybody attended all those NIMS classes, the 700, 800, 100, 200, 300, 400 classes depending on the level of your supervision. Yeah, we did have to, you know, do the formal training and the formal education process (Senior Miami Dade County Fire Official (2B))

Another Miami Dade county official echoed this sentiment in terms of the amount of training required to comply with the new regulatory framework created by NIMS:

It's the Incident Command System, which required by the National Incident Management System and so every one of our employees is trained in ICS depending on the level whatever their level is in the organization, so - which is quite an undertaking when that when that was mandated, but it has been accomplished...(Senior Miami Dade County Fire Official (1A))

Like I said, we evaluate and look at from a state perspective, the state emergency response plan that I discussed and how we can tweak it and how we can change it and what were some of the lessons learned even down to simple things like creating a form that is easier to track and to put in there the requirements that FEMA will need later on for reimbursement which doesn't seem like that critical but if you were the individual charged with having to provide all of the information that FEMA requires, that is a huge task. (Senior Miami Dade County Fire Official (1A))

An analysis of the total amount of resources reveals that federal resources in terms of grants and training amount to approximately $10 \%$ of all homeland security outlays from the Department of Homeland Security, despite the increased operational tempo of homeland security related incidents and exercises. For example, in 2006, funding for local agencies totaled approximately 9\% of the $\$ 41$ billion for the FY2006 DHS budget. 
Figure 8: Total and State and Local Government Coordination Program SLGCP Funding for FY 2004 - FY 2006

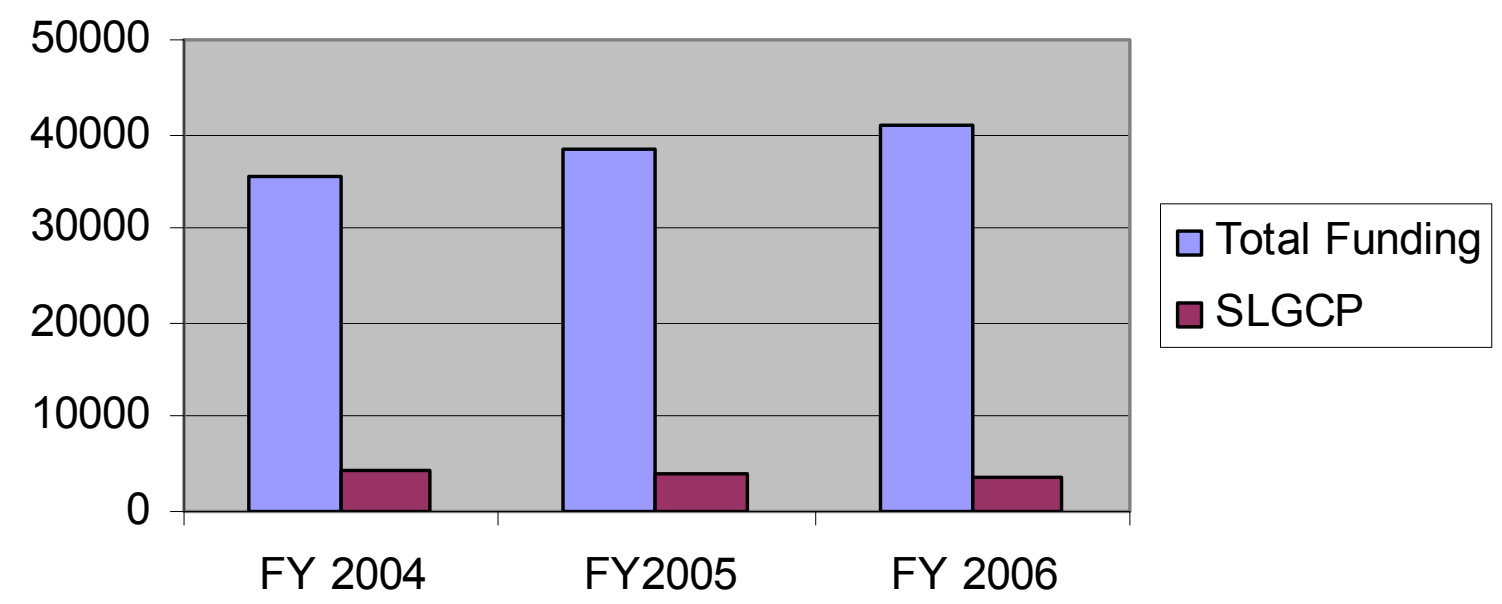

The National Governor's Association and the United States Conference of Mayors estimate that states and localities have spent approximately $\$ 8.6$ billion on homeland security related projects in 2006; with cities alone spending \$2.6 billion (Report by NGA and USCM). Despite an increase in overall funding of $15 \%$ from FY2004 - FY2006, funding for SLGCP decreased by 15\%. This trend has continued. In FY 2009, grants were $\$ 4,245,700$ or $7 \%$ of the overall DHS budget (FY 2009 Budget in Brief from the DHS, p.17-19). In FY 2010, total FEMA grants were $\$ 4,165,200$ or $7 \%$ of the total DHS budget (FY 2010 Budget in Brief from the DHS, p. 15-17). Funding in FY2011 remained at FY 2010 levels due to passage of a continuing resolution. 
Figure 9: U.S. Department of Homeland Security Funding Breakdown for SLGCP (In Millions)

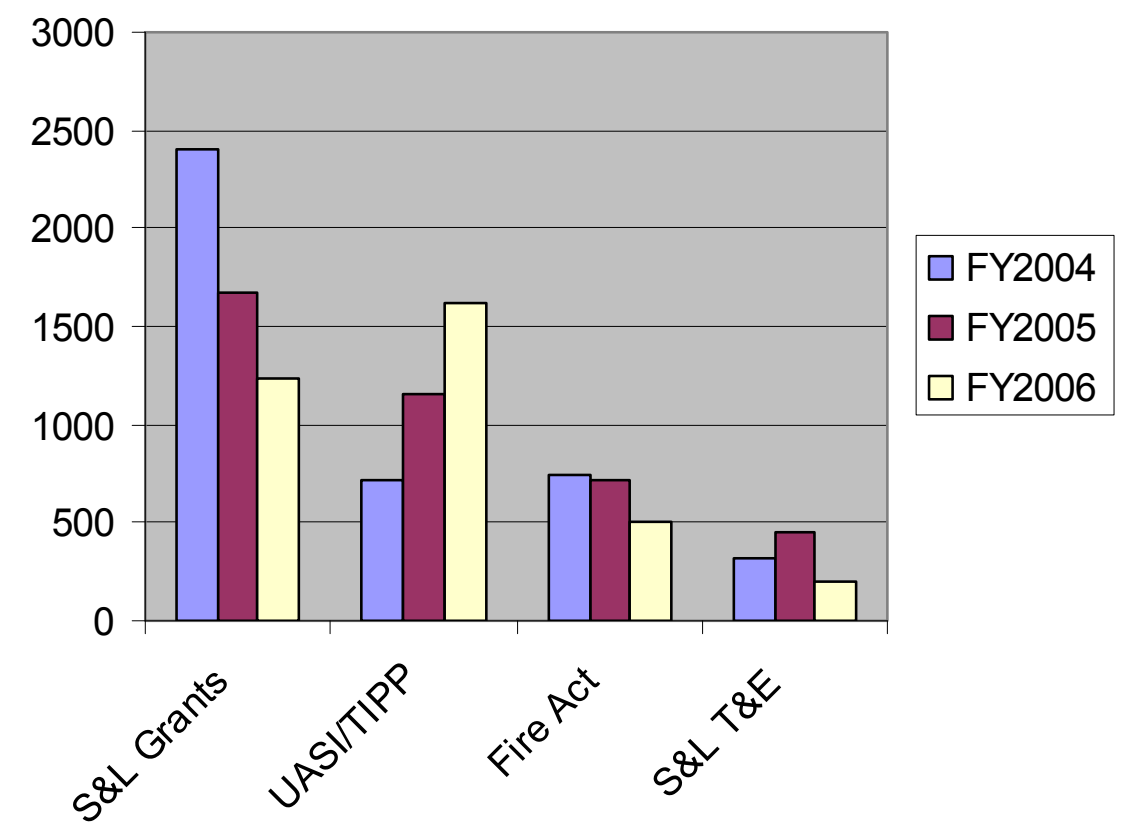

Despite the increased operational speed since 2001, and especially during the 2004-2005 hurricane seasons, funding for local programs from the DHS actually declined as a percentage of overall DHS funding. During the period FY2004 - FY2006, funding decreased markedly for all programs except UASI/TIPP (Urban Area Security Initiative/Targeted Infrastructure Protection Program). Program funding for State and Local Grants (S\&L Grants) decreased by $49 \%$ while Fire Act grants decreased by $33 \%$ and State and Local Training and Education funds decreased by 34\%. In contrast, funding for UASI/TIPP has increased by $124 \%$. Figure 9 presents these trends. 
The level of funding is not the only facet of homeland security financing that changed during this time period. In FY2004, State and Local grants comprised a majority of the funding coming from SLGCP. In FY2006, this pattern changed significantly with a majority of funding going to Urban Areas and Targeted Infrastructure. The trend is depicted in Figure 10 below.

Figure 10: Total USDHS State and local funding by program type for: FY 2004 to FY 2006

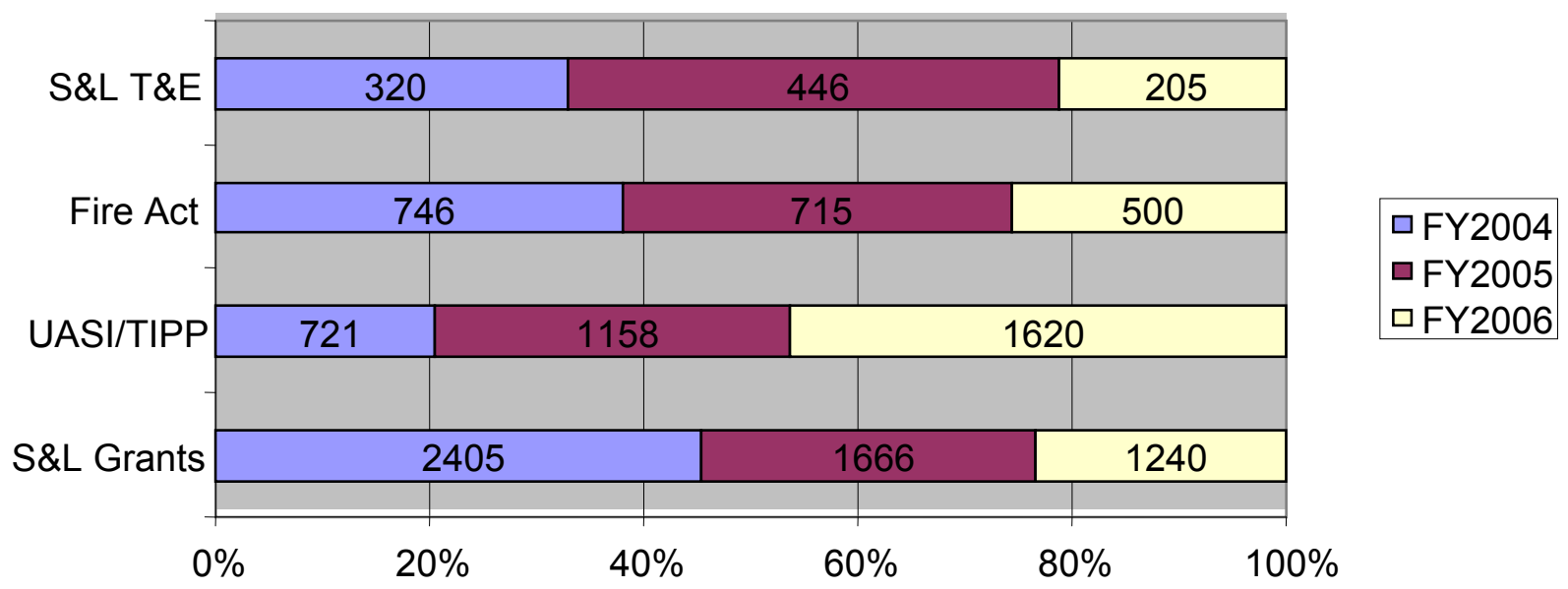

Since the 2004-2005 hurricane seasons, funding mechanisms have continued to evolve and yet the funding levels have remained the same or even decreased. In FY 2011, more than $\$ 3$ billion in grants were distributed which represented approximately $7 \%$ of the revised enacted FY2009 DHS budget (FY 2011 Budget in Brief, DHS, 2011, 13 and 111). Beginning in FY 2009, the various programs were consolidated into a new grants system and put under the management of the Federal Emergency Management Agency (FEMA). Under the new system, the National Preparedness Guidelines were used for allocating funds. 
These guidelines are the final product of a year's long planning process that began with Homeland Security Presidential Directive 8, which was issued on December 17, 2003. They are designed to accomplish five objectives (1) "organize and synchronize" efforts to fund priorities: (2) "guide investments [in] national preparedness"; (3) "incorporate lessons learned from past disasters into national preparedness priorities; (4) "facilitate investments" in priorities that were based on capabilities and risk assessment; and (5) "establish metrics" to evaluate the overall readiness of the "nation's preparedness capability to respond to major events, especially those involving acts of terrorism". (DHS, n.a., paragraph 1 www.dhs.gov/files/publications/gc_1189788256647.shtm)

The significance of homeland security grants for local governments is demonstrated in the following comment:

The Department of Homeland Security has grants available to us through FEMA and the State Homeland Security Grant Program - even though, in my opinion, is not implemented right in the state of Florida - does offer us some opportunities to bring in homeland security dollars into this region. The UASI program also brings much needed support to the region along with all the other - the port security, the transit security, Operation Stonegarden will also enhance our abilities, but all of the homeland security grants are good sources for funding for our region. (Senior Miami Dade County Fire Official (2B))

The fact that total DHS funding for state and local governments has comprised less than $10 \%$ of total DHS budgetary outlays the increased operational tempo of natural and man-made disasters has led officials to wear "multiple hats". Moreover, declining budgetary resources combined with the increased operational speed, mandated by several natural disasters, has led to the creation of new programs such as the Community Emergency Response Teams and Citizen Corps Councils. It has also led to 
an increased reliance on existing mutual aid agreements, which will be discussed in more depth in the next section.

\section{Institutional Constraints:}

In addition to the mentioned budgetary constraints, there are several institutional constraints in the form of a new regulatory framework that has been erected to deal with man-made and natural disasters. As in the introduction to this chapter, among the greatest issues facing local homeland security officials responding to focal events was the lack of communication and coordination among the various organizations involved in emergency management. When asked what the greatest homeland security issues were facing his jurisdiction, a Miami Dade County official said:

The most important issue for us is intelligence and sharing intelligence information. We've done a lot of work on preparation and equipping our people and training, but I still think there's a huge gap in intelligence sharing, especially between the law enforcement side and the responder side. (Senior Miami Dade County Fire Official (4D))

When asked what the greatest opportunity was, the Miami Dade County official responded:

Well, I think opportunity wise I think we have made - since September $11^{\text {th }}$ - have made tremendous strides in, how do I want to say it, creating an environment where all the stakeholders meet. We have - we've created these Regional Domestic Security Task Forces. (Senior Miami Dade County Fire Official (4D))

Overall, this Miami Dade county official described the institutional constraints in terms of governmental response in this way:

The challenges I think we're getting into now is the whole law of recency and everybody seems to, you know, as time goes, forgets about how bad things could be and budgets get tighter, grants get less, and so the challenge is, I see is keeping the momentum to say listen, it's not a matter of if but when and continuing to make sure we do everything we can to prepare. (Senior Miami Dade County Fire Official (4D)) 
To deal with these "focal events" and especially with the new regulatory architecture, these officials have created a new organizational framework which serves to connect all organizations involved in responding to man- made and natural disasters. The new organizational framework, or community, does not supplant but superimposes a new regulatory framework on top of these organizations. When asked to elaborate on the creation of these organizations, entitled Regional Domestic Security Task Forces, Senior Miami Dade County official responded:

The State of Florida - I'm not sure if every state does it, but the State of Florida after September $11^{\text {th }}$ then coordinated a joint effort between the Florida Department of Law Enforcement, that's kind of the lead agency, FDLE, and the local sheriff's offices. Every county in Florida, all 67, have a sheriff's office, created Regional Domestic Security Task Forces. There are seven in the state. They created them along the lines of our Division of Emergency Management Zones, so the seven regions have already existed...(Senior Miami Dade County Fire Official (4D))

When asked to elaborate on what the role of the Regional Domestic Security Task Forces were and what these Domestic Security Task Forces are, he stated:

I can perhaps show you a picture of how it's broken down, but essentially there are various work groups and then an Executive Board, and it's just - in a nutshell basically a multi-disciplined group that meets with their disciplines and then collectively. In other words, as an example, in May, we'll have our quarterly meeting, so I chair the fire group, so I'll be meeting with all my counterparts from Palm Beach to Monroe County about fire issues and Law Enforcement is doing their thing and Marine Operations is doing their thing, Agriculture is involved - the agroterrorism issue, health department is involved, all these entities will meet for a couple hours on their issues and then we all convene and meet collectively as a region - what are we doing collectively so with the idea being I'm talking about communication issues, police and agriculture and health might have the same communications issues so we try to channel things towards a joint effort. (Senior Miami Dade County Fire Official (4D))

The Senior Miami Dade fire official also elaborated on the role of federal funding in this new regulatory framework: 
Coupled with the UASI which is the Urban Area Security Initiative, which is kind of the pot of money that allows us to operate, really forces all the players to the table because, you know, we would like to say that it's a noble cause to just meet and make sure we do the right thing, but when you talk about money and everybody has an opportunity to take a piece of the pie, it tends to bring the players to the table and hold them there a lot longer so we've been able to develop these relationships through these Domestic Security Task Forces, and then those all combine and work up towards the Domestic Security Oversight Committee, the DSOC we call it in the State of Florida, so each region then is represented at the DSOC... ((Senior Miami Dade County Fire Official (4D))

When asked to describe in detail what this DSOC was, the Senior Miami Dade Official stated:

The DSOC takes the core disciplines - law enforcement, fire, health, and critical infrastructure and each region then has a representative of those disciplines that work together at the DSOC (Senior Miami Dade County Fire Official (4D))

In other words, each of the seven regions of the state has a representative from each of the organizations involved in emergency management. These regional representatives are then assigned to work with other regional representatives at the state level. It is important to note here that these officials are not employed by the DSOC, but by local, or in some cases regional, organizations involved in homeland security policy. Their responsibilities in the DSOC, or in their region for that matter, are in addition to whatever duties they have at their respective organizations.

The new regulatory framework is a result of concerted efforts on the part of officials to increase the level of communication and coordination between not just fire officials, or even law enforcement officials, but all those officials involved in emergency preparedness and management. A common mechanism used to increase coordination and communication is the use of mutual aid agreements. These agreements have existed for 
decades. Many of these agreements in South Florida date back to the response and recovery related Hurricane Andrew in 1992.

According to FEMA, mutual aid consists of:

Agreements between agencies, organizations, and jurisdictions that provide a mechanism to quickly obtain emergency assistance in the form of personnel, equipment, materials, and other associated services (FEMA website accessed at http://www.fema.gov/emergency/nims/ResourceMngmnt.shtm)

The primary objective is to facilitate rapid, short-term deployment of emergency support prior to, during, and after an incident.

When asked to elaborate on the use of mutual aid agreements in South Florida, the Broward County official responded:

We do have mutual aid agreements with - all of the agencies in Broward County belong to the Fire Chiefs Association of Broward County and as such, they were the promulgators of the mutual aid agreement back in, again, in the 80's, so since then all of the agencies in the county have signed on to that system, and there's a universal agreement, a universal service that goes with that. One of the things that - and it has been a very successful program. Mutual aid is essentially the first step in would be requesting assistance (Senior Broward County Fire Official (3C))

Thus mutual aid agreements are predicated on the knowledge that local assistance in the form of resources and personnel from other jurisdictions and municipalities or even states, will arrive before federal assistance. The development of the State Emergency Response Plan (SERP) was in part a response to focal events and predates the requirements of NIMS. In particular, the Senior Miami- Dade County Fire Official (2B) stated that experience has led them to increase the amount of communication and coordination between local organizations.

It has been tested over and over again. It has been proven very successful through the nine hurricanes in 2004/2005 to the wildfires in '98 and '03 and then '07, so we've really tested that system, and locally within the county, mutual aid exists between all of the 
agencies, and while there are no formal documents, it's something that just is inherent to provide the support. (Senior Miami Dade County Fire Official (2B))

It's crucial being a city of our size that we have mutual aid with the surrounding governments... but we also like to share resources and capabilities if they're needed elsewhere as well, so it's pretty critical." (Senior Miami Dade County Fire Official (2B))

When asked to describe how his organization has responded to NIMS operational requirements, the Senior Broward County Fire Official related his personal experience with the previous fire chief

Well, he came in '97, so he was here [when] 9/11 went down, and obviously still here when Hurricane Wilma, so he grew us through a bunch of this stuff, the succession planning in the building and the redundant systems, etc., so to go back to the operational question, yeah. We've implemented an Emergency Management division that reports directly to the Fire Chief. (Senior Broward County Fire Official (3C))

When asked what role the new Emergency Management coordinator played he outlined his responsibilities in this way:

He has been tasked with community outreach, community preparation for storms. He's gotten nearly - I think its right around 100 CERT volunteers through the CERT program, and I don't know if you're familiar... (Senior Broward County Fire Official (3C))

Elaborating on the role of the CERT program in his jurisdiction, the Broward County official detailed the history of the program and how it would operate in the event of a natural disaster:

...it's really a unique program. It came out of LA originally many, many years ago but what it basically does is it takes citizen volunteers - it's the Community Emergency Response Teams - CERT, so what it does is it takes these volunteers through classroom sessions, hands on sessions, they learn CPR, first aid, light search and rescue, all of kinds of, you know, communications techniques, radio protocol and basically they are geographically located out in the community in groups, so we've got several groups in target areas in the community so that if an event goes down - tornado touches down, hurricane, something like that - these people already have equipment, the uniforms, they've got radios, they can talk directly to our EOC, directly with our Emergency Official: Management Coordinator, and they'll give an onsite report of damage, injuries, 
flooding, any of that kind of thing from right in the community where they live. (Senior Broward County Fire Official (3C))

Specifically, the Broward County Official detailed the role of these CERT volunteers in a natural disaster in this way:

We're pulling in volunteers so and then again, the key part of it is they're out there in the community in their neighborhoods where the people know them, so if they come up to their neighbors and they're, you know, they see that they're flooded or they're lightly trapped or they need first aid, it's not like a stranger, you know, coming up to them.. (Senior Broward County Fire Official (3C))

The Broward county official also went on to state the volunteers for CERTs were "self selected", specifically that "they sign up" and gave his assessment of the program and how it has changed his "operation".

It's a nationally known program. It's federally supported through FEMA, and we've gotten a couple of grants that have supported the equipment and the education for that and it has been very successful, very well received in the community, very well supported by the commission and the city administration, so that's part of how the operation has changed. (Senior Broward County Fire Official (3C))

The aftermath of $9 / 11$ produced an influx of citizen participation which needed to be channeled. This was done to help support local emergency managers. According to the CCC guide, published in 2002, the purpose of CCCs is to:

Develop a systematic, efficient, and effective method for providing public education and training opportunities, stimulating wide-spread participation, and organizing volunteer programs to increase the safety of your community. (CCC guide, 2002, DHS, 12).

Citizen Corps Councils are formed by concerned citizens and must be "endorsed" by a local elected official, or city or county administrator. One can use existing resources and organizations to start a CCC if they are firmly established in the community. The 
geographic boundaries and membership are determined not by federal fiat but by the needs of local leaders in the governmental, nongovernmental and private sectors.

Membership is not limited to those involved in emergency management, but includes multiple community groups from faith-based organizations, transportation outlets (airports, bus and rail), multicultural organizations, and even local media executives (CCC guide, 2002, DHS, 12):

The primary qualification to participating on the Council is making a commitment to educate the public on safety, to help citizens take an active role in protecting themselves from harm, to teach citizens what to do in the event of a crisis, and to expand volunteer opportunities that will make the community safer. (CCC guide, 2002, DHS, 12).

State and local level CCCs were created on an as needed basis in response to community desire and focal events, such as hurricanes, acts of terrorism and wildfires. In chapter four, it was shown how CCCs and CERTs developed in Broward County through the years 1996 to 2011 as a reaction to focal events. The first five years of the network, from 1996 to 2000, saw slow but consistent growth with three CERTs being formed in Fort Lauderdale (1996), Pompano Beach (1997) and Hallandale Beach (1999). The CERTs; however, were not connected to each other but served as stand- alone organizations.

The next five years, 2001-2005, represent a significant period in the development of the network for several reasons. Seven hurricanes hit the state of Florida during the years of 2004 and 2005 with Hurricanes Rita, Katrina, and Wilma affecting Broward County in 2005. From 2001 to 2005, the network grew to include one CCC, the statewide CCC, and five CERTs. Also, the amount of interconnectedness increased as the network became more complex. 
The period of the most significant growth occurred in the last five years, 2006 to 2011. During this period the number of organizations grew from five to nineteen. In 2008, the DHS issued a mandate that every county needed to form at least one CERT. Between 2008 and 2011, two more CCCs and fourteen additional CERTs were formed and interconnectedness increased significantly.

In essence, the evolution of mutual aid agreements among first responders, the CERTs and the CCCs that coordinate their actions represent the growth of new policy communities to deal with the institutional constraints that have and continue to exist (Stone, 2002, 20).

\section{Political Constraints}

In addition to budgetary and institutional constraints, there are also political constraints embedded in emergency management. Among the most important constraints are the different roles played by elected officials and first responders. Elected officials are generally familiar with emergency management while first responders are technical specialists. Each group has their own perspective concerning the implementation of emergency management. Elected officials, as representatives of the general public, are concerned not only with the objective facts and actions on the ground, but the perception of these actions in the larger society (i.e., role of accountability and role of the media). First responders have a different mandate in terms of their mission to protect the health and safety of the public regardless of the perception of these actions in the larger society. The difference in roles leads to a natural tension between the two groups as they respond to focal events. Each of the groups has a separate, though not always conflicting goal, as 
they respond to focal events. One former elected official described this tension in the following manner:

There is a personality of a mindset to that that I think many people would agree tends to let us take control and just move out of the way and let us do our job. You don't have to worry about it and we'll get it done and then we'll pass you back the - your job or your role in it or whatever, and I don't think, I mean as our natural and manmade disasters have escalated especially in our most recent years, I think that model probably isn't very productive anymore. (Senior Palm Beach County Official (6F)).

The difference in perception also leads to a difference in management style. When asked what the greatest challenge facing municipalities was, the Palm Beach county official responded:

You can plan extensively and exhaustively for things that you know are going to occur or things - anticipating how things might occur or putting tried and true systems onto perceived threats and operational responses to those threats, but perhaps the biggest fear would be something that is not contemplated or something that is not - if contemplated, not scaled appropriately to an actual magnitude of an event that might occur, so that's a challenge. (Senior Palm Beach County Official (6F)).

Since elected officials are not as familiar with the technical details of emergency management, the official also emphasized the need to work together with first responders. In particular, the need for coordination and communication was seen as a central issue as illustrated in the following comments:

I see the challenge as a communication and relationship equation that better defines and shares amongst intergovernmental jurisdictions. (Senior Palm Beach County Official $(6 \mathrm{~F}))$.

When asked to elaborate on this statement the Palm Beach county official stated:

That's what we do is look for those commonalities and by design we're trying to find how do we break down the silos, how do we break down the jurisdictional barriers and share information and leverage resources in such a way to get the best return on investment for a host of reasons which include not only efficiently responding to disaster, but at the same time trying to make government and government systems more 
affordable, more implementable and appropriate. (Senior Palm Beach County Official $(6 \mathrm{~F}))$.

These comments were echoed by a Miami Dade County official, when asked to describe how the events of September $11^{\text {th }}$ affected emergency management efforts:

I mean prior to September $11^{\text {th }}$, everything was pretty much stove-piped, you know, law enforcement did their job, the Feds did their job, fire rescue did their job. (Senior Miami Dade County Fire Official (4D))

The pressure of the political constraints lies in the fact that the elected officials will be held accountable in the public domain. Their actions or inactions will be scrutinized in view of the aftermath of the focal event. Among the most important aspects of this constraint is the relationship between the elected officials, first responders, and the public; specifically, the responsibility of the elected officials to society, as demonstrated by the following comments:

It's not all about can we assign a larger portion of budget to this or can we put more people on it or can we double production out of the factory of mitigative tools. It's a mindset and a communications component that I think our real challenge will be how do you instill educationally and from the sense of a societal responsibility appropriate responses that you want out of everybody that's involved in the system to respond to whatever it is that occurs. (Senior Palm Beach County Official $(6 \mathrm{~F})$ ).

The need for the public to support themselves in their neighborhoods is reflected in the following statement:

They immediately go to work at repairing that which is around them and I've seen that observationally with people in hurricanes. While we're sitting in the bunker worrying about how we get heavy equipment down street A or street B or back into inaccessible area $\mathrm{C}$, the people that live there are already out there picking stuff up. They're already firing up their chain saws. They're already carting debris to the curb. They're already assisting neighbors. They're already doing things by default that we're contemplating or planning on doing, (Senior Palm Beach County Official (6F)).

When asked to explain what this meant in practice for emergency managers the senior Palm Beach Official stated the following: 
I think that's a very imperative lesson for planners and system designers to keep cognizant of in a way that what their systems and their resources ought to be doing is leveraging and enhancing and incentivizing that versus coming from the point of view of we've got a better mousetrap. Move out of our way and let us move in and take over because they're never there when it starts. (Senior Palm Beach County Official (6F)).

The elected officials operate on the basis on consent given by those who elected them.

First responders are in charge with protecting the public from whichever incident occurs.

\section{Combining the constraints}

The key to understanding the interaction of first responders and CERT volunteers lies in viewing their interactions as the result of a complex adaptive system with mutual aid, CCCs, and CERTs representing adaptations to the budgetary, institutional and political constraints. They are often behind the curve and see response as a linear process where they plan, prepare, respond, and recover, when it is a complex multifaceted process. It requires elected officials, first responders who understand the interactions between the fiscal pressures facing local governments, the institutional pressures of working within a new regulatory framework, and the political pressures of bringing together different levels of government with different perspectives and agendas. 


\section{CHAPTER SEVEN}

\section{GETTING AHEAD OF THE CURVE:}

\section{THE IMPLICATIONS OF VIEWING LOCAL EMERGENCY MANAGEMENT IN THE STATE OF FLORIDA AS A COMPLEX ADAPTIVE SYSTEM}

September 11, 2011 is an important date not just for the nation in general, but for emergency management in particular. The months leading up to this anniversary produced a spate of articles concerning the 9/11 attacks. These articles have focused primarily on the progress made and steps yet to be taken. What most of these articles reveal is that there has been a significant amount of effort, both in terms of time, resources and staff, devoted to ensuring that another attack does not happen. In addition to the estimated $\$ 400$ billion which have been spent on "security" in the last decade (Trotta, 2011), there is a new cabinet level department, the Department of Homeland Security, which is the third largest in the federal government, behind the Departments of Defense and Veterans Affairs (DHS Budget in brief, FY2012, 37 and Zakaria, 2011). At the local level, the adoption of NIMS has produced significant changes in how local governments operate and how they respond to natural and man-made disasters.

All of this effort leads inevitably to the question "Is it working?" In particular, are the reforms working as they were intended? Do they prevent or at least mitigate the damage that will result from a future attack or natural disaster? The answer to this question must be equivocal. Yes, we are "safer" than we were; but no, we are not "completely prepared." The most important reason for this equivocation includes the scarcity of focal events either natural or man-made to test the system developed. Since the 2004-2005 hurricane seasons, there has been only one focal event that has affected 
the state of Florida and that is the Gulf Oil Spill of 2010. The best way to test this system short of evaluating its performance in an actual focal event is in the use of full scale training exercises. Federal Emergency Management Agency conducts a series of these exercises through the Homeland Security Exercise and Evaluation Program (HSEEP) and state and regional organizations also hold their own exercise. Furthermore, Objectives 17 and 18 of the FY 2009 NIMS compliance objectives, mandate planning and participation in such exercises (FEMA, 2009, 1). Despite all the training and the founding of dozens of organizations, their effectiveness in an actual focal event is also largely untried in most areas of the state.

Despite this fact, the state and indeed the country has moved from a state of relative ignorance to one that is "ever vigilant". In essence, we are experiencing a "new normal" (Trotta, 2011). There has been a shift in attitude, even of focus, in which governments at all levels have recognized the need to change from a "culture of need to know" to one of "need to share" (Zakaria, 2011). Emblematic of these changes is a statement made by Secretary of Homeland Security Janet Napolitano, who declared in the first State of Homeland Security Address on January 27, 2011:

"The kinds of threats we now face demonstrate that our homeland security is a shared responsibility. Only a "whole nation approach" will bring us to the level of security and resilience we require."

(DHS website accessed at http://www.dhs.gov/ynews/speeches/sp_1296152572413.shtm)

This "new normal" however, has many of the characteristics of the "old normal" where governments, due to budgetary, institutional and political constraints, respond to the latest "focal event" with incremental approaches that often leave them behind the curve. They see emergency management as a linear process in which we plan, prepare, 
respond and recover. This is true at every level of government but especially, the federal level.

Nine out of the forty-one recommendations from the 9/11 Commission Report has yet to be enacted. Of these, the most important to local first responders is the continued lack of a common communication system for police, fire and other emergency management personnel in less-populated areas of the United States (Zakaria, 2011). New

funding limitations have also been enacted to deal with the increased budgetary constraints brought on by the economic downturn felt throughout the economy since 2008. This is true even at the federal level with projected spending on local preparedness projected to remain at the same level or less (DHS Budget in Brief, 2012), as discussed in chapter six.

Despite the partial implementation of these recommendations, there is evidence that local first responders have created novel methods of increasing cooperation and communication in the event of a natural or man- made disaster. Increased reliance on mutual aid agreements and the continued development of the network of CCCs and CERTs in the state of Florida are examples of this trend. Despite budgetary, institutional and political constraints, local first responders and the volunteers who have assisted them have adapted to this "new normal".

\section{Limitations of the study}

Given the continued presence of these constraints and the likelihood of yet unforeseen natural and man-made disasters, how can local first responders get ahead of the curve in terms of their planning, preparing, responding and recovering from natural and man- made disasters? 
At least a partial answer lies in changing the way public administrators of all levels evaluate these focal events. In particular, it is in adopting a system in which first responders and the volunteers who assist them are seen as "actors" in a complex adaptive system which responds to feedback and adjusts its strategy to its environment. Employing Social Network Analysis is a first step in revealing the "emergent" behavior within the system that occurs before, during and after a natural or man- made disaster. The analyses conducted in this study have revealed how first responders are adapting to the budgetary, institutional, and political constraints, allowing them to be more flexible and proactive in how they prepare, plan, respond and recover from disasters. The presence of these constraints is not limited to the network of CCCs and CERTs; however, there are many other actors who can and should be included, but were beyond the scope of this dissertation. Among the actors that should be included are: nongovernmental organizations, private sector businesses and tribal organizations that interact with local homeland security organizations.

The current project analyzed the network of organizations composed of CCCs and CERTs in the state of Florida from the years 2002-2011. Only organizations registered at the official Citizen Corps Website were used in collecting data for the social network analysis. Also, for both conceptual and methodological reasons, this analysis was limited to only two measures of centrality, degree and betweenness centrality. Conceptually, social network analysis is seen as the best tool to model complex adaptive systems, like the network of CCCs and Community Emergency Response Teams. Methodologically, social network analysis is seen as the best tool available to track the development of these 
two sets of organizations and especially the patterns of interconnections that exist among them.

As a result, this dissertation did not conduct a statistical analysis of the attributes of these organizations, but concentrated on the pattern of interconnections among them. This dissertation specifically does not address the quality or richness of the communication between the organizations and individuals involved in this network. Furthermore, this dissertation does not analyze the effectiveness of the response to focal events but rather depicts the development of the network over the years 2002-2011. An evaluation of the effectiveness of the network would require a more detailed analysis of the actors of the network and their attributes that are beyond the current scope of the dissertation. Examples of this analysis include: an analysis of the cliques (sub groups that are all connected to each other), the presence of homophyly or reciprocity among actors in the network and the amount of transitivity or clustering of like minded sets of organizations present in the network.

This study was concerned with how two sets of organizations, CCCs and CERTs, adapted to three types of constraints; budgetary, institutional, and political as defined in chapter two of this dissertation. The conclusions from this research are only applicable to the network under study as defined in chapter three. Other networks may be similar, but a more robust statistical analysis of this network would be needed before any conclusions can be drawn regarding the patterns found in this study.

Given the limitations of this study, further research is necessary to better understand the interconnections between CCCs and CERTS and other organizations. Examples of the next steps in this research agenda include expanding the number of 
actors included in the social network analysis, to include other first responders such as medical personnel, or other organizations involved in planning, preparing, responding and recovering from natural and man- made disasters.

Further studies can include not just discrete organizations, but also other groups or networks in the analysis. One such network of organizations is the growing number of "Fusion Centers" currently being created across the country. "Fusion Centers" serve as clearinghouses for information on the various types of threats impacting local, state and federal organizations. These centers exist at every level of government, but are concentrated at the local level. The Department of Justice's Bureau of Justice Assistance (BJA) recently issued guidelines for local, regional, statewide, and federal fusion centers which are defined as "the collaborative effort of two or more agencies that provide resources, expertise and information to the center with the goal of maximizing their ability to detect, prevent, investigate, and respond to criminal and terrorist activity (BJA, 2009, 2)." There are currently seventy- two fusion centers operating in the United States that form what is termed the "national network." (GAO, 201, 3) Evaluating the role of these "fusion centers" and the interconnections among them with other local emergency managers is an important next step in understanding the patterns present in the larger network of homeland security organizations.

\section{Implications for Public Administration Theory and Practice}

Finally, understanding how these officials and the organizations they represent have adapted to these constraints has important implications for public administration theory and practice. First, this dissertation reveals the importance of using methods that are able to capture the process of this adaptation. Using social network analysis, this 
dissertation has evaluated the process of adaptation that has occurred among CCCs and CERTs over the last decade. Second, it is important to apply theories that focus on the patterns of interactions among practitioners not just their attributes. Using complex adaptive systems theory, this dissertation reveals how the pattern of development over the last decade of two sets of organizations: CCCs and CERTs was not linear in nature but rather the product of many interacting actors, which responded to feedback from their environment and adjusted their strategies or adapted to constraints they encountered. Overall, in terms of the theory and practice of public administration, my dissertation reveals the importance of analyzing not just the attributes of individual actors but the patterns of interactions among local officials and their effect on implementation of national and state level policy. 


\section{REFERENCES}

Publications and News Articles

Agranoff, R, (2007), Managing within Networks, Georgetown University Press, Washington, D.C.

Bellavita, C., (2006). Changing Homeland Security: Shape Patterns Not Programs, Homeland Security Affairs, 2 (3): 1-21

Birkland, T, (1997), After Disaster: Agenda Setting, Public Policy and Focusing Events, Georgetown University Press, Washington, DC.

, (2006) Lessons of Disaster: Policy Change after Catastrophic Events, Georgetown University Press, Washington, DC.

Bureau of Justice Assistance, Fusion Center Guidelines: Developing and Sharing Information in a New Era, accessed at http://it.ojp.gov/documents/fusion_center_guidelines_law_enforcement.pdf

Caruson, K, MacManus, S., Kohen, M., Watson, T, (2005), Homeland Security Preparedness: The Rebirth of Regionalism. Publius, 35 (1): 143-168.

Caruson, K. and MacManus, S. (2006), Mandates and Management Challenges in the Trenches: An Intergovernmental Perspective on Homeland Security, Public Administration Review, 66 (4): 522-536.

Cox, L, (2008) Some Limitations of "Risk $=$ Threat $\times$ Vulnerability $\times$ Consequence" for Risk Analysis of Terrorist Attacks, Risk Analysis, 28 (6): 1749-1761

Currao, 2009, New Role for Emergency Management: Fostering Trust to Enhance Collaboration in Complex Adaptive Emergency Response Systems, Naval Post Graduate School, Master's Thesis. Accessed at https://www.hsdl.org/?view\&did=30814

Eisenger, P. 2006. Imperfect Federalism: the intergovernmental partnership for homeland security. Public Administration Review 66 (4): 537-545. 
Gerber, B, Cohen, D, Stewart K, (2007). U.S. Cities and Homeland Security: Examining the Role of Financial Conditions and Administrative Capacity in Municipal Preparedness Efforts. Public Finance and Management, 7 (2): 152-188.

Hay, C, 2010, et al. New Directions In Political Science: Responding To The Challenges Of An Interdependent World, Basingstoke: Palgrave Macmillan

Hanneman, R.A. and Riddle, M. (2005). Introduction to social network methods, Riverside, CA: University of California, Riverside (published in digital form at http://faculty.ucr.edu/ hanneman/)

Johnson, N., (2009). Simply Complexity, One World Publications, Oxford, England.

Kapucu, N. Augustin, M.E., Garayev, V.; Interstate Partnerships in Emergency Management:Emergency Management Assistance Compact in Response to Catastrophic Disasters; Public Administration Review, March/ April 2009, Vol. 69 (2) 297-313

Kettl, D. 2004, System Under Stress: Homeland Security and American Politics, CQ Press, Washington DC,

Kingdon, J. (1984), Agendas, Alternatives and Public Policies, in Shafritz, J., Hyde, A. and Parkes, S. 2004, Classics of Public Administration, $5^{\text {th }}$ Edition Thompson/Wadsworth, Pearson, Educational Resources, Belmont, CA

Knoke, D. and Yang, S. (2008), Social Network Analysis, $2^{\text {nd }}$ Edition, Sage Publications, Los Angeles

Krueger, S; Jennings, E; and Kendra, J. (2009) "Local Emergency Management Funding: An Evaluation of County Budgets," Journal of Homeland Security and Emergency Management: Vol. 6 : Iss. 1, Article 43.

Moran, M., 2010, Policymaking in an interdependent world; in Hay, C., New directions in political science: responding to the challenges of an interdependent world, Basingstoke: Palgrave Macmillan

O’Hanlon, M. "Homeland Security Funding: Urban Area Grant Maze, The Washington Times, June 9, 2006" 
Reddick, C.G., \& Frank, H.A. (2006). Homeland Security Administration and Finance: A Survey of Texas County Officials. Journal of Homeland Security and Emergency Management, 3(3), 1-21.

Reddick, C. and Frank, H. "The Relationship between Risk and Homeland Security Financing: A Survey of Florida City Managers and Fire Chiefs", unpublished manuscript, 2008

Scavo, C., Kearney, R., and Kilroy, R., (2008) Challenges to Federalism: Homeland Security and Disaster Response; Publius 38 (1): 81-110.

Stone, D. 2002, Policy Paradox: The Art of Political Decision Making, Revised Edition, W.W. Norton and Co. New York, New York.

Trotta, D, “U.S. safer 10 years after 9/11, but at what cost?”, Reuters, September 7, 2011

The 9/11 commission report: final report of the national commission on terrorist attacks upon the United States (9/11 report): Government Printing Office, Washington, DC, (2004)

U.S. Congress, House of Representatives, A Failure of Initiative: Final Report of the Select Bipartisan Committee to Investigate Preparation for and Response to Hurricane Katrina, 109th Congress, 2nd Session, Report 109-377 (2006); White House, The Federal Response to Hurricane Katrina: Lessons Learned (2006).

Wasserman, S. and Faust, K, (1994), Social Network Analysis: Methods and Applications: Cambridge University Press, New York, New York

Waugh, W. 2004. Terrorism and the all-hazards model. Paper delivered at the IDS Emergency Management On-Line Conference, June 28 to July 16 http://training.fema.gov/emiweb/downloads/Waugh\%2020Terrorism\%20and\%20Planning.doc

Wise, C., (2002). Organizing for Homeland Security; Public Administration Review, 62 (2):131-144

(2006). Organizing for Homeland Security after Katrina: Is Adaptive Management What's Missing? Public Administration Review 66 (3): 302-318 
Wise, C. and Nader, R., (2002). Organizing the Federal System for Homeland Security: Problems, Issues and Dilemmas" Public Administration Review, 62 Special Issue: 44-57.

Zakaria, T, "Post-9/11 U.S. intelligence reforms take root, problems remain", Reuters, September 8, 2011

\section{SOFTWARE PACKAGES}

Borgatti, S., Everett, M., and Freeman, L., (2002). Ucinet for Windows: Software for Social Network Analysis. Harvard, MA: Analytic Technologies.

Borgatti, S. (2002) Netdraw Network Visualization, Harvard, MA: Analytic Technologies

\section{WEBSITES}

Citizen Corps Council Website found at http://www.citizencorps.gov/citizencorps/councils/councilindex.shtm and http://www.citizencorps.gov/cc/CouncilMapIndex.do?submitState\&state=FL

, Citizen Corps: A Guide for Local Officials,

Federal Emergency Management Agency, Tribal Government and Local Jurisdiction Compliance Activities: Federal Fiscal Year 2006 (October 1, 2005-september 30, 2006) http://www.fema.gov/pdf/emergency/nims/nims_tribal_local_compliance_activities.pdf

, FY 2009 NIMS implementation objectives, accessed at http://www.fema.gov/pdf/emergency/nims/FY2009_NIMS_Implementation_Chart.pdf

Florida Community Emergency Response Team Website accessed at http://www.citizencorps.gov/cc/CertIndex.do?reportsForState\&cert=\&state=FL

The National Strategy for Homeland Security as found at website http://www.whitehouse.gov/homeland/book/. First issued by the U.S. Department of Homeland Security in FY 2004 and updated periodically

Department of Homeland Security Budget in Brief, p. 10 accessed at http://www.dhs.gov/interweb/assetlibrary/Budget_BIB-FY2006.pdf

http://www.dhs.gov/interweb/assetlibrary/Budget_BIB-FY2010.pdf

Department of Homeland Security, State of America's Homeland Security Address, accessed at http://www.dhs.gov/ynews/speeches/sp_1296152572413.shtm) 
FY 2006 Homeland Security National Training Program Grant Application Guidance Kit, p. 1 Department of Homeland Security, Office of Grants and Training website found at http://www.ojp.usdoj.gov/odp/welcome.html

Government Accountability Office Report no. GAO-05-139, (2005). Department of Homeland Security: A Comprehensive and Sustained Approach Needed to Achieve Management Integration

Report no. GAO-05-300 (2005), Results-Oriented Government: Improvements to DHS's Planning Process Would Enhance Usefulness and Accountability.

National Hurricane Center (NHC), Tropical Cyclone Reports, accessed at http://www.nhc.noaa.gov/2004atlan.shtml and http://www.nhc.noaa.gov/2005atlan.shtml , Beven II, 2004, TCR-AL062004_Frances, , Cobb and Lawrence, TCR-AL112004_Jeanne, 2005 , Knabb, Rhome, Brown, TCR-AL122005_Katrina, 2005 , Knabb, Rhome, Brown, TCR-AL182005_Rita, 2005 , Pasch, Blake, Cobb III, and Roberts, TCR-AL252005_Wilma, 2006 , Pasch, Brown, and Blake, TCR-AL032004_Charley, 2004 , Stewart, Hurricane Ivan, TCR-AL092004_Ivan, 2004

National Commission on BP Deepwater Horizon Oil Spill and Offshore Drilling, Deep Water: The Gulf Oil Disaster and the Future of Offshore Drilling, accessed at http://www.oilspillcommission.gov/final-report, 2011

National Response Framework Brochure, 2008, found at http://www.fema.gov/pdf/emergency/nrf/about_nrf.pdf

National Response Framework, 2008, as found at http://www.fema.gov/pdf/emergency/nrf/nrf-core.pdf 
National Strategy for Homeland Security, Department of Homeland Security Office of State and Local Government Coordination and Preparedness now at http://www.ojp.usdoj.gov/odp/welcome.htm

National Strategy for Homeland Security as found at website http://www.whitehouse.gov/homeland/book/. First issued by the U.S. Department of Homeland Security in FY 2004 and updated periodically

President's Budget FY2006, Office of Management and Budget, Executive Office of the President, as found at website http://www.whitehouse.gov/omb/pdf/Homeland-06.pdf

President's Budget FY2009, Office of Management and Budget, Executive Office of the President and Department Of Homeland Security Budget in Brief, p. 10 as found at website http://www.dhs.gov/interweb/assetlibrary/Budget_BIB-FY2009.pdf

President's Budget FY 2012, Office of Management and Budget, Executive Office of the President, and Department Of Homeland Security Budget in Brief, p. 17-18 as found at http://www.dhs.gov/interweb/assetlibrary/Budget_BIB-FY2012.pdf

Ryan, A (2006) Emergence is coupled to scope, not level. arXiv:nlin/0609011v1 as found at Cornell University Library website: http://arxiv.org/abs/nlin/0609011v1 


\section{APPENDICES}

\section{APPENDIX A}

Matrices of Florida CCCs and CERTs for 2002 and 2005

See Supplementary File 1 for the Matrix of Florida CCCs and CERTs for 2011 


\section{Matrix for FL CCCs and CERTs 2002}

(1) Statewide CCC

(2) Rockledge CERT

(3) Fort Lauderdale CERT

$\begin{array}{lllllllllllllllllll}1 & 1 & 1 & 1 & 1 & 1 & 1 & 1 & 1 & 1 & 0 & 0 & 0 & 0 & 1 & 1 & 1 & 1 & 1\end{array}$

(4) Pompano Beach CERT

$\begin{array}{llllllllllllllllll}0 & 0 & 0 & 0 & 0 & 0 & 0 & 0 & 0 & 0 & 0 & 0 & 0 & 0 & 0 & 0 & 0 & 0\end{array}$

(5) Hallendale Beach CERT

$\begin{array}{lllllllllllllllllll}1 & 0 & 0 & 0 & 0 & 0 & 0 & 0 & 0 & 0 & 0 & 0 & 0 & 0 & 0 & 0 & 0 & 0 & 0\end{array}$

(6) Citrus County CERT

(7) Hernando County Sheriff's Office CERT

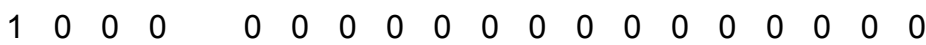

(7) Hernando County Sherift

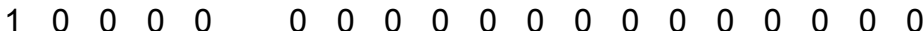

(9) North Fort Myers CERT

(10) Miami Dade CERT

(11) Orlando Fire Department CERT

(12) Palm Beach County CCC

(13) Delray Beach Fire Rescue CERT

$\begin{array}{llllllll}1 & 0 & 0 & 0 & 0 & 0\end{array}$

$0 \begin{array}{llllllllllll}0 & 0 & 0 & 0 & 0 & 0 & 0 & 0 & 0 & 0 & 0 & 0\end{array}$

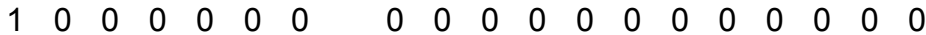

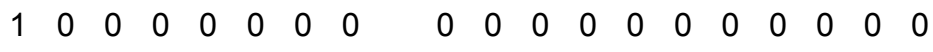

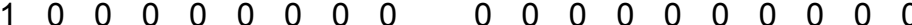

$\begin{array}{lllllllllllllllllll}1 & 0 & 0 & 0 & 0 & 0 & 0 & 0 & 0 & 0 & 0 & 0 & 0 & 0 & 0 & 0 & 0 & 0 & 0\end{array}$

$\begin{array}{lllllllllllllllllll}0 & 0 & 0 & 0 & 0 & 0 & 0 & 0 & 0 & 0 & 0 & 1 & 1 & 1 & 0 & 0 & 0 & 0 & 0\end{array}$

(14) RiverWalk CERT

(15) West Palm Beach CERT

(16) Treasure Island CERT

(17) Polk County CERT

(18) City of Deland Fire Rescue CERT
(19) City of Debary CERT

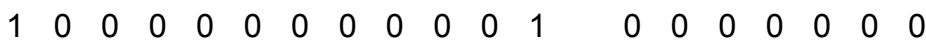

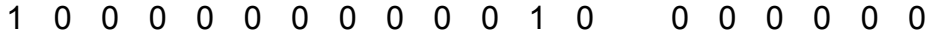

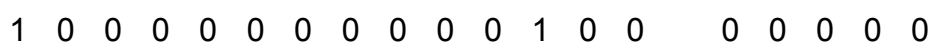

$\begin{array}{llllllllllllllllllll}1 & 0 & 0 & 0 & 0 & 0 & 0 & 0 & 0 & 0 & 0 & 0 & 0 & 0 & 0 & & 0 & 0 & 0 & 0\end{array}$

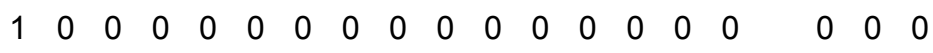

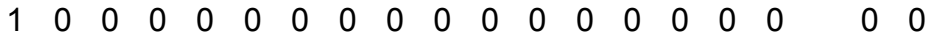

(20) South Daytona CERT

$\begin{array}{lllllllllllllllllll}1 & 0 & 0 & 0 & 0 & 0 & 0 & 0 & 0 & 0 & 0 & 0 & 0 & 0 & 0 & 0 & 0 & 0 & 0\end{array}$

$\begin{array}{lllllllllllllllllll}1 & 0 & 0 & 0 & 0 & 0 & 0 & 0 & 0 & 0 & 0 & 0 & 0 & 0 & 0 & 0 & 0 & 0 & 0\end{array}$ 
Matrix for Florida CCCs and CERTs in 2005

(1) Statewide

(2) Bradford County CERT

(3) Rockledge CERT

(4) Miramar CERT

(5) Hallendale Beach CERT

(6) Fort Lauderdale CERT

(7) Dania Beach CERT

(8) Coral Springs CERT

(9) Pompano Beach CER

(10) Citrus County CERT

(11) Big Corkscrew Island Fire Rescue CERT

(12) Jax CERT

(13) Escambia County CERT

(14) Flagler County CERT

(15) Hernando County Nature Coast CCC

(16) Hernando County Sheriff's Office CERT

(17) Gulfport CERT

(18) Sun City Center CERT

(19) Hillsborough County CERT

(20) Hillsborough County CCC

(21) lona-McGregor Fire Protection/Rescue CERT

(22) Manatee County CERT

(23) CERT of the Villages

(24) North Miami Beach CERT

(25) Miami Dade CERT

(26) Okaloosa County CERT

(27) Orange County Florida CERT

(28) Orange County Florida CCC

(29) Orlando Fire Department CERT

(30) Palm Beach County CCC

(31) Palm Beach County CERT

(32) RiverWalk CERT

(33) Jupiter Police CERT

(34) Delray Beach Fire Rescue CERT

(35) West Palm Beach CERT

(36) Pasco County CCC

(37) Treasure Island CERT

(38) East Lake CERT

(39) Pinellas Suncoast Fire Rescue CERT

(40) Polk County CERT

(41) Navarre CERT

(42) Santa Rosa County CERT

(43) Sarasota COAD/CCC

(44) Sarasota County CERT

(45) Daytona Beach CERT

(46) City of Debary CERT

(47) City of Deland Fire Rescue CERT

(48) South Daytona CERT $\begin{array}{llllllllllllllllllllllllllllllllllllllllllllllll}1 & 1 & 1 & 1 & 1 & 1 & 1 & 1 & 1 & 1 & 1 & 1 & 1 & 0 & 0 & 0 & 0 & 0 & 0 & 1 & 1 & 1 & 1 & 1 & 1 & 0 & 0 & 0 & 0 & 0 & 0 & 0 & 0 & 0 & 0 & 1 & 1 & 1 & 1 & 1 & 1 & 0 & 0 & 1 & 1 & 1 & 1\end{array}$ $\begin{array}{llllllllllllllllllllllllllllllllllllllllllllllll}0 & 0 & 0 & 0 & 0 & 0 & 0 & 0 & 0 & 0 & 0 & 0 & 0 & 0 & 0 & 0 & 0 & 0 & 0 & 0 & 0 & 0 & 0 & 0 & 0 & 0 & 0 & 0 & 0 & 0 & 0 & 0 & 0 & 0 & 0 & 0 & 0 & 0 & 0 & 0 & 0 & 0 & 0 & 0 & 0 & 0\end{array}$ $\begin{array}{lllllllllllllllllllllllllllllllllllllllllllllll}1 & 0 & 0 & 0 & 0 & 0 & 0 & 0 & 0 & 0 & 0 & 0 & 0 & 0 & 0 & 0 & 0 & 0 & 0 & 0 & 0 & 0 & 0 & 0 & 0 & 0 & 0 & 0 & 0 & 0 & 0 & 0 & 0 & 0 & 0 & 0 & 0 & 0 & 0 & 0 & 0 & 0 & 0 & 0 & 0 & 0 & 0\end{array}$ $\begin{array}{lllllllllllllllllllllllllllllllllllllllllllllll}1 & 0 & 0 & 0 & 1 & 0 & 0 & 0 & 0 & 0 & 0 & 0 & 0 & 0 & 0 & 0 & 0 & 0 & 0 & 0 & 0 & 0 & 0 & 0 & 0 & 0 & 0 & 0 & 0 & 0 & 0 & 0 & 0 & 0 & 0 & 0 & 0 & 0 & 0 & 0 & 0 & 0 & 0 & 0 & 0 & 0 & 0\end{array}$ $\begin{array}{lllllllllllllllllllllllllllllllllllllllllllllll}1 & 0 & 0 & 0 & 1 & 0 & 0 & 0 & 0 & 0 & 0 & 0 & 0 & 0 & 0 & 0 & 0 & 0 & 0 & 0 & 0 & 0 & 0 & 0 & 0 & 0 & 0 & 0 & 0 & 0 & 0 & 0 & 0 & 0 & 0 & 0 & 0 & 0 & 0 & 0 & 0 & 0 & 0 & 0 & 0 & 0 & 0\end{array}$ $\begin{array}{llllllllllllllllllllllllllllllllllllllllllllllll}1 & 0 & 0 & 1 & 1 & 1 & 0 & 0 & 0 & 0 & 0 & 0 & 0 & 0 & 0 & 0 & 0 & 0 & 0 & 0 & 0 & 0 & 0 & 0 & 0 & 0 & 0 & 0 & 0 & 0 & 0 & 0 & 0 & 0 & 0 & 0 & 0 & 0 & 0 & 0 & 0 & 0 & 0 & 0 & 0 & 0 & 0\end{array}$ $\begin{array}{llllllllllllllllllllllllllllllllllllllllllllllll}1 & 0 & 0 & 0 & 0 & 1 & 0 & 0 & 0 & 0 & 0 & 0 & 0 & 0 & 0 & 0 & 0 & 0 & 0 & 0 & 0 & 0 & 0 & 0 & 0 & 0 & 0 & 0 & 0 & 0 & 0 & 0 & 0 & 0 & 0 & 0 & 0 & 0 & 0 & 0 & 0 & 0 & 0 & 0 & 0 & 0 & 0\end{array}$ $\begin{array}{lllllllllllllllllllllllllllllllllllllllllllllllll}1 & 0 & 0 & 0 & 0 & 1 & & 0 & 0 & 0 & 0 & 0 & 0 & 0 & 0 & 0 & 0 & 0 & 0 & 0 & 0 & 0 & 0 & 0 & 0 & 0 & 0 & 0 & 0 & 0 & 0 & 0 & 0 & 0 & 0 & 0 & 0 & 0 & 0 & 0 & 0 & 0 & 0 & 0 & 0 & 0 & 0 & 0 \\ 1 & 0 & 0 & 0 & 0 & 0 & 0 & & 1 & 0 & 0 & 0 & 0 & 0 & 0 & 0 & 0 & 0 & 0 & 0 & 0 & 0 & 0 & 0 & 0 & 0 & 0 & 0 & 0 & 0 & 0 & 0 & 0 & 0 & 0 & 0 & 0 & 0 & 0 & 0 & 0 & 0 & 0 & 0 & 0 & 0 & 0 & 0\end{array}$

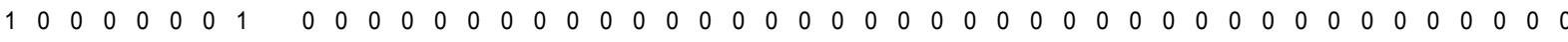
$1 \quad 0 \quad 0 \quad 0 \begin{array}{llllllllllllllllllllllllllllllllllllllllllll} & 0 & 0 & 0 & 0 & 0 & 0 & 0 & 0 & 0 & 0 & 0 & 0 & 0 & 0 & 0 & 0 & 0 & 0 & 0 & 0 & 0 & 0 & 0 & 0 & 0 & 0 & 0 & 0 & 0 & 0 & 0 & 0 & 0 & 0 & 0 & 0 & 0 & 0 & 0 & 0 & 0 & 0 & 0\end{array}$ $\begin{array}{lllllllllllllllllllllllllllllllllllllllllllllllll}1 & 0 & 0 & 0 & 0 & 0 & 0 & 0 & 0 & 0 & 0 & 0 & 0 & 0 & 0 & 0 & 0 & 0 & 0 & 0 & 0 & 0 & 0 & 0 & 0 & 0 & 0 & 0 & 0 & 0 & 0 & 0 & 0 & 0 & 0 & 0 & 0 & 0 & 0 & 0 & 0 & 0 & 0 & 0 & 0 & 0 & 0\end{array}$ $\begin{array}{llllllllllllllllllllllllllllllllllllllllllllllll}1 & 0 & 0 & 0 & 0 & 0 & 0 & 0 & 0 & 0 & 0 & 0 & 0 & 0 & 0 & 0 & 0 & 0 & 0 & 0 & 0 & 0 & 0 & 0 & 0 & 0 & 0 & 0 & 0 & 0 & 0 & 0 & 0 & 0 & 0 & 0 & 0 & 0 & 0 & 0 & 0 & 0 & 0 & 0 & 0 & 0 & 0\end{array}$ $\begin{array}{llllllllllllllllllllllllllllllllllllllllllllllll}1 & 0 & 0 & 0 & 0 & 0 & 0 & 0 & 0 & 0 & 0 & 0 & 0 & 0 & 0 & 0 & 0 & 0 & 0 & 0 & 0 & 0 & 0 & 0 & 0 & 0 & 0 & 0 & 0 & 0 & 0 & 0 & 0 & 0 & 0 & 0 & 0 & 0 & 0 & 0 & 0 & 0 & 0 & 0 & 0 & 0 & 0\end{array}$ $\begin{array}{llllllllllllllllllllllllllllllllllllllllllllllllllllllll}1 & 0 & 0 & 0 & 0 & 0 & 0 & 0 & 0 & 0 & 0 & 0 & 0 & 0 & 0 & 0 & 0 & 0 & 0 & 0 & 0 & 0 & 0 & 0 & 0 & 0 & 0 & 0 & 0 & 0 & 0 & 0 & 0 & 0 & 0 & 0 & 0 & 0 & 0 & 0 & 0 & 0 & 0 & 0 & 0 & 0 & 0\end{array}$ $\begin{array}{llllllllllllllllllllllllllllllllllllllllllllllll}0 & 0 & 0 & 0 & 0 & 0 & 0 & 0 & 0 & 0 & 0 & 0 & 0 & 0 & & 1 & 0 & 0 & 0 & 0 & 0 & 0 & 0 & 0 & 0 & 0 & 0 & 0 & 0 & 0 & 0 & 0 & 0 & 0 & 0 & 0 & 0 & 0 & 0 & 0 & 0 & 0 & 0 & 0 & 0 & 0 & 0 & 0\end{array}$ $\begin{array}{llllllllllllllllllllllllllllllllllllllllllllllll}0 & 0 & 0 & 0 & 0 & 0 & 0 & 0 & 0 & 0 & 0 & 0 & 0 & 0 & 1 & 0 & 0 & 0 & 0 & 0 & 0 & 0 & 0 & 0 & 0 & 0 & 0 & 0 & 0 & 0 & 0 & 0 & 0 & 0 & 0 & 0 & 0 & 0 & 0 & 0 & 0 & 0 & 0 & 0 & 0 & 0 & 0\end{array}$ $\begin{array}{llllllllllllllllllllllllllllllllllllllllllllllll}0 & 0 & 0 & 0 & 0 & 0 & 0 & 0 & 0 & 0 & 0 & 0 & 0 & 0 & 0 & 0 & 0 & 1 & 1 & 0 & 0 & 0 & 0 & 0 & 0 & 0 & 0 & 0 & 0 & 0 & 0 & 0 & 0 & 0 & 0 & 0 & 0 & 0 & 0 & 0 & 0 & 0 & 0 & 0 & 0 & 0 & 0\end{array}$ $\begin{array}{llllllllllllllllllllllllllllllllllllllllllllllll}0 & 0 & 0 & 0 & 0 & 0 & 0 & 0 & 0 & 0 & 0 & 0 & 0 & 0 & 0 & 0 & 0 & 1 & 1 & 0 & 0 & 0 & 0 & 0 & 0 & 0 & 0 & 0 & 0 & 0 & 0 & 0 & 0 & 0 & 0 & 0 & 0 & 0 & 0 & 0 & 0 & 0 & 0 & 0 & 0 & 0 & 0 & 0\end{array}$ $\begin{array}{llllllllllllllllllllllllllllllllllllllllllllllll}0 & 0 & 0 & 0 & 0 & 0 & 0 & 0 & 0 & 0 & 0 & 0 & 0 & 0 & 0 & 0 & 1 & 1 & 1 & 0 & 0 & 0 & 0 & 0 & 0 & 0 & 0 & 0 & 0 & 0 & 0 & 0 & 0 & 0 & 0 & 0 & 0 & 0 & 0 & 0 & 0 & 0 & 0 & 0 & 0 & 0 & 0\end{array}$ $\begin{array}{llllllllllllllllllllllllllllllllllllllllllllllllll}0 & 0 & 0 & 0 & 0 & 0 & 0 & 0 & 0 & 0 & 0 & 0 & 0 & 0 & 0 & 0 & 1 & 1 & 1 & 0 & 0 & 0 & 0 & 0 & 0 & 0 & 0 & 0 & 0 & 0 & 0 & 0 & 0 & 0 & 0 & 0 & 0 & 0 & 0 & 0 & 0 & 0 & 0 & 0 & 0 & 0 & 0\end{array}$

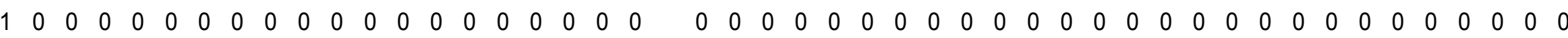
$\begin{array}{llllllllllllllllllllllllllllllllllllllllllllllll}1 & 0 & 0 & 0 & 0 & 0 & 0 & 0 & 0 & 0 & 0 & 0 & 0 & 0 & 0 & 0 & 0 & 0 & 0 & 0 & 0 & 0 & 0 & 0 & 0 & 0 & 0 & 0 & 0 & 0 & 0 & 0 & 0 & 0 & 0 & 0 & 0 & 0 & 0 & 0 & 0 & 0 & 0 & 0 & 0 & 0 & 0\end{array}$

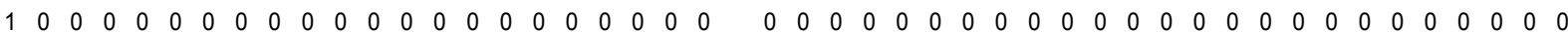
$\begin{array}{lllllllllllllllllllllllllllllllllllllllllllllllll}1 & 0 & 0 & 0 & 0 & 0 & 0 & 0 & 0 & 0 & 0 & 0 & 0 & 0 & 0 & 0 & 0 & 0 & 0 & 0 & 0 & 0 & 0 & 0 & 0 & 0 & 0 & 0 & 0 & 0 & 0 & 0 & 0 & 0 & 0 & 0 & 0 & 0 & 0 & 0 & 0 & 0 & 0 & 0 & 0 & 0 & 0\end{array}$ $\begin{array}{lllllllllllllllllllllllllllllllllllllllllllllll}1 & 0 & 0 & 0 & 0 & 0 & 0 & 0 & 0 & 0 & 0 & 0 & 0 & 0 & 0 & 0 & 0 & 0 & 0 & 0 & 0 & 0 & 0 & 0 & 0 & 0 & 0 & 0 & 0 & 0 & 0 & 0 & 0 & 0 & 0 & 0 & 0 & 0 & 0 & 0 & 0 & 0 & 0 & 0 & 0 & 0 & 0\end{array}$ $\begin{array}{llllllllllllllllllllllllllllllllllllllllllllllll}1 & 0 & 0 & 0 & 0 & 0 & 0 & 0 & 0 & 0 & 0 & 0 & 0 & 0 & 0 & 0 & 0 & 0 & 0 & 0 & 0 & 0 & 0 & 0 & 0 & 0 & 0 & 0 & 0 & 0 & 0 & 0 & 0 & 0 & 0 & 0 & 0 & 0 & 0 & 0 & 0 & 0 & 0 & 0 & 0 & 0 & 0\end{array}$ $\begin{array}{lllllllllllllllllllllllllllllllllllllllllllllllll}0 & 0 & 0 & 0 & 0 & 0 & 0 & 0 & 0 & 0 & 0 & 0 & 0 & 0 & 0 & 0 & 0 & 0 & 0 & 0 & 0 & 0 & 0 & 0 & 0 & 0 & 1 & 1 & 0 & 0 & 0 & 0 & 0 & 0 & 0 & 0 & 0 & 0 & 0 & 0 & 0 & 0 & 0 & 0 & 0 & 0 & 0\end{array}$ $\begin{array}{lllllllllllllllllllllllllllllllllllllllllllllllllllllll}0 & 0 & 0 & 0 & 0 & 0 & 0 & 0 & 0 & 0 & 0 & 0 & 0 & 0 & 0 & 0 & 0 & 0 & 0 & 0 & 0 & 0 & 0 & 0 & 0 & 0 & 1 & 0 & 0 & 0 & 0 & 0 & 0 & 0 & 0 & 0 & 0 & 0 & 0 & 0 & 0 & 0 & 0 & 0 & 0 & 0 & 0\end{array}$ $\begin{array}{llllllllllllllllllllllllllllllllllllllllllllllll}0 & 0 & 0 & 0 & 0 & 0 & 0 & 0 & 0 & 0 & 0 & 0 & 0 & 0 & 0 & 0 & 0 & 0 & 0 & 0 & 0 & 0 & 0 & 0 & 0 & 0 & 1 & 1 & 0 & 0 & 0 & 0 & 0 & 0 & 0 & 0 & 0 & 0 & 0 & 0 & 0 & 0 & 0 & 0 & 0 & 0 & 0\end{array}$ $\begin{array}{llllllllllllllllllllllllllllllllllllllllllllllll}0 & 0 & 0 & 0 & 0 & 0 & 0 & 0 & 0 & 0 & 0 & 0 & 0 & 0 & 0 & 0 & 0 & 0 & 0 & 0 & 0 & 0 & 0 & 0 & 0 & 0 & 0 & 0 & 0 & 1 & 1 & 1 & 1 & 1 & 0 & 0 & 0 & 0 & 0 & 0 & 0 & 0 & 0 & 0 & 0 & 0 & 0\end{array}$ $\begin{array}{lllllllllllllllllllllllllllllllllllllllllllllllll}0 & 0 & 0 & 0 & 0 & 0 & 0 & 0 & 0 & 0 & 0 & 0 & 0 & 0 & 0 & 0 & 0 & 0 & 0 & 0 & 0 & 0 & 0 & 0 & 0 & 0 & 0 & 0 & 0 & 1 & 1 & 1 & 1 & 1 & 0 & 0 & 0 & 0 & 0 & 0 & 0 & 0 & 0 & 0 & 0 & 0 & 0\end{array}$ $\begin{array}{llllllllllllllllllllllllllllllllllllllllllllllll}0 & 0 & 0 & 0 & 0 & 0 & 0 & 0 & 0 & 0 & 0 & 0 & 0 & 0 & 0 & 0 & 0 & 0 & 0 & 0 & 0 & 0 & 0 & 0 & 0 & 0 & 0 & 0 & 0 & 1 & 1 & 0 & 0 & 0 & 0 & 0 & 0 & 0 & 0 & 0 & 0 & 0 & 0 & 0 & 0 & 0 & 0\end{array}$ $\begin{array}{llllllllllllllllllllllllllllllllllllllllllllllll}0 & 0 & 0 & 0 & 0 & 0 & 0 & 0 & 0 & 0 & 0 & 0 & 0 & 0 & 0 & 0 & 0 & 0 & 0 & 0 & 0 & 0 & 0 & 0 & 0 & 0 & 0 & 0 & 0 & 1 & 1 & 0 & 0 & 0 & 0 & 0 & 0 & 0 & 0 & 0 & 0 & 0 & 0 & 0 & 0 & 0 & 0\end{array}$ $\begin{array}{llllllllllllllllllllllllllllllllllllllllllllllll}0 & 0 & 0 & 0 & 0 & 0 & 0 & 0 & 0 & 0 & 0 & 0 & 0 & 0 & 0 & 0 & 0 & 0 & 0 & 0 & 0 & 0 & 0 & 0 & 0 & 0 & 0 & 0 & 0 & 1 & 1 & 0 & 0 & 0 & 0 & 0 & 0 & 0 & 0 & 0 & 0 & 0 & 0 & 0 & 0 & 0 & 0\end{array}$ $\begin{array}{lllllllllllllllllllllllllllllllllllllllllllllllllllll}0 & 0 & 0 & 0 & 0 & 0 & 0 & 0 & 0 & 0 & 0 & 0 & 0 & 0 & 0 & 0 & 0 & 0 & 0 & 0 & 0 & 0 & 0 & 0 & 0 & 0 & 0 & 0 & 0 & 1 & 1 & 0 & 0 & 0 & 0 & 0 & 0 & 0 & 0 & 0 & 0 & 0 & 0 & 0 & 0 & 0 & 0 & 0\end{array}$ $\begin{array}{llllllllllllllllllllllllllllllllllllllllllllllllllllllllllll}0 & 0 & 0 & 0 & 0 & 0 & 0 & 0 & 0 & 0 & 0 & 0 & 0 & 0 & 0 & 0 & 0 & 0 & 0 & 0 & 0 & 0 & 0 & 0 & 0 & 0 & 0 & 0 & 0 & 0 & 0 & 0 & 0 & 0 & 0 & 0 & 0 & 0 & 0 & 0 & 0 & 0 & 0 & 0 & 0 & 0 & 0 & 0\end{array}$ $\begin{array}{llllllllllllllllllllllllllllllllllllllllllllllll}1 & 0 & 0 & 0 & 0 & 0 & 0 & 0 & 0 & 0 & 0 & 0 & 0 & 0 & 0 & 0 & 0 & 0 & 0 & 0 & 0 & 0 & 0 & 0 & 0 & 0 & 0 & 0 & 0 & 0 & 0 & 0 & 0 & 0 & 0 & 0 & 0 & 0 & 0 & 0 & 0 & 0 & 0 & 0 & 0 & 0 & 0\end{array}$ $\begin{array}{llllllllllllllllllllllllllllllllllllllllllllllll}1 & 0 & 0 & 0 & 0 & 0 & 0 & 0 & 0 & 0 & 0 & 0 & 0 & 0 & 0 & 0 & 0 & 0 & 0 & 0 & 0 & 0 & 0 & 0 & 0 & 0 & 0 & 0 & 0 & 0 & 0 & 0 & 0 & 0 & 0 & 0 & 0 & 0 & 0 & 0 & 0 & 0 & 0 & 0 & 0 & 0 & 0\end{array}$ $\begin{array}{llllllllllllllllllllllllllllllllllllllllllllllll}1 & 0 & 0 & 0 & 0 & 0 & 0 & 0 & 0 & 0 & 0 & 0 & 0 & 0 & 0 & 0 & 0 & 0 & 0 & 0 & 0 & 0 & 0 & 0 & 0 & 0 & 0 & 0 & 0 & 0 & 0 & 0 & 0 & 0 & 0 & 0 & 0 & 0 & 0 & 0 & 0 & 0 & 0 & 0 & 0 & 0 & 0\end{array}$

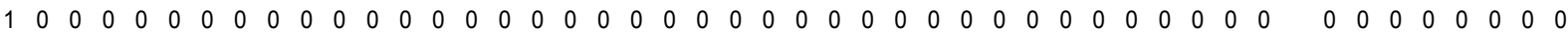
$\begin{array}{llllllllllllllllllllllllllllllllllllllllllllllllll}1 & 0 & 0 & 0 & 0 & 0 & 0 & 0 & 0 & 0 & 0 & 0 & 0 & 0 & 0 & 0 & 0 & 0 & 0 & 0 & 0 & 0 & 0 & 0 & 0 & 0 & 0 & 0 & 0 & 0 & 0 & 0 & 0 & 0 & 0 & 0 & 0 & 0 & 0 & 0 & 0 & 0 & 0 & 0 & 0 & 0 & 0\end{array}$ $\begin{array}{llllllllllllllllllllllllllllllllllllllllllllllll}1 & 0 & 0 & 0 & 0 & 0 & 0 & 0 & 0 & 0 & 0 & 0 & 0 & 0 & 0 & 0 & 0 & 0 & 0 & 0 & 0 & 0 & 0 & 0 & 0 & 0 & 0 & 0 & 0 & 0 & 0 & 0 & 0 & 0 & 0 & 0 & 0 & 0 & 0 & 0 & 0 & 0 & 0 & 0 & 0 & 0 & 0\end{array}$ $\begin{array}{llllllllllllllllllllllllllllllllllllllllllllllll}0 & 0 & 0 & 0 & 0 & 0 & 0 & 0 & 0 & 0 & 0 & 0 & 0 & 0 & 0 & 0 & 0 & 0 & 0 & 0 & 0 & 0 & 0 & 0 & 0 & 0 & 0 & 0 & 0 & 0 & 0 & 0 & 0 & 0 & 0 & 0 & 0 & 0 & 0 & 0 & 0 & 0 & 1 & 0 & 0 & 0 & 0\end{array}$ $\begin{array}{llllllllllllllllllllllllllllllllllllllllllllllll}0 & 0 & 0 & 0 & 0 & 0 & 0 & 0 & 0 & 0 & 0 & 0 & 0 & 0 & 0 & 0 & 0 & 0 & 0 & 0 & 0 & 0 & 0 & 0 & 0 & 0 & 0 & 0 & 0 & 0 & 0 & 0 & 0 & 0 & 0 & 0 & 0 & 0 & 0 & 0 & 0 & 0 & 1 & 0 & 0 & 0 & 0\end{array}$

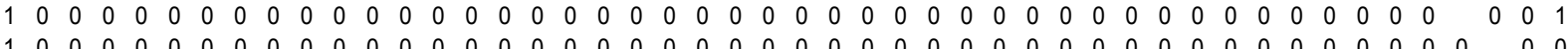

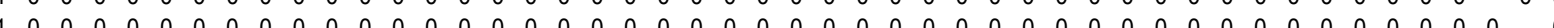
$\begin{array}{llllllllllllllllllllllllllllllllllllllllllllllll}1 & 0 & 0 & 0 & 0 & 0 & 0 & 0 & 0 & 0 & 0 & 0 & 0 & 0 & 0 & 0 & 0 & 0 & 0 & 0 & 0 & 0 & 0 & 0 & 0 & 0 & 0 & 0 & 0 & 0 & 0 & 0 & 0 & 0 & 0 & 0 & 0 & 0 & 0 & 0 & 0 & 0 & 0 & 0 & 1 & 0 & 0\end{array}$ 
APPENDIX B

Network Centrality Measures for 2002, 2005, 2011 
Florida CCCs and CERTs 2002

FREEMAN'S DEGREE CENTRALITY MEASURES:

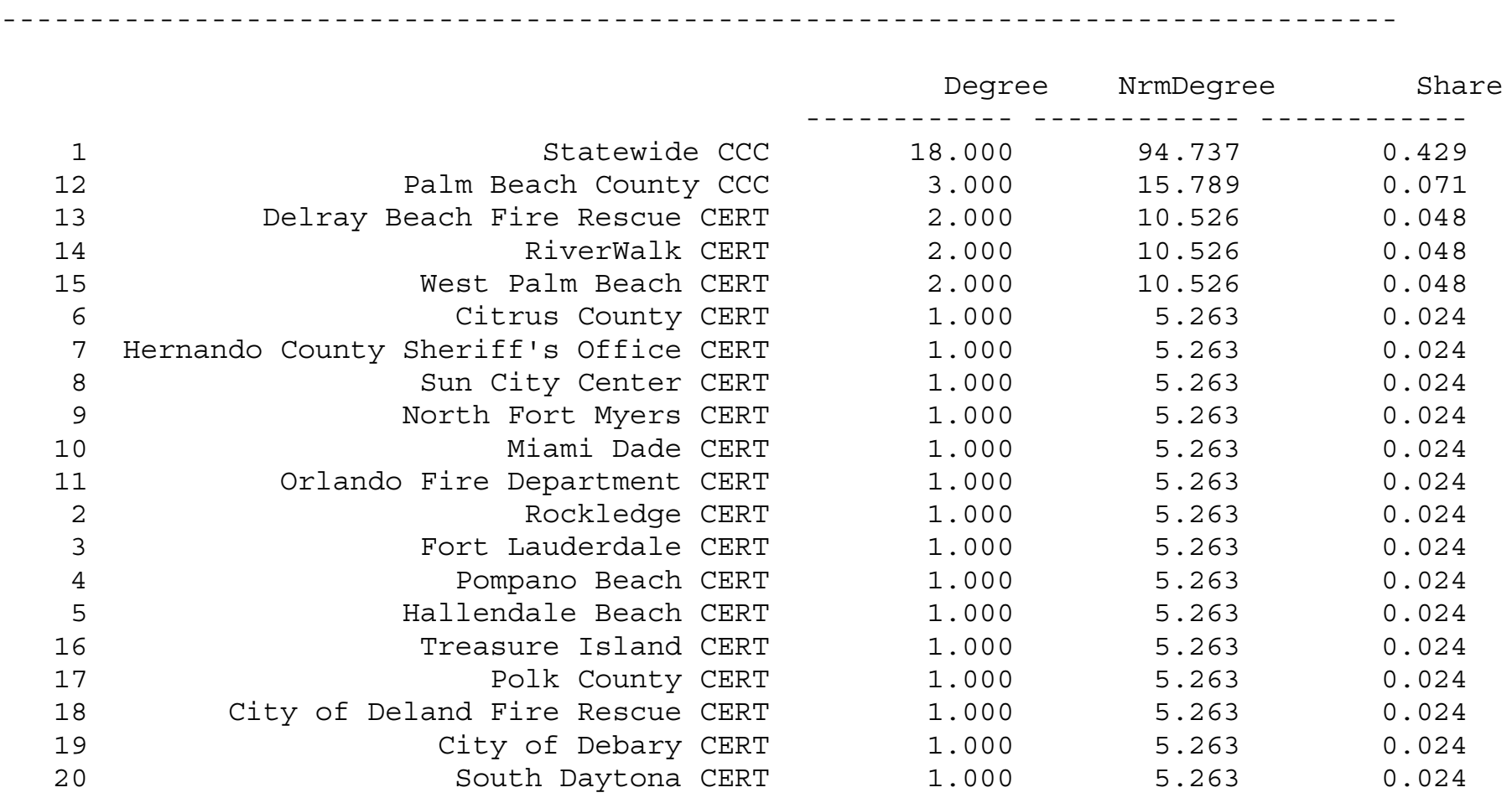

DESCRIPTIVE STATISTICS

$\begin{array}{rrrrr} & & 1 & 2 & 3 \\ & & \text { Degree } & \text { NrmDegree } & \text { Share } \\ 1 & \text { Mean } & 2.100 & 11.053 & 0.050 \\ 2 & \text { Std Dev } & 3.686 & 19.402 & 0.088 \\ 3 & \text { Sum } & 42.000 & 221.053 & 1.000 \\ 4 & \text { Variance } & 13.590 & 376.454 & 0.008 \\ 5 & \text { SSQ } & 360.000 & 9972.299 & 0.204\end{array}$




$\begin{array}{rrrrr}6 & \text { MCSSQ } & 271.800 & 7529.085 & 0.154 \\ 7 & \text { Euc Norm } & 18.974 & 99.861 & 0.452 \\ 8 & \text { Minimum } & 1.000 & 5.263 & 0.024 \\ 9 & \text { Maximum } & 18.000 & 94.737 & 0.429 \\ 10 & \text { N of Obs } & 20.000 & 20.000 & 20.000\end{array}$

Network Centralization $=92.98 \%$

Blau Heterogeneity $=20.41 \%$. Normalized $($ IQV $)=16.22 \%$

Copyright (c) 2002-11 Analytic Technologies 
Florida CCCS and CERTs 2005

FREEMAN'S DEGREE CENTRALITY MEASURES:

30
31
6
20
19
5
8
27
4
35
9
34
32
45
28
17
48
7
29
33
18
22
2
13
14
15
16
23
12
25
26

Palm Beach Cour Palm Beach County CERT Fort Lauderdale CERT Hillsborough County Citizen Corps Council Hillsborough County CERT Hallendale Beach CERT Coral springs CERT Orange County Florida CERT Miramar CERT West Palm Beach CERT Pompano Beach CERT Delray Beach Fire Rescue CERT RiverWalk CERT Daytona Beach CERT

Orange County Florida Citizen Corps Council Gulfport CERT South Daytona CERT Dania Beach

Orlando Fire Department CERT Jupiter Police CERT Sun City Center CERT Manatee County CERT Bradford County Escambia County CERT Flagler County CERT Hernando County Nature Coast Citizen Corps Hernando County Sheriff's Office CERT CERT of the Villages Jax CERT Miami Dade CERT Okaloosa County CERT

\begin{tabular}{|c|c|c|}
\hline Degree & NrmDegree & Share \\
\hline----------- & ------------ & ----------- \\
\hline 29.000 & 61.702 & 0.274 \\
\hline 5.000 & 10.638 & 0.047 \\
\hline 5.000 & 10.638 & 0.047 \\
\hline 4.000 & 8.511 & 0.038 \\
\hline 3.000 & 6.383 & 0.028 \\
\hline 3.000 & 6.383 & 0.028 \\
\hline 2.000 & 4.255 & 0.019 \\
\hline 2.000 & 4.255 & 0.019 \\
\hline 2.000 & 4.255 & 0.019 \\
\hline 2.000 & 4.255 & 0.019 \\
\hline 2.000 & 4.255 & 0.019 \\
\hline 2.000 & 4.255 & 0.019 \\
\hline 2.000 & 4.255 & 0.019 \\
\hline 2.000 & 4.255 & 0.019 \\
\hline 2.000 & 4.255 & 0.019 \\
\hline 2.000 & 4.255 & 0.019 \\
\hline 2.000 & 4.255 & 0.019 \\
\hline 2.000 & 4.255 & 0.019 \\
\hline 2.000 & 4.255 & 0.019 \\
\hline 2.000 & 4.255 & 0.019 \\
\hline 2.000 & 4.255 & 0.019 \\
\hline 2.000 & 4.255 & 0.019 \\
\hline 1.000 & 2.128 & 0.009 \\
\hline 1.000 & 2.128 & 0.009 \\
\hline 1.000 & 2.128 & 0.009 \\
\hline 1.000 & 2.128 & 0.009 \\
\hline 1.000 & 2.128 & 0.009 \\
\hline 1.000 & 2.128 & 0.009 \\
\hline 1.000 & 2.128 & 0.009 \\
\hline 1.000 & 2.128 & 0.009 \\
\hline 1.000 & 2.128 & 0.009 \\
\hline 1.000 & 2.128 & 0.009 \\
\hline
\end{tabular}




\begin{tabular}{|c|c|c|c|c|}
\hline & Rockledge CERT & 1.000 & 2.128 & 0.009 \\
\hline & Citrus County CERT & 1.000 & 2.128 & 0.009 \\
\hline & Big Corkscrew Island Fire Rescue CERT & 1.000 & 2.128 & 0.009 \\
\hline & North Miami Beach CERT & 1.000 & 2.128 & 0.009 \\
\hline & Treasure Island CERT & 1.000 & 2.128 & 0.009 \\
\hline & East Lake CERT & 1.000 & 2.128 & 0.009 \\
\hline & Pinellas Suncoast Fire Rescue CERT & 1.000 & 2.128 & 0.009 \\
\hline & Polk County CERT & 1.000 & 2.128 & 0.009 \\
\hline & Navarre CERT & 1.000 & 2.128 & 0.009 \\
\hline & Santa Rosa County CERT & 1.000 & 2.128 & 0.009 \\
\hline & Sarasota COAD/Citizens Corps Council & 1.000 & 2.128 & 0.009 \\
\hline & Sarasota County CERT & 1.000 & 2.128 & 0.009 \\
\hline Iona-McGregor Fire & Protection \& Rescue Service District & 1.000 & 2.128 & 0.009 \\
\hline & City of Debary CERT & 1.000 & 2.128 & 0.009 \\
\hline & City of Deland Fire Rescue CERT & 1.000 & 2.128 & 0.009 \\
\hline & Pasco County Citizen Corps Council & 0.000 & 0.000 & 0.000 \\
\hline
\end{tabular}

DESCRIPTIVE STATISTICS

$\begin{array}{rrrrr} & & 1 & 2 & 3 \\ & & \begin{array}{r}\text { Degree } \\ \text { NrmDegree }\end{array} & \text { Share } \\ 1 & \text { Mean } & 2.208 & 4.699 & 0.021 \\ 2 & \text { Std Dev } & 4.031 & 8.576 & 0.038 \\ 3 & \text { Sum } & 106.000 & 225.532 & 1.000 \\ 4 & \text { Variance } & 16.248 & 73.555 & 0.001 \\ 5 & \text { SSQ } & 1014.000 & 4590.313 & 0.090 \\ 6 & \text { MCSSQ } & 779.917 & 3530.633 & 0.069 \\ 7 & \text { Euc Norm } & 31.843 & 67.752 & 0.300 \\ 8 & \text { Minimum } & 0.000 & 0.000 & 0.000 \\ 9 & \text { Maximum } & 29.000 & 61.702 & 0.274 \\ 10 & \text { N of Obs } & 48.000 & 48.000 & 48.000\end{array}$

Network Centralization $=59.48 \%$

Blau Heterogeneity $=9.02 \%$. Normalized $(\mathrm{IQV})=7.09 \%$ 
Florida CCCS and CERTs 2011

FREEMAN'S DEGREE CENTRALITY MEASURES:

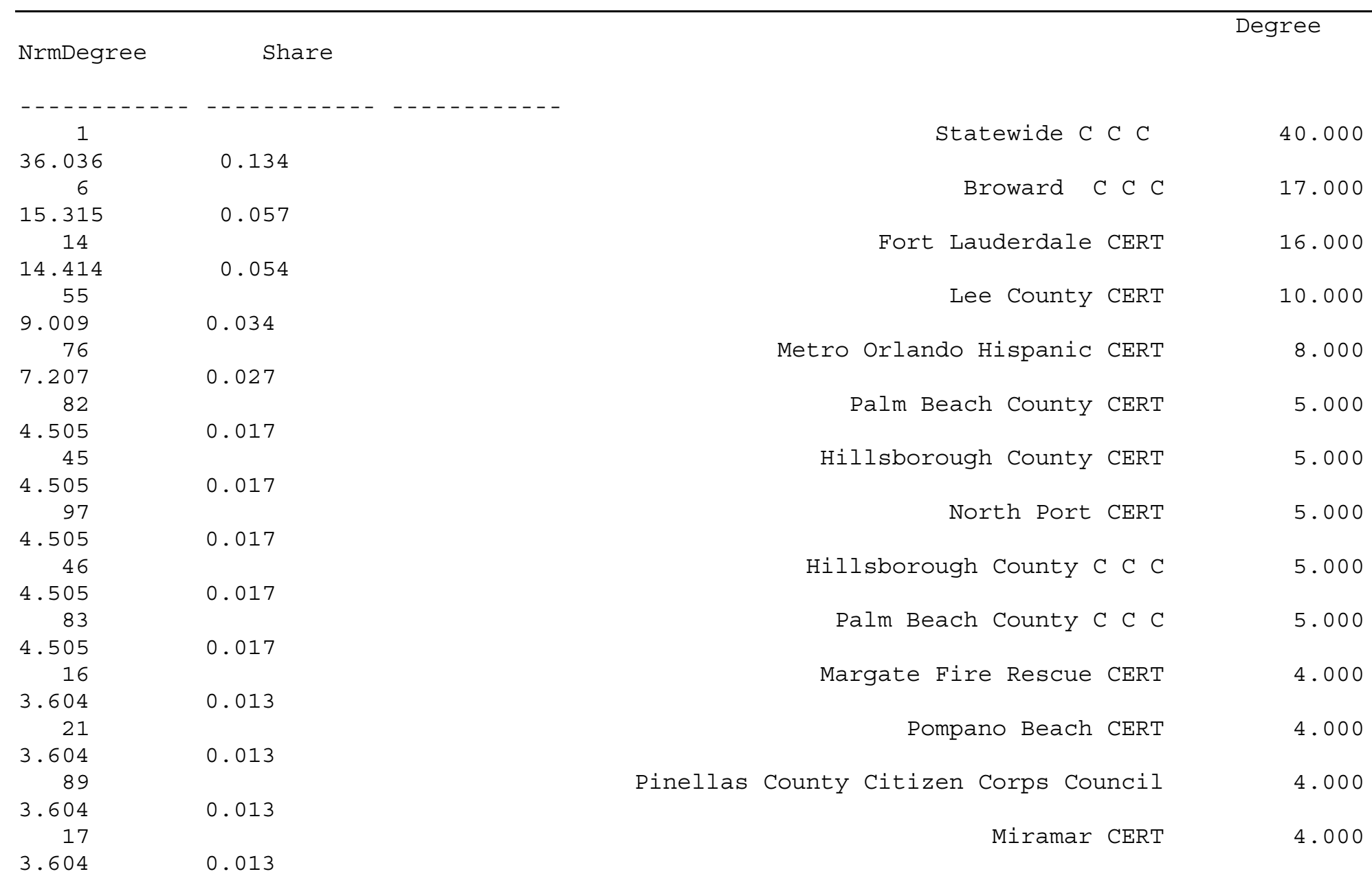




$\begin{array}{rl}68 & \\ 3.604 & 0.013 \\ 8 & \\ 2.703 & 0.010 \\ 79 & \\ 2.703 & 0.010 \\ 95 & \\ 2.703 & 0.010 \\ 15 & \\ 2.703 & 0.010 \\ 38 & \\ 2.703 & 0.010 \\ 109 & \\ 2.703 & 0.010 \\ 78 & \\ 2.703 & 0.010 \\ 96 & \\ 2.703 & 0.010 \\ 35 & \\ 2.703 & 0.010 \\ 77 & \\ 2.703 & 0.010 \\ 36 & \\ 2.703 & 0.010 \\ 94 & \\ 2.703 & 0.010 \\ 34 & \\ 2.703 & 0.010 \\ 110 & \\ 2.703 & 0.010 \\ 20 & 0.010 \\ 2.703 & 0.007 \\ 58 & 0.007 \\ 1.802 & \\ 4 & 0.007 \\ 1.802 & \\ 9 & \\ 1.802 & \end{array}$

$\begin{array}{rr}\text { Miami Dade County C C C } & 4.000 \\ \text { Coconut Creek CERT Team } & 3.000 \\ \text { Orange County Florida CERT } & 3.000 \\ \text { Santa Rosa County CERT } & 3.000 \\ \text { Hallendale Beach CERT } & 3.000 \\ \text { Escambia County CERT } & 3.000 \\ \text { Daytona Beach CERT } & 3.000 \\ \text { Orlando Fire Department CERT } & 3.000 \\ \text { Santa Rosa County C C C } & 3.000 \\ \text { Escambia County C C C } & 3.000 \\ \text { Orange County C C C } & 3.000 \\ \text { City of Pensacola C C C } & 3.000 \\ \text { Navarre CERT } & 3.000 \\ \text { Brevard Fire Rescue CERT } & 3.000 \\ \text { City of Pensacola CERT } & 3.000 \\ \text { South Daytona CERT } & 3.000 \\ \text { Pembroke Pines CERT } & 2.000 \\ \text { Rescue Service District } & 2.000\end{array}$




\begin{tabular}{|c|c|}
\hline 59 & \\
\hline .802 & 0.007 \\
\hline 60 & \\
\hline .802 & 0.007 \\
\hline 44 & \\
\hline .802 & 0.007 \\
\hline 107 & \\
\hline .802 & 0.007 \\
\hline 84 & \\
\hline .802 & 0.007 \\
\hline 85 & \\
\hline 1.802 & 0.007 \\
\hline 19 & \\
\hline .802 & 0.007 \\
\hline 24 & \\
\hline .802 & 0.007 \\
\hline 11 & \\
\hline .802 & 0.007 \\
\hline 43 & \\
\hline .802 & 0.007 \\
\hline 23 & \\
\hline 1.802 & 0.007 \\
\hline 98 & \\
\hline 1.802 & 0.007 \\
\hline 18 & \\
\hline 1.802 & 0.007 \\
\hline 5 & \\
\hline 1.802 & 0.007 \\
\hline 108 & \\
\hline 1.802 & 0.007 \\
\hline 7 & \\
\hline 1.802 & 0.007 \\
\hline 106 & \\
\hline 1.802 & 0.007 \\
\hline 47 & \\
\hline 802 & 0.007 \\
\hline 10 & \\
\hline 1.802 & 0.007 \\
\hline
\end{tabular}

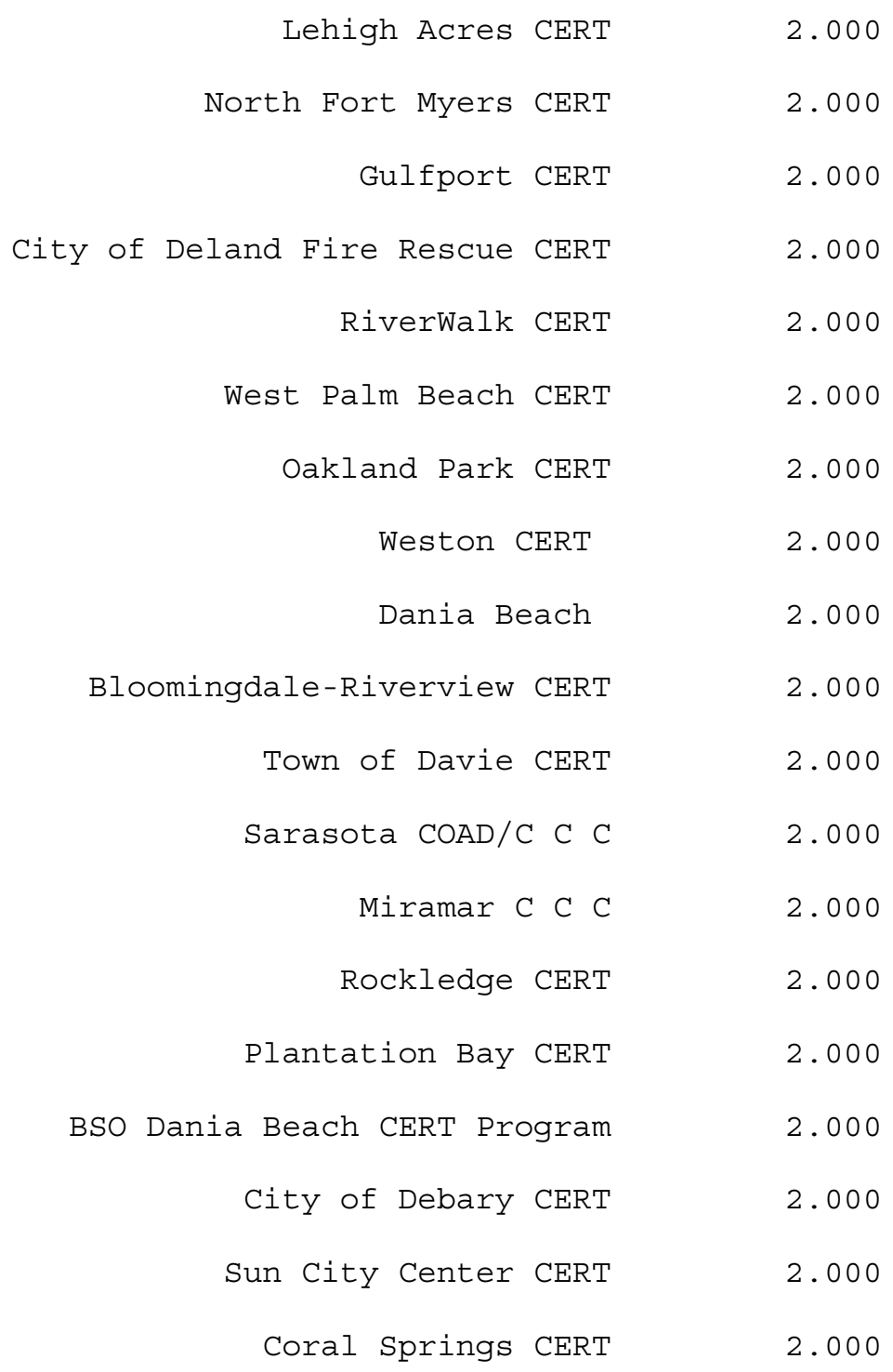




\begin{tabular}{|c|c|}
\hline 81 & \\
\hline 1.802 & 0.007 \\
\hline 57 & \\
\hline 1.802 & 0.007 \\
\hline 13 & \\
\hline 1.802 & 0.007 \\
\hline 56 & \\
\hline 1.802 & 0.007 \\
\hline 63 & \\
\hline 1.802 & 0.007 \\
\hline 61 & \\
\hline 1.802 & 0.007 \\
\hline 80 & \\
\hline 1.802 & 0.007 \\
\hline 111 & \\
\hline 1.802 & 0.007 \\
\hline 64 & \\
\hline 1.802 & 0.007 \\
\hline 62 & \\
\hline 1.802 & 0.007 \\
\hline 22 & \\
\hline 1.802 & 0.007 \\
\hline 112 & \\
\hline 1.802 & 0.007 \\
\hline 12 & \\
\hline 1.802 & 0.007 \\
\hline 48 & \\
\hline 1.802 & 0.007 \\
\hline 99 & \\
\hline 1.802 & 0.007 \\
\hline 30 & \\
\hline 0.901 & 0.003 \\
\hline 32 & \\
\hline 0.901 & 0.003 \\
\hline 2 & \\
\hline 0.901 & 0.003 \\
\hline 37 & \\
\hline 0.901 & 0.003 \\
\hline
\end{tabular}

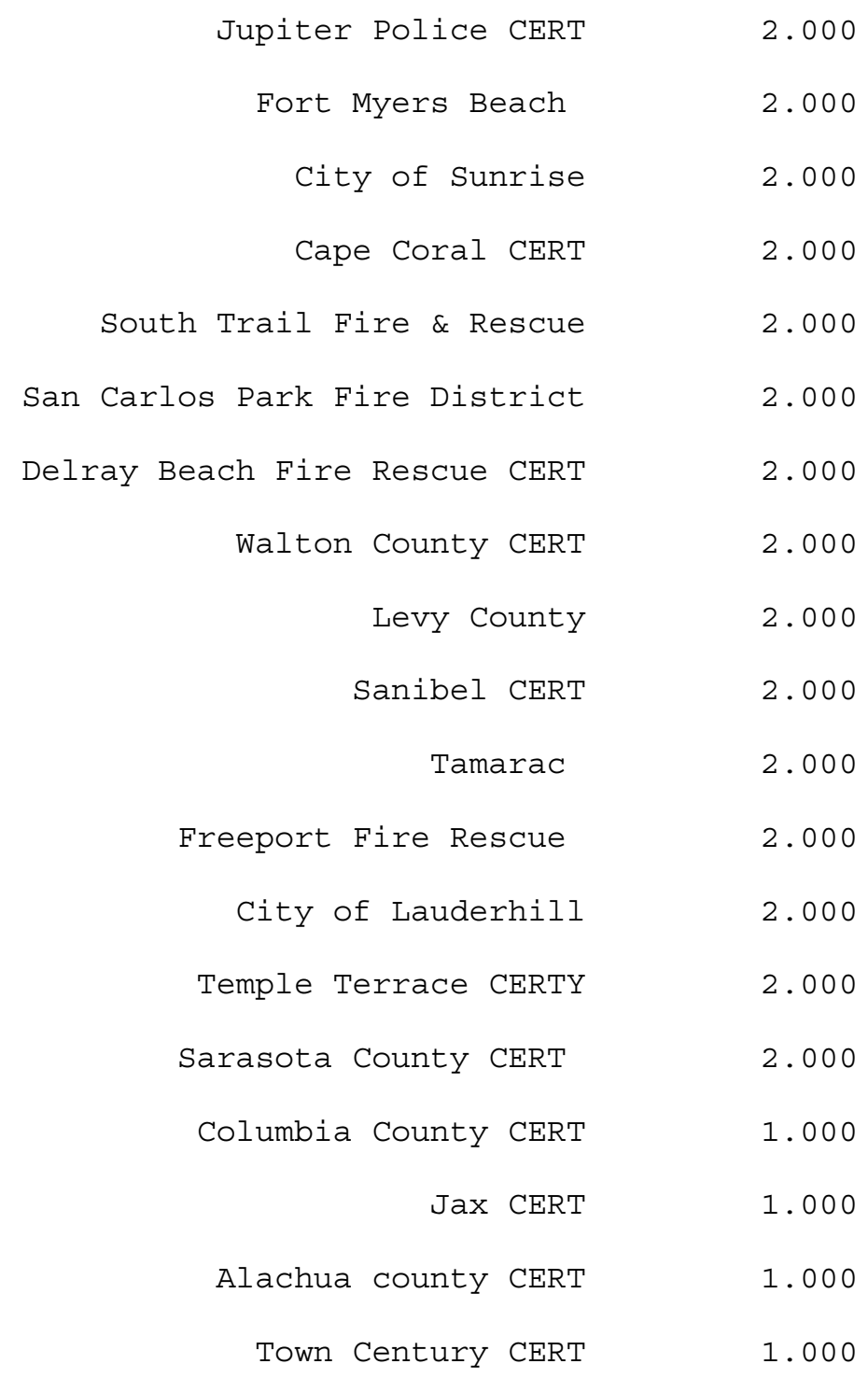




\begin{tabular}{|c|c|}
\hline 31 & \\
\hline 0.901 & 0.003 \\
\hline 67 & \\
\hline 0.901 & 0.003 \\
\hline 74 & \\
\hline 0.901 & 0.003 \\
\hline 72 & \\
\hline 0.901 & 0.003 \\
\hline 3 & \\
\hline 0.901 & 0.003 \\
\hline 49 & \\
\hline 0.901 & 0.003 \\
\hline 75 & \\
\hline 0.901 & 0.003 \\
\hline 65 & \\
\hline 0.901 & 0.003 \\
\hline 101 & \\
\hline 0.901 & 0.003 \\
\hline 25 & \\
\hline 0.901 & 0.003 \\
\hline 26 & \\
\hline 0.901 & 0.003 \\
\hline 69 & \\
\hline 0.901 & 0.003 \\
\hline 70 & \\
\hline 0.901 & 0.003 \\
\hline 29 & \\
\hline 0.901 & 0.003 \\
\hline 100 & \\
\hline 0.901 & 0.003 \\
\hline 87 & \\
\hline 0.901 & 0.003 \\
\hline 88 & \\
\hline 0.901 & 0.003 \\
\hline 33 & \\
\hline 0.901 & 0.003 \\
\hline 90 & \\
\hline 0.901 & 0.003 \\
\hline
\end{tabular}

\begin{tabular}{|c|c|c|}
\hline & Dixie County & 1.000 \\
\hline & CERT of the Villages & 1.000 \\
\hline & Okaloosa County CERT & 1.000 \\
\hline & North Miami Beach CERT & 1.000 \\
\hline & Bradford County & 1.000 \\
\hline & Indian County River CERT & 1.000 \\
\hline & Okaloosa County C C C & 1.000 \\
\hline & Lakewood Ranch CERT Inc & 1.000 \\
\hline & Sanford: Sanford P D Volunteers & 1.000 \\
\hline & Citrus County CERT & 1.000 \\
\hline Big & Corkscrew Island Fire Rescue CERT & 1.000 \\
\hline Canes & Emergency Response Team (UM CERT) & 1.000 \\
\hline & Miami Dade CERT & 1.000 \\
\hline & North Naples Fire District & 1.000 \\
\hline & Longwood Fire Department CERT Team & 1.000 \\
\hline & East Lake CERT & 1.000 \\
\hline & Lealman Fire District CERT & 1.000 \\
\hline & Town of Century C C C & 1.000 \\
\hline & Pinellas Suncoast Fire Rescue CERT & 1.000 \\
\hline
\end{tabular}




\begin{tabular}{|c|c|}
\hline 91 & \\
\hline 0.901 & 0.003 \\
\hline 92 & \\
\hline 0.901 & 0.003 \\
\hline 93 & \\
\hline 0.901 & 0.003 \\
\hline 66 & \\
\hline 0.901 & 0.003 \\
\hline 39 & \\
\hline 0.901 & 0.003 \\
\hline 40 & \\
\hline 0.901 & 0.003 \\
\hline 41 & \\
\hline 0.901 & 0.003 \\
\hline 42 & \\
\hline 0.901 & 0.003 \\
\hline 71 & \\
\hline 0.901 & 0.003 \\
\hline 51 & \\
\hline 0.901 & 0.003 \\
\hline 52 & \\
\hline 0.901 & 0.003 \\
\hline 102 & \\
\hline 0.901 & 0.003 \\
\hline 103 & \\
\hline 0.901 & 0.003 \\
\hline 104 & \\
\hline 0.901 & 0.003 \\
\hline 105 & \\
\hline 0.901 & 0.003 \\
\hline 50 & \\
\hline 0.901 & 0.003 \\
\hline 54 & \\
\hline 0.901 & 0.003 \\
\hline 27 & \\
\hline 0.901 & 0.003 \\
\hline 53 & \\
\hline 0.901 & 0.003 \\
\hline
\end{tabular}

\section{Teasure Island CERT}

Polk County CERT

Polk County C C C

Manatee County CERT

Flagler County CERT

Hamilton County CERT

Hernando County Nature Coast C C C Hernando County Sheriff's Office CERT

Miami Gardens Police Department

Jackson County CERT

Jefferson County CERT

Renaissance Charter School

Sumter County CERT

Sumter C C C

Suwanne County CERT

Jackson County C C C

Leesburg Florida CERT

Golden Gate Fire Control and Rescue District CERT

Lafayette County CERT
1.000

1.000

1.000

1. 000

1.000

1.000

1.000

1.000

1. 000

1.000

1.000

1.000

1.000

1. 000

1.000

1.000

1.000

1.000

1. 000 


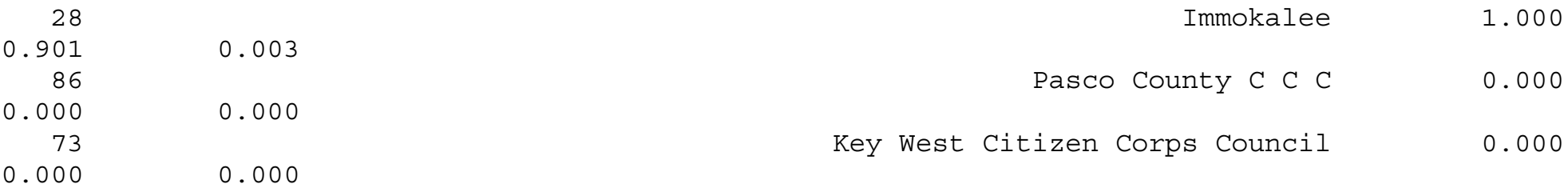

DESCRIPTIVE STATISTICS

$\begin{array}{rrrrr} & & 1 & 2 & 3 \\ & & \text { Degree } & \text { NrmDegree } & \text { Share } \\ 1 & \text { Mean } & 2.661 & 2.397 & 0.009 \\ 2 & \text { Std Dev } & 4.275 & 3.852 & 0.014 \\ 3 & \text { Sum } & 298.000 & 268.468 & 1.000 \\ 4 & \text { Variance } & 18.278 & 14.835 & 0.000 \\ 5 & \text { SSQ } & 2840.000 & 2305.008 & 0.032 \\ 6 & \text { MCSSQ } & 2047.107 & 1661.478 & 0.023 \\ 7 & \text { Euc Norm } & 53.292 & 48.010 & 0.179 \\ 8 & \text { Minimum } & 0.000 & 0.000 & 0.000 \\ 9 & \text { Maximum } & 40.000 & 36.036 & 0.134 \\ 10 & \text { N of Obs } & 112.000 & 112.000 & 112.000\end{array}$

Network Centralization $=34.25 \%$

Blau Heterogeneity $=3.20 \%$ Normalized $(\mathrm{IQV})=2.33 \%$ 
Freeman Betweeness Centrality Measures for 2002, 2005, 2011 
Un-normalized centralization: 4767.000

Betweenness nBetweenness

$\begin{array}{rr}252.000 & 73.684\end{array}$

Statewide CCC

Palm Beach County CCC

Delray Beach Fire Rescue CERT

RiverWalk CERT

West Palm Beach CERT

Citrus County CERT

Hernando County Sheriff's Office CERT

Sun City Center CERT

North Fort Myers CERT

Miami Dade CERT

Orlando Fire Department CERT Rockledge CERT

Fort Lauderdale CERT Pompano Beach CERT Hallendale Beach CERT Teasure Island CERT Polk County CERT

City of Deland Fire Rescue CERT

City of Debary CERT South Daytona CERT
6.000

5.000

5.000

5.000

0.000

0.000

0.000

0.000

0.000

0.000

0.000

0.000

0.000

0.000

0.000

0.000

0.000

0.000

0.000

73.684
1.754

1.462

1. 462

1. 462

0.000

0.000

0.000

0.000

0.000

0.000

0.000

0.000

0.000

0.000

0.000

0.000

0.000

0.000

0.000 
DESCRIPTIVE STATISTICS FOR EACH MEASURE

Betweenness nBetweenness

$\begin{array}{rr}13.650 & 3.991 \\ 54.721 & 16.000 \\ 273.000 & 79.825 \\ 2994.427 & 256.013 \\ 63615.000 & 5438.853 \\ 59888.551 & 5120.255 \\ 252.220 & 73.749 \\ 0.000 & 0.000 \\ 252.000 & 73.684 \\ 20.000 & 20.000\end{array}$

Network Centralization Index $=73.36 \%$

FREEMAN BETWEENNESS CENTRALITY

Un-normalized centralization: 37535.000

Betweenness nBetweenness

Statewide Palm Beach County Citizen Corps Council Palm Beach County CERT Fort Lauderdale CERT Hillsborough County Citizen Corps Council Hillsborough County CERT Orange County Florida CERT Hallendale Beach CERT Bradford County Miramar CERT Big Corkscrew Island Fire Rescue CERT

$\begin{array}{rr}799.000 & 36.957 \\ 6.000 & 0.278 \\ 6.000 & 0.278 \\ 3.000 & 0.139 \\ 1.000 & 0.046 \\ 1.000 & 0.046 \\ 1.000 & 0.046 \\ 0.000 & 0.000 \\ 0.000 & 0.000 \\ 0.000 & 0.000 \\ 0.000 & 0.000\end{array}$


Pompano Beach CERT

Citrus County CERT

Flagler County CERT

Hernando County Nature Coast Citizen Corps Hernando County Sheriff's Office CERT

Gulfport CERT JaX CERT

Escambia County CERT

Coral Springs CERT

Iona-McGregor Fire Protection \& Rescue Service District

Manatee County CERT

CERT of the Villages North Miami Beach CERT

Miami Dade CERT

Okaloosa County CERT Rockledge CERT

Orange County Florida Citizen Corps Council

Orlando Fire Department CERT

Sun City Center CERT Dania Beach

RiverWalk CERT

Jupiter Police CERT

Delray Beach Fire Rescue CERT

West Palm Beach CERT

Pasco County Citizen Corps Council

Treasure Island CERT East Lake CERT

Pinellas Suncoast Fire Rescue CERT Polk County CERT Navarre CERT

Santa Rosa County CERT Sarasota COAD/Citizens Corps Council Sarasota County CERT Daytona Beach CERT City of Debary CERT City of Deland Fire Rescue CERT South Daytona CERT

$\begin{array}{ll}0.000 & 0.000 \\ 0.000 & 0.000 \\ 0.000 & 0.000 \\ 0.000 & 0.000 \\ 0.000 & 0.000 \\ 0.000 & 0.000 \\ 0.000 & 0.000 \\ 0.000 & 0.000 \\ 0.000 & 0.000 \\ 0.000 & 0.000 \\ 0.000 & 0.000 \\ 0.000 & 0.000 \\ 0.000 & 0.000 \\ 0.000 & 0.000 \\ 0.000 & 0.000 \\ 0.000 & 0.000 \\ 0.000 & 0.000 \\ 0.000 & 0.000 \\ 0.000 & 0.000 \\ 0.000 & 0.000 \\ 0.000 & 0.000 \\ 0.000 & 0.000 \\ 0.000 & 0.000 \\ 0.000 & 0.000 \\ 0.000 & 0.000 \\ 0.000 & 0.000 \\ 0.000 & 0.000 \\ 0.000 & 0.000 \\ 0.000 & 0.000 \\ 0.000 & 0.000 \\ 0.000 & 0.000 \\ 0.000 & 0.000 \\ 0.000 & 0.000 \\ 0.000 & 0.000 \\ 0.000 & 0.000 \\ 0.000 & 0.000 \\ 0.000 & 0.000\end{array}$


DESCRIPTIVE STATISTICS FOR EACH MEASURE

1

Betweenness nBetweenness

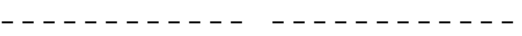

$\begin{array}{lll}\text { Mean } & 17.021 & 0.787\end{array}$

Std Dev $\quad 114.070 \quad 5.276$

Sum $\quad 817.000 \quad 37.789$

$13012.063 \quad 27.838$

$638485.000 \quad 1365.964$

$624579.000 \quad 1336.214$

$799.053 \quad 36.959$

$0.000 \quad 0.000$

$799.000 \quad 36.957$

$48.000 \quad 48.000$

Network Centralization Index $=36.94 \%$ 
FREEMAN BETWEENNESS CENTRALITY

Un-normalized centralization: 130898.500

nBetweenness

- -

9.962

6

1.430

14

0.709

75
517

55
0.238

17

0.158

109

0.130

106

0.130

107

0.130

105

0.130

108

0.130

88

0.100

68

0.100

82

0.071

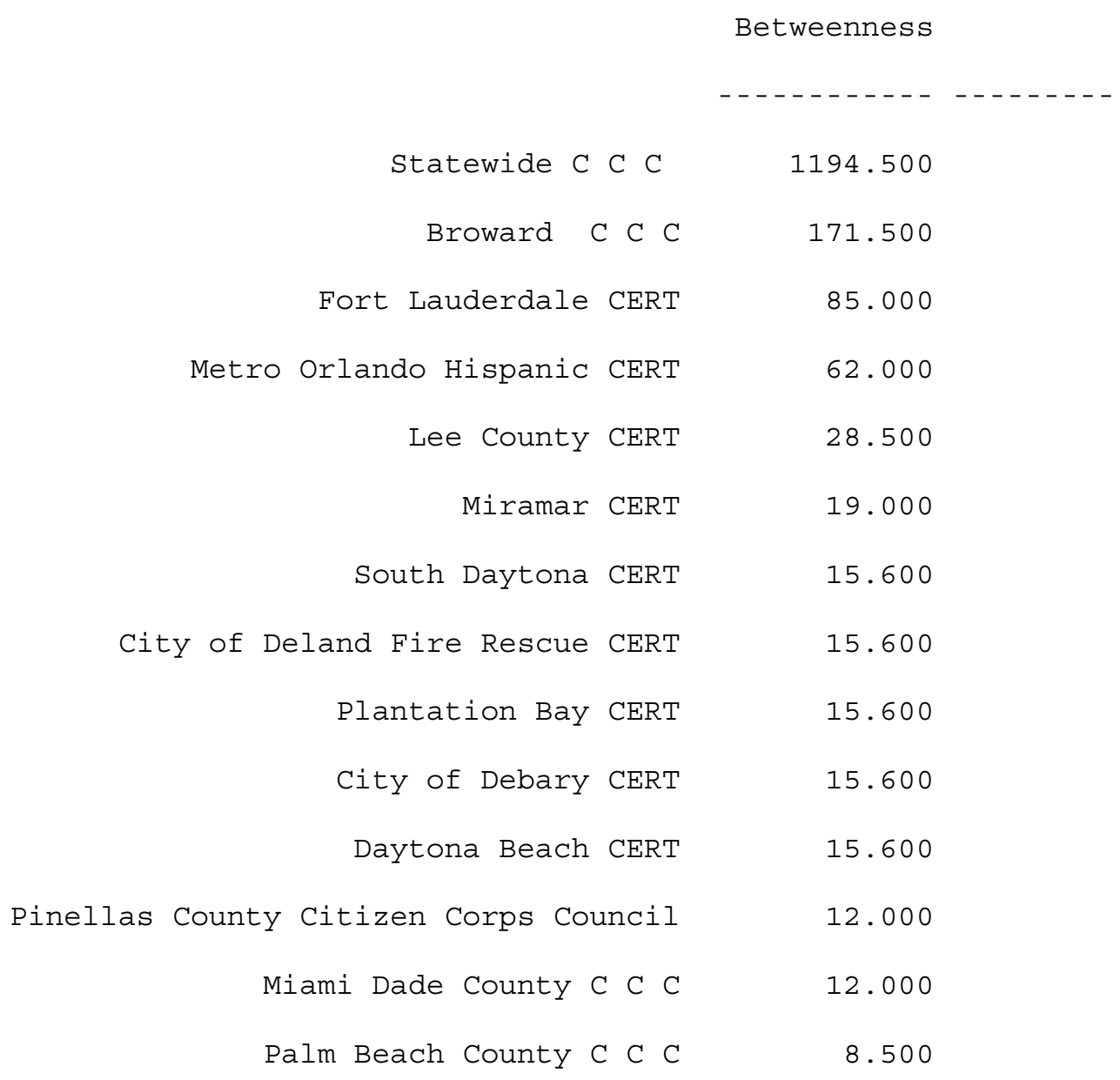




$$
\begin{array}{r}
96 \\
0.050 \\
45 \\
0.038 \\
46 \\
0.038 \\
81 \\
0.021 \\
95 \\
0.008 \\
16 \\
0.004 \\
20 \\
0.004 \\
8 \\
0.004 \\
5 \\
0.000 \\
11 \\
0.000 \\
12 \\
0.000 \\
4 \\
0.000 \\
9 \\
0.000 \\
33 \\
0.000 \\
10 \\
0.000 \\
30 \\
0.000 \\
31 \\
0.000 \\
32 \\
0.000 \\
7 \\
0.000
\end{array}
$$

\begin{tabular}{|c|c|}
\hline North Port CERT & 6.000 \\
\hline Hillsborough County CERT & 4.500 \\
\hline Hillsborough County C C C & 4.500 \\
\hline Palm Beach County CERT & 2.500 \\
\hline Santa Rosa County C C C & 1.000 \\
\hline Margate Fire Rescue CERT & 0.500 \\
\hline Pembroke Pines CERT & 0.500 \\
\hline Coconut Creek CERT Team & 0.500 \\
\hline Rockledge CERT & 0.000 \\
\hline Dania Beach & 0.000 \\
\hline City of Lauderhill & 0.000 \\
\hline Brevard Fire Rescue CERT & 0.000 \\
\hline Cooper City CERT & 0.000 \\
\hline Bradford County & 0.000 \\
\hline Coral Springs CERT & 0.000 \\
\hline Columbia County CERT & 0.000 \\
\hline Dixie County & 0.000 \\
\hline Jax CERT & 0.000 \\
\hline
\end{tabular}




$$
\begin{array}{r}
22 \\
0.000 \\
29 \\
0.000 \\
36 \\
0.000 \\
37 \\
0.000 \\
38 \\
0.000 \\
39 \\
0.000 \\
34 \\
0.000 \\
35 \\
0.000 \\
42 \\
0.000 \\
43 \\
0.000 \\
44 \\
0.000 \\
18 \\
0.000 \\
19 \\
0.000 \\
2 \\
0.000 \\
21 \\
0.000 \\
49 \\
0.000 \\
23 \\
0.000 \\
24 \\
0.000 \\
25 \\
0.000
\end{array}
$$

\begin{tabular}{|c|c|c|}
\hline & Tamarac & 0.000 \\
\hline & North Naples Fire District & 0.000 \\
\hline & City of Pensacola C C C & 0.000 \\
\hline & Town Century CERT & 0.000 \\
\hline & Escambia County CERT & 0.000 \\
\hline & Flagler County CERT & 0.000 \\
\hline & City of Pensacola CERT & 0.000 \\
\hline & Escambia County C C C & 0.000 \\
\hline Hernando & County Sheriff's Office CERT & 0.000 \\
\hline & Bloomingdale-Riverview CERT & 0.000 \\
\hline & Gulfport CERT & 0.000 \\
\hline & Miramar C C C & 0.000 \\
\hline & Oakland Park CERT & 0.000 \\
\hline & Alachua county CERT & 0.000 \\
\hline & Pompano Beach CERT & 0.000 \\
\hline & Indian County River CERT & 0.000 \\
\hline & Town of Davie CERT & 0.000 \\
\hline & Weston CERT & 0.000 \\
\hline & Citrus County CERT & 0.000 \\
\hline
\end{tabular}


47

0.000

15

0.000

28

0.000

56

57

0.000

58

0.000

59

0.000

60

0.000

61

62
0.000

63

0.000

64

0.000

65

0.000

66

0.000

67
.000

13

0.000

69

0.000

70

0.000

71

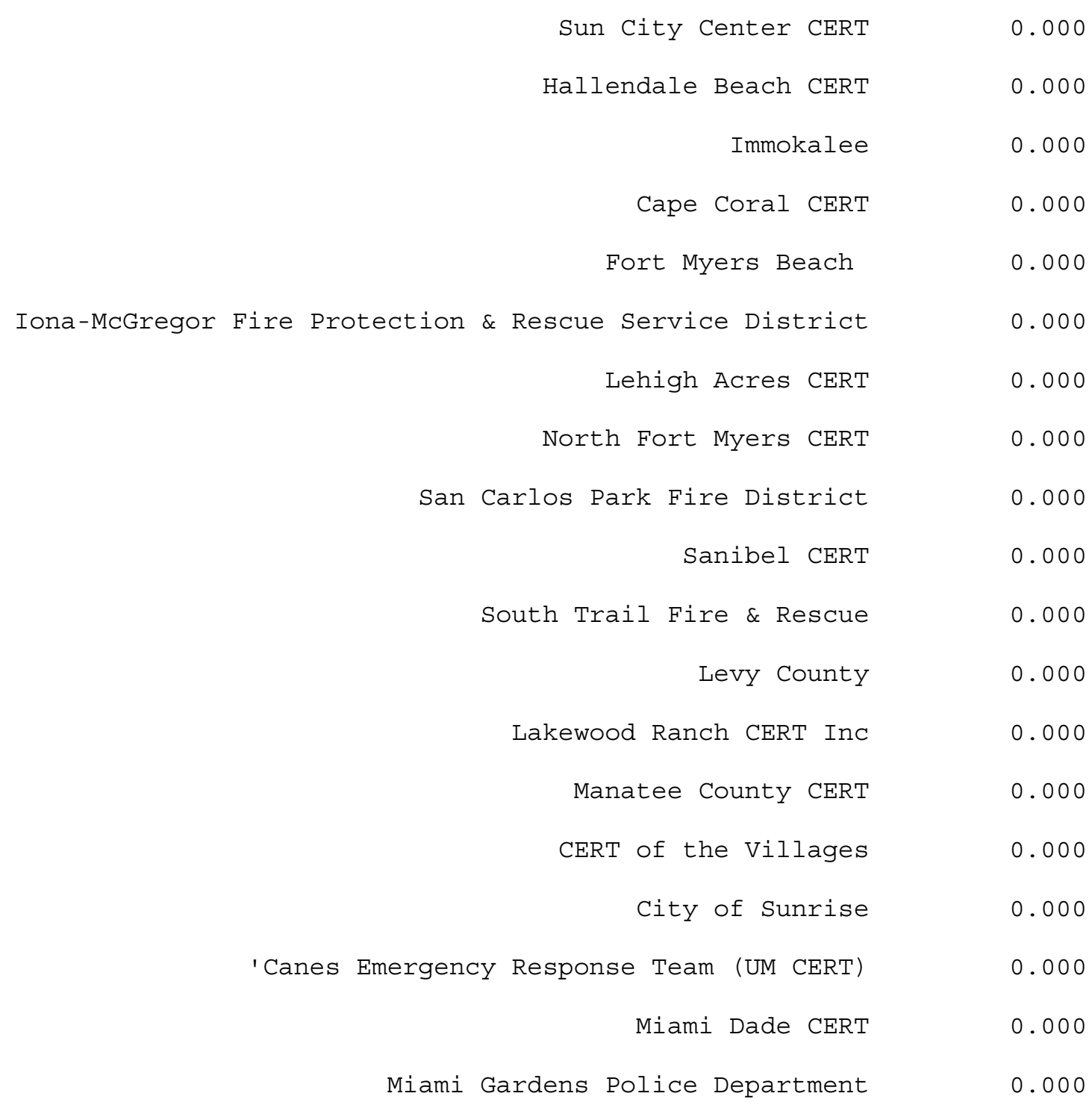

0.000

0.000

000

.000

.000

.000

.000

.000

.000

.000

.000

0.000 


$$
\begin{array}{r}
72 \\
0.000 \\
73 \\
0.000 \\
74 \\
0.000 \\
48 \\
0.000 \\
76 \\
0.000 \\
77 \\
0.000 \\
78 \\
0.000 \\
79 \\
0.000 \\
80 \\
0.000 \\
26 \\
0.000 \\
27 \\
0.000 \\
83 \\
0.000 \\
84 \\
0.000 \\
85 \\
0.000 \\
86 \\
0.000 \\
87 \\
0.000 \\
33 \\
0.000 \\
89 \\
0.000 \\
90 \\
0.000
\end{array}
$$

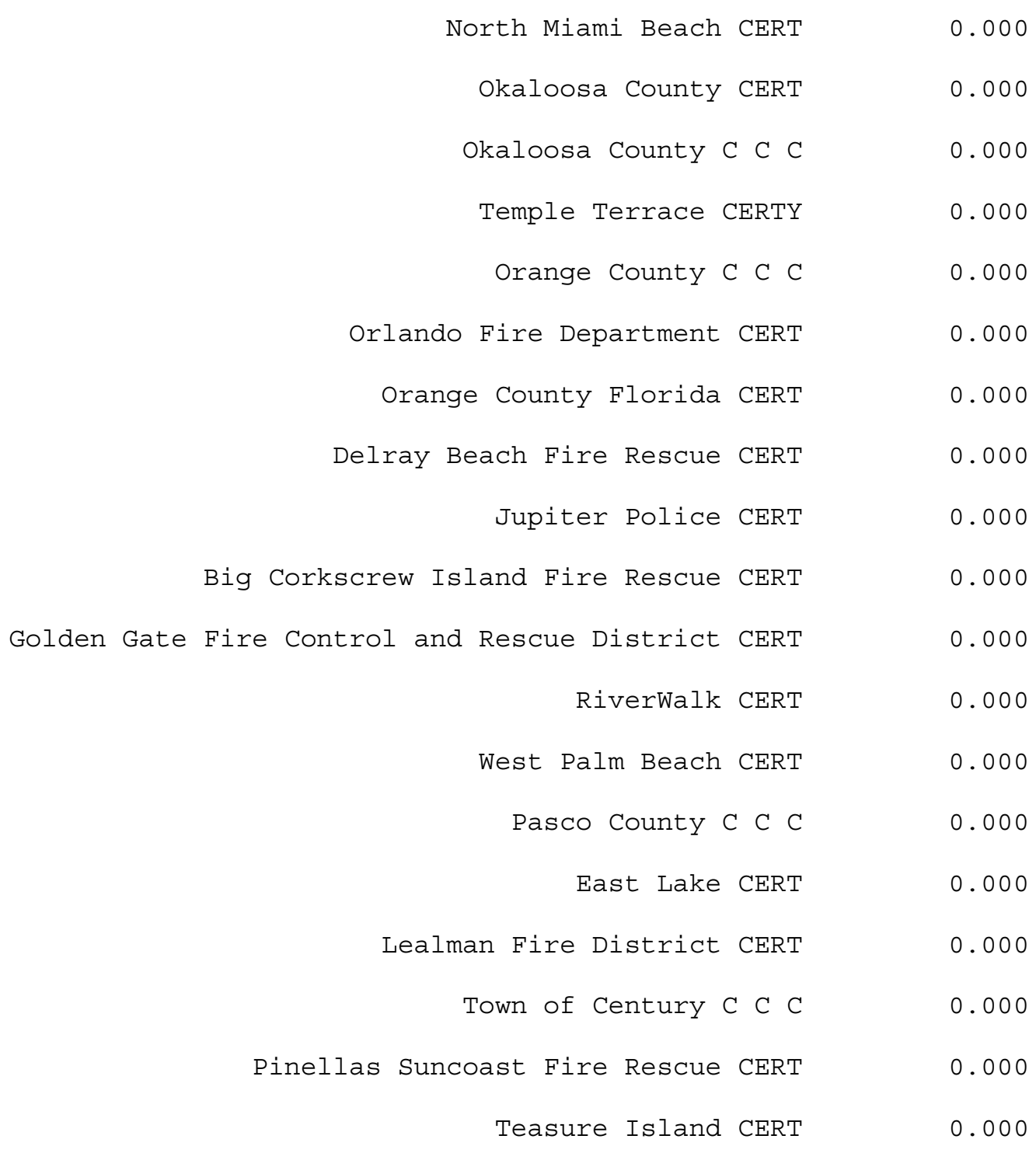
.000
0.000
0.000
0.000
0.000
0.000
0.000
.000
000
0.000 


$$
\begin{array}{r}
91 \\
0.000 \\
92 \\
0.000 \\
93 \\
0.000 \\
94 \\
0.000 \\
40 \\
0.000 \\
41 \\
0.000 \\
97 \\
0.000 \\
98 \\
0.000 \\
99 \\
0.000 \\
100 \\
0.000 \\
101 \\
0.000 \\
102 \\
0.000 \\
103 \\
0.000 \\
104 \\
0.000 \\
50 \\
0.000 \\
51 \\
0.000 \\
52 \\
0.000 \\
53 \\
0.000 \\
54 \\
0.000
\end{array}
$$

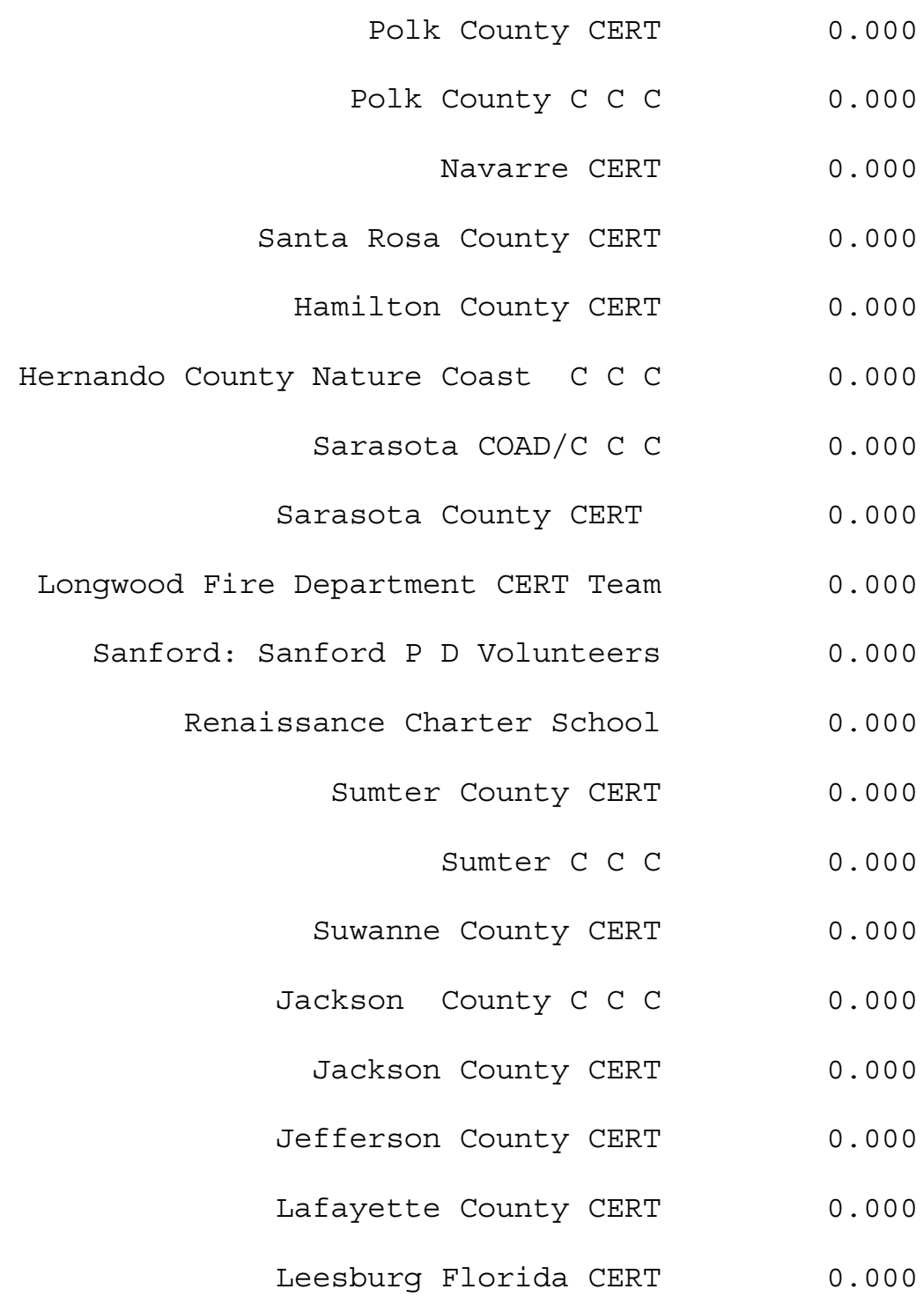




$$
110
$$

0.000

111

0.000

73

0.000

DESCRIPTIVE STATISTICS FOR EACH MEASURE

$\begin{array}{rrrr} & & 1 & 2 \\ & & \text { Betweenness } & \text { nBetweenness } \\ 1 & \text { Mean } & 15.234 & 0.127 \\ 2 & \text { Std Dev } & 114.072 & 0.951 \\ 3 & \text { Sum } & 1691.000 & 14.103 \\ 4 & \text { Variance } & 13012.479 & 0.905 \\ 5 & \text { SSQ } & 1470146.250 & 102.264 \\ 6 & \text { MCSSQ } & 1444385.250 & 100.472 \\ 7 & \text { Euc Norm } & 1212.496 & 10.113 \\ 8 & \text { Minimum } & 0.000 & 0.000 \\ 9 & \text { Maximum } & 1194.500 & 9.962 \\ 10 & \text { N of Obs } & 112.000 & 112.000\end{array}$

Network Centralization Index $=9.92 \%$

.264

0.472

0.113

9.962

112.000
Freeport Fire Rescue

0.000

Key West Citizen Corps Council

0.000 
VITA

\section{PATRICK MICHAEL BELL}

1986-1990

1991-1993

1995-1998

1997-2000

2000-2001

2001

2003

2006-2012
B.A., Political Science

Stetson University

Deland, Florida

M.P.A. Public Administration

Florida Atlantic University

Boca Raton, Florida

M.A. Political Management

The George Washington University

Washington, D.C.

Enforcement Policy Advisor

Office of the Undersecretary (Enforcement)

United States Department of the Treasury

Special Assistant

Office of Assistant Deputy Undersecretary of Defense

(Environmental Security/Cleanup)

Office of the Secretary of Defense

United States Department of Defense

Award for Outstanding Achievement

Office of the Secretary of Defense

United States Department of Defense

Adjunct Faculty

Florida International University

Miami, Florida

Doctoral Candidate/Research/Teaching Assistant

Florida International University

Miami, Florida 


\section{PUBLICATIONS AND PRESENTATIONS}

Bell, P., Combating Urban Sprawl, (May 1994) paper presented at the $3^{\text {rd }}$ International Conference on Environment and Security held at Tufts University, Medford, Massachusetts.

Rosenbaum, A, Kolisnechenko, N and Bell, P. (September 2006) Regime Transformation and Civil Service Reform: The Case of Poland and Ukraine, $102^{\text {nd }}$ Annual Meeting of the American Political Science Association (APSA), Philadelphia, Pennsylvania.

Bell, P. and Scutelnicu, G., (2007) Determinants of Success: Lessons to be learned from light rail transit systems development in Miami Dade and Dallas Counties, Transylvanian Review of Administrative Sciences, 19 (E), 21-35.

Frank, H, Bell, P. and Wedderburn, N. (2008) Comparative Performance Measurement in Florida: A View from Florida's City Managers, Journal of Budgeting, Accounting and Financial Management, 20, (2), 153 - 180. 